University of Denver

Digital Commons @ DU

Fuel Efficiency Automobile Test Publications Fuel Efficiency Automobile Test Data Repository

2020

\title{
Vehicle Exhaust Remote Sensing Device Method to Screen Vehicles for Evaporative Running Loss Emissions
}

\author{
Gary A. Bishop \\ University of Denver, gbishop@du.edu \\ Timothy H. DeFries \\ Eastern Research Group \\ James A. Sidebottom \\ Colorado Department of Health and Environment \\ James M. Kemper \\ Colorado Department of Health and Environment
}

Follow this and additional works at: https://digitalcommons.du.edu/feat_publications

Part of the Environmental Chemistry Commons

\section{Recommended Citation}

Bishop, G. A.; DeFries, T. H.; Sidebottom, J. A.; Kemper, J. M. (2020) Vehicle Exhaust Remote Sensing Device Method to Screen Vehicles for Evaporative Running Loss Emissions, Environ. Sci. Tech. 54, 14627-14634. DOI: 10.1021/acs.est.0c05433

\section{(c) (1) (9)}

This work is licensed under a Creative Commons Attribution-NonCommercial 4.0 International License This Article is brought to you for free and open access by the Fuel Efficiency Automobile Test Data Repository at Digital Commons @ DU. It has been accepted for inclusion in Fuel Efficiency Automobile Test Publications by an authorized administrator of Digital Commons @ DU. For more information, please contact jennifer.cox@du.edu,digcommons@du.edu. 


\section{Vehicle Exhaust Remote Sensing Device Method to}

\section{Screen Vehicles for Evaporative Running Loss}

\section{Emissions}

Gary A. Bishop ${ }^{\dagger *}$, Timothy H. DeFries ${ }^{\star}$, James A. Sidebottom ${ }^{\S}$ and James M. Kemper ${ }^{\S}$

${ }^{\dagger}$ Department of Chemistry and Biochemistry, University of Denver, Denver, Colorado 80208, United States

${ }^{\ddagger}$ Eastern Research Group, Inc., 3508 Far West Blvd., Suite 210, Austin, TX 78731, United States

${ }^{\S}$ Colorado Department of Public Health and Environment, 4300 Cherry Creek Drive South, Denver, Colorado 80246, United States

\section{Abstract}

Vehicle hydrocarbon (HC) emissions can be emitted from either tailpipe or non-tailpipe locations and understanding their fleet apportionment is important for successful air pollution policy. Vehicles initially misidentified as having elevated tailpipe $\mathrm{HC}$ emissions first indicated that roadside exhaust sensors could detect the presence of evaporative $\mathrm{HC}$ emissions as increased noise in the $\mathrm{HC} /$ carbon dioxide $\left(\mathrm{CO}_{2}\right)$ correlation measurement. The $90^{\text {th }}$ percentile of the largest residual of the $\mathrm{HC} / \mathrm{CO}_{2}$ correlation is defined as a running loss index (RLI) for each measurement. An RLI that is three standard deviations or greater above the instruments noise 
indicates possible evaporative running loss emissions with the probability increasing with larger RLI values. Two databases of vehicle emission measurements previously collected in West Los Angeles in 2013 and 2015 were screened using this method. The screening estimated 0.09\% $(31 / 33,806)$ and $0.18 \%(49 / 27,413)$ of the attempted measurements indicated evaporative running loss emissions from a 9-year-old fleet. California LEV I certified vehicles (1994 - 2003 model years) accounted for the largest age group for both. Minimum detection limits for the instrument used were estimated at 2.8 and $1.6 \mathrm{~g} / \mathrm{mile}$ on a propane basis for the 2013 and 2015 data respectively or 32 to 56 times the Federal Tier 2 and Tier 3 standards of $0.05 \mathrm{~g} / \mathrm{mile}$.

\section{INTRODUCTION}

With the continuing advances in vehicle combustion management, after-treatment technologies and improved reliability, on-road vehicle tailpipe emissions in the United States (U.S.) have experienced profound reductions. ${ }^{1-3}$ Fuel based emission inventory estimates for Los Angeles, Houston and New York City have shown that carbon monoxide (CO) and non-methane hydrocarbon emissions, predominantly from vehicles, decreased by 80 to $90 \%$ between 1990 and 2010 though fuel use increased. ${ }^{4}$ Over this same time period gasoline engine oxides of nitrogen $\left(\mathrm{NO}_{\mathrm{x}}\right)$ emissions are estimated to have decreased by $65 \%$ in Los Angeles. ${ }^{5}$ The California Vehicle Surveillance Program similarly found that tailpipe volatile organic compound (VOCs) emissions of California vehicles decreased by $80 \%$ between 1995 and $2003 .^{6}$

These reductions have been driven by the need for many areas in the U.S. to meet National Ambient Air Quality Standards (NAAQS) as part of the requirements of the Federal Clean Air

Act. ${ }^{7,8}$ Mobile source contributions to several NAAQS, such as $\mathrm{CO}$, nitrogen dioxide $\left(\mathrm{NO}_{2}\right)$ and sulfur dioxide $\left(\mathrm{SO}_{2}\right)$, have been accomplished through controlling the direct emissions of these 
species and removing sulfur from fuels. Ozone, however, is a pollutant not directly emitted by vehicles but is a non-linear product of the mixture of VOCs, nitrogen oxides $\left(\mathrm{NO}_{\mathrm{x}}=\mathrm{NO}+\mathrm{NO}_{2}\right)$ and sunlight that has proven to be difficult to reduce. In California's South Coast Air Basin, vehicles are major sources of VOCs and $\mathrm{NO}_{\mathrm{x}}$ emissions, and while ozone concentrations have been reduced significantly over the last 50 years, unhealthy levels still persist in many parts of the basin. ${ }^{9,10}$ The recent decrease of the eight-hour ozone NAAQS to 70ppb will likely mean that the South Coast Air Basin will remain out of compliance for several more decades requiring additional reductions in $\mathrm{VOC}$ and $\mathrm{NO}_{\mathrm{x}}$ emissions to comply. ${ }^{11}$

Mobile source VOC emissions from the tailpipe are due to incomplete combustion from cold starts or combustion management problems and from non-tailpipe sources that involve fuel evaporation, leaks or permeation. In the U.S., light-duty vehicles are certified for evaporative emissions under three modes, running losses (liquid or vapor leaks while in operation), hot soaks (liquid or vapor leaks from a fully warmed up vehicle that is subsequently parked with the engine off), and diurnal emissions (liquid or vapor losses from a parked vehicle over a $24 \mathrm{hr}$ ambient temperature cycle). In-use testing of vehicles has demonstrated that evaporative emissions, like tailpipe emissions, have also declined significantly. The California Vehicle Surveillance Program found that hot-soak emission rates for the majority of hydrocarbon compounds found in California gasoline decreased by more than $95 \%$ between the 1999 and 2003 California vehicle fleets. ${ }^{6}$ These improvements have continued with the introduction of U.S. Tier 2 vehicles as recent research has shown evaporative emission control efficiencies in excess of $98 \% .^{12}$

As emissions have decreased, the relative contributions to the atmosphere of evaporative and tailpipe emissions have been studied and debated. Pierson et al.'s review in the late 1990's concluded that 65 to $93 \%$ of ambient non-methane hydrocarbon emissions were attributable to 
the tailpipe. ${ }^{13}$ Into the early 2000's, measurements still estimated that tailpipe emissions constituted the majority of the mobile source hydrocarbon (HC) emissions. ${ }^{14,15}$ The gap between the fraction of the total HC's predicted by computer models to be contributed by evaporative emissions and tailpipe emissions has continued to shrink. The current California vehicle emissions computer model (EMFAC2017) predicts for the South Coast Air Basin for the gasoline fleet in the summer of 2015 that the two groups are approaching equal contributions. Tailpipe emissions (running, idle and starting) of total organic gases are estimated to be $49 \%$ of the total, and non-tailpipe emissions (running losses, resting losses, diurnal and hot soak) are $41 \%$ (diesel and natural gas vehicles make up the remainder, see supporting information). ${ }^{16}$ However, analysis of vehicle emissions and ambient measurements have disagreed over whether this is the case. ${ }^{17,18}$ This is an important distinction to resolve as the two sources can contribute different classes of compounds which may affect the results from air quality models and forecasts differently, especially when control of ozone is desired. ${ }^{19}$

One piece of information that would be helpful in addressing this question would be to know the fraction of in-use vehicles suspected of having measurable running loss emissions. U.S. certification tests for evaporative emissions involve a temperature controlled SHED which can be sealed with the test vehicle inside and the necessary instruments to record the amount and type of hydrocarbons emitted during the test. ${ }^{20}$ The accuracy and precision of this certification test is unmatched but the time and cost required preclude its use on large numbers of vehicles and recruiting a representative fleet for this type of testing is not realistic. In the U.S., surveys have been conducted at State Inspection and Maintenance (I/M) stations using a handheld combustible gas detector for recruitment purposes or as a fleet survey mechanism. While I/M stations are a logical sampling location and the handheld sniffers are inexpensive, most states 
exempt large numbers of new and old vehicles from such testing, and the testing frequency is low (typically biennial) limiting the ability to survey a representative in-use fleet. On-road vehicle exhaust remote sensing devices (RSD) allow for a large number of vehicles to be unobtrusively tested, and measurements collected with this method have successfully demonstrated an ability to define the fleet-wide emission distributions. ${ }^{9,21-23}$ Development of an evaporative emissions screening tool for RSDs could expand its usefulness allowing an in-use fleet evaporative emissions survey.

In the spring of 2013 and 2015 the University of Denver collected on-road emission measurements from an in-use fleet that uses the La Brea Ave. and I-10 interchange in West Los Angeles as part of a California Air Resources Board sponsored project (see the supporting information for a measurement summary of these campaigns). ${ }^{24}$ Vehicle emission measurements have been collected at this site since 1999 and it was chosen because it collects vehicles from many areas across the Los Angeles Basin and is isolated from significant local traffic eliminating cold start vehicles. Using the Fuel Efficiency Automobile Test (FEAT) instrument the 2013 and 2015 measurements included the collection and storage of the high frequency data as part of each vehicle's emissions measurement. These individual measurement files were post-processed in this study to search the West Los Angeles fleet for vehicles suspected of running loss emissions using a new evaporative emission screening method enabling for the first time an estimate of the fleet fraction suspected of having measurable running loss emissions.

\section{MATERIALS AND METHODS}

FEAT is an RSD developed and used by the University of Denver that is composed of a dual beam infrared (IR) and ultraviolet (UV) light source located on one side of a single lane road and 
a multi-wavelength detector unit opposite it with the beams approximately $36 \mathrm{~cm}$ above the roadway. Four nondispersive lead selenide IR detectors provide a reference channel $(3.9 \mu \mathrm{m}), \mathrm{CO}$ (3.6 $\mu \mathrm{m})$, carbon dioxide $\left(\mathrm{CO}_{2}\right)(4.3 \mu \mathrm{m}), \mathrm{HC}(3.3 \mu \mathrm{m})$ and two dispersive ultraviolet spectrometers measure $\mathrm{NO}, \mathrm{SO}_{2}$ and ammonia $\left(\mathrm{NH}_{3}\right)$ between 198 to $227 \mathrm{~nm}$ while the second records $\mathrm{NO}_{2}$ spectra between 430 and $450 \mathrm{~nm}$. The $3.3 \mu \mathrm{m}$ region used for detecting $\mathrm{HC}$ emissions corresponds to the $\mathrm{C}-\mathrm{H}$ stretching region and while it is most sensitive to alkane species more commonly found in evaporative emissions, the absorbance values reported by the detector are the sum of all the species found in vehicle emissions. ${ }^{25}$ The $\mathrm{HC}$ detector is calibrated with known amounts of propane and all $\mathrm{HC}$ measurements are reported as propane equivalents. Absorbance measurements on all of the detectors, which are background corrected using the air in front of the vehicle, are collected at $100 \mathrm{~Hz}$ and the system and methods have been fully described in the literature. ${ }^{26-28}$

In the mid-2000's, researchers at the Colorado Department of Public Health and Environment (CDPHE) found evidence that RSD's could possibly detect running loss emissions from vehicles. Several RSD-identified in-use high $\mathrm{HC}$ emitters brought to state I/M Technical Centers for confirmatory exhaust emissions tests were found to easily pass the tailpipe standards but were subsequently found to have gasoline vapor and/or liquid fuel leaks. CDPHE staff corroborated these previous observations by performing several simple experiments using test vehicles with deliberately defeated evaporative emissions control systems to challenge a commercial RSD instrument that resulted in the successful detection of the evaporative emissions.

RSD instruments were designed to exploit the observation that a vehicle's exhaust constituents are well mixed when they leave the tailpipe and that, despite any associated turbulence, will disperse proportionally over short time scales (< a few seconds). This allows the various exhaust 
species to be correlated against $\mathrm{CO}_{2}$ with the slope of this linear correlation corresponding to the fuel specific emissions for that species. ${ }^{28}$ What the CDPHE researchers discovered was that when there is an additional source of $\mathrm{HC}$ that is not associated with combustion emissions from the tailpipe it can disrupt the linear correlation between $\mathrm{HC}$ and $\mathrm{CO}_{2}$. When a vehicle exits the FEAT sensing beam it triggers the collection of $100 \mathrm{~Hz}$ data on all detector channels for $0.5 \mathrm{~s}$ behind the vehicle. Figure $1 \mathrm{~A}$ shows an example of this time series for $\mathrm{CO}, \mathrm{CO}_{2}$ and $\mathrm{HC}$ collected behind a 1967 sedan measured on-road in Los Angeles. The initial rapid increase in emissions for all three species is followed by their decline as they disperse behind the vehicle. Figures $1 \mathrm{~B}$ and $1 \mathrm{C}$ are the resulting correlation plots for $\mathrm{CO}$ versus $\mathrm{CO}_{2}$ and $\mathrm{HC}$ versus $\mathrm{CO}_{2}$. Figure 1B shows the expected linear correlation between $\mathrm{CO}$ and $\mathrm{CO}_{2}$ with the slope of the bestfit line adequately describing their relationship. Figure 1C shows the lack of agreement between the data and the best-fit line due to the likely introduction of an additional source of $\mathrm{HC}$ not correlated with exhaust $\mathrm{CO}_{2}$ that overlaps with the tailpipe $\mathrm{HC}$ emissions.

Based on CDPHE's early findings, they conducted a large staged running loss testing study, over 3500 metered propane releases from test vehicles, to investigate the possibility of using RSD to detect and quantify in-use running loss emissions (see the supporting information). Eastern Research Group used the data to develop a running loss index (RLI) as a proxy that ranks any scatter caused by $\mathrm{HC}$ plumes not originating from the vehicle's tailpipe. ${ }^{29}$ After the linear fit is determined for the $\mathrm{HC}$ versus $\mathrm{CO}_{2}$ correlation plot, fitting residuals are calculated and are the measured $\mathrm{HC}$ value minus the fit predicted $\mathrm{HC}$ value (see equation 1). The residuals are then ordered from largest to smallest and the value of the $90^{\text {th }}$ percentile is the RLI value expressed in parts per million-centimeter (see the residual plot for the data in Figure 1C in Figure $\mathrm{S} 1$ in the supporting information) for that vehicle. Using the $90^{\text {th }}$ percentile as opposed to the 

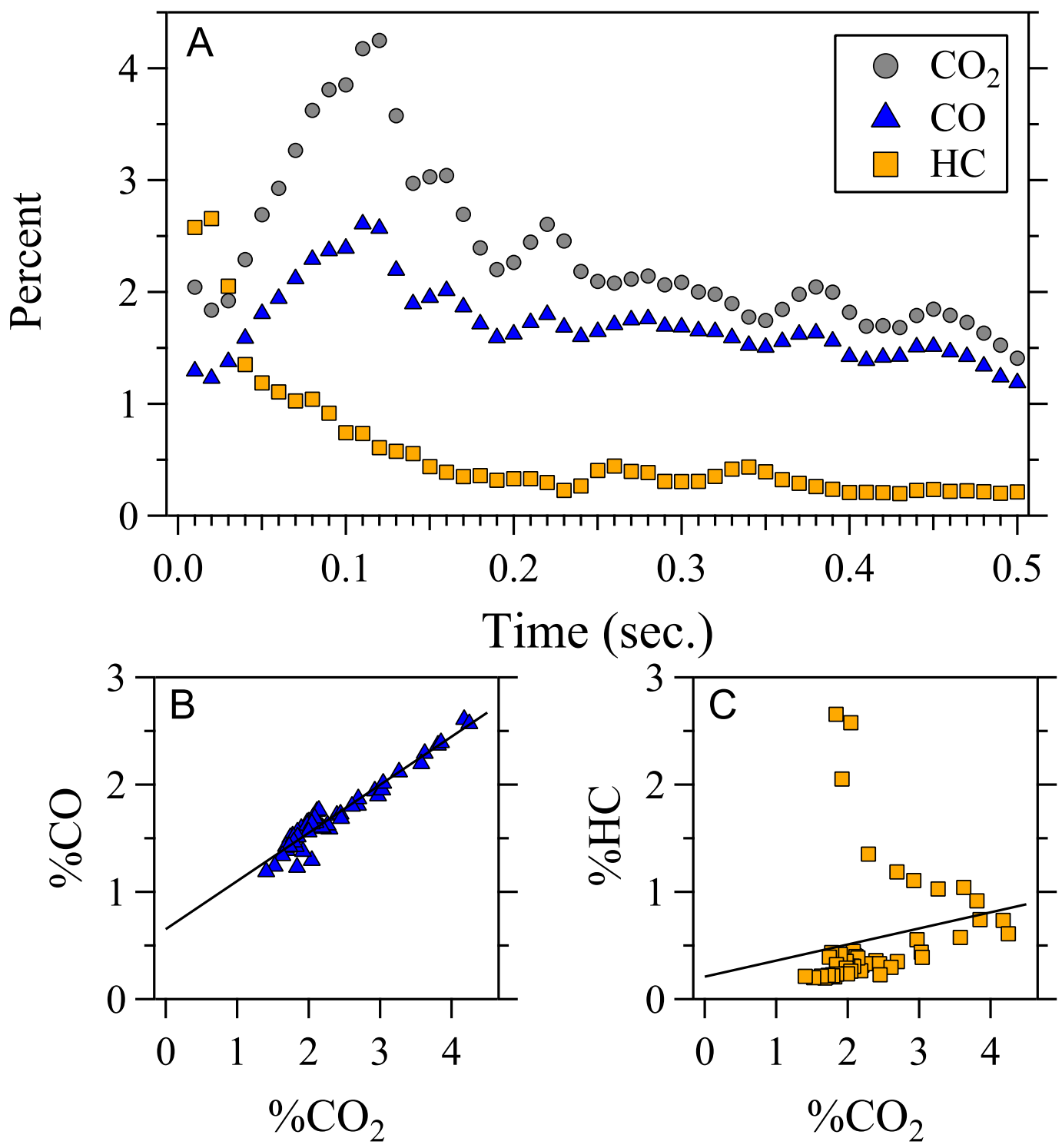

Figure 1. A) Percent emissions versus time for a 1967 sedan measured at the West LA site in 2015 with the University of Denver's FEAT instrument. Percentages are calculated assuming that all of the vehicle's exhaust has been compressed into an $8 \mathrm{~cm}$ cell. Correlation graphs for $\% \mathrm{CO}$ versus $\% \mathrm{CO}_{2}(\mathrm{~B})$ and $\% \mathrm{HC}$ versus $\% \mathrm{CO}_{2}(\mathrm{C})$ for the data in graph $\mathrm{A}$ and least squares best fit lines are shown. The lack of correlation between the observed $\mathrm{HC}$ and $\mathrm{CO}_{2}$ emissions resulted in an invalid $\mathrm{HC}$ exhaust measurement as determined by the FEAT software. 
largest residual increases the level of certainty in detection and reduces the occurrence of false positives.

$$
\begin{aligned}
\mathrm{HC}(\mathrm{ppm} \cdot \mathrm{cm})_{\text {residual }} & =\mathrm{HC}(\mathrm{ppm} \cdot \mathrm{cm})_{\text {measured }}-\mathrm{HC}(\mathrm{ppm} \cdot \mathrm{cm})_{\text {predicted }} \\
\mathrm{RLI}(\mathrm{ppm} \cdot \mathrm{cm}) & \equiv\left\{\mathrm{HC}(\mathrm{ppm} \cdot \mathrm{cm})_{\text {residual }}\right\}^{90 \mathrm{th} \text { Percentile }}
\end{aligned}
$$

Results from the running loss staged testing data indicated that the RLI value is only dependent on the vehicle's running loss emissions rate and the RSD instrument noise (see the supporting information). Because the running loss signal and the instrument noise are both random variables, we described their combined effects on the measured RLI using the square root of the sum of their squares:

$$
R L I(p p m \cdot c m)=\sqrt{R L I_{\text {Signal }}^{2}+R L I_{\text {Noise }}^{2}}
$$

This relationship has good properties for the two asymptotic behaviors of RLI: 1) when $\operatorname{RLI}_{\text {Signal }} \gg \operatorname{RLI}_{\text {Noise }}, \mathrm{RLI}=\mathrm{RLI}_{\text {Signal }}$ and 2) when $\operatorname{RLI}_{\text {Noise }} \gg \operatorname{RLI}_{\text {Signal }}, \mathrm{RLI}=\mathrm{RLI}_{\text {Noise. }}$ Regression modeling using the staged testing data was used to investigate the dependencies of $\mathrm{RLI}_{\text {Signal. }}$ Exhaust $\mathrm{HC}$ was not expected to influence the running loss signal, but a term was included in the model statement in the event that an effect was present. The resulting regression model statement for the running loss signal is given by:

$$
\mathrm{RLI}_{\text {Signal }}=\exp \left[\text { Location }+\mathrm{a} * \ln (\text { Propane })+\mathrm{b} * \ln (\text { Speed })+\mathrm{c}^{*} \text { Exhaust_HC }\right]
$$

where the location is a categorical variable for the propane release point, Propane is the flow rate in $\mathrm{g} / \mathrm{hr}$, Speed is the vehicle speed in miles/hr and Exhaust_HC is the tailpipe exhaust HC concentration in parts per thousand propane. 
The $\mathrm{RLI}_{\text {Noise }}$ value is dominated by the instrument's electronic noise, which was found to change over time, but there can be other measurement or environmental factors that may impact this component. The staged testing found that the slope of the exhaust $\mathrm{HC}$ vs. $\mathrm{CO}_{2}$ correlation also influences instrument noise and while speed was not expected to be a factor a term was included in the model statement in case an effect was present. The resulting regression model statement for the noise signal is:

$$
\mathrm{RLI}_{\mathrm{Noise}}=\text { Instrument }+\mathrm{d} * \operatorname{abs}(\text { Exhaust_HC })+\mathrm{e} * \text { Speed }
$$

where the Instrument coefficient is a categorical variable for the specific instrument being used, Exhaust_HC is the tailpipe exhaust HC concentration in parts per thousand propane and Speed is the vehicle speed in miles/hr. When exhaust HC concentrations are zero, the zero slope can be either positive or negative, because zero measurements are normally distributed around zero, necessitating using the absolute value (abs) of this term.

Regression modeling of equations 3 and 4 using the staged testing data found that all the emissions release locations displayed a major response but without a significant difference between the nine tested locations. In addition, coefficients $a, b, c$ and e were found to not be significantly different from 1, -1, 0 and 0, respectively (see Tables S8 and S9 and the discussion in the supporting information). With these substitutions, equation 3 reduces to:

$$
\mathrm{RLI}_{\text {Signal }}=22.8 \mathrm{ppm} \cdot \mathrm{cm} / \mathrm{g} / \mathrm{mile} * \text { PropaneEmissionRate }(\mathrm{g} / \mathrm{mile})
$$

showing that $\mathrm{RLI}_{\text {Signal }}$ is simply proportional to the running loss emissions rate in $\mathrm{g} / \mathrm{mile}$, independent of vehicle speed, leak location and body shape. Equation 4 reduces to:

$$
\left.\mathrm{RLI}_{\text {Noise }}=\text { Instrument }+13.2 \mathrm{ppm} \cdot \mathrm{cm} / \mathrm{ppthC}_{3} * \text { Exhaust_HC }(\mathrm{ppthC})_{3}\right)
$$


where the noise component is a function of the instrument coefficient and exhaust $\mathrm{HC}$ concentration. When the Exhaust_HC of the vehicle is zero then RLI $\mathrm{Noise}_{\text {is }}$ equal to the Instrument noise coefficient allowing $\mathrm{RLI}_{\text {Noise }}$ to be calculated by averaging RLI values of the newest model year vehicles and assuming their running loss emissions are close to zero ( $\mathrm{RLI}_{\mathrm{Noise}}$ >> RLI $\left.I_{\text {Signal }}\right)$.

Since for the majority of vehicles the instrument noise ( $\left.\mathrm{RLI}_{\text {Noise }}\right)$ will generally be larger than the measured RLI, it is not possible to solve equation 2 for the running loss emissions rate. However, the RLI values can be used to rank the probability that a vehicle's measured RLI is higher than what would be measured if the vehicle had a zero running loss emission rate. The dependence between RLI and a vehicle's tailpipe HC emissions arises in part because as the $\mathrm{HC} / \mathrm{CO}_{2}$ slope increases with tailpipe emissions, the magnitude of the fitting residuals will also increase even for well-correlated data. Instead of correcting the RLI values, the RLI values are binned using bin boundaries that are dependent on the observed HC tailpipe emissions. This compensates for any positive bias introduced with increasing $\mathrm{HC}$ emissions. Bin values for each measurement are the number of standard deviations that the transformed measured RLI is above the transformed RLI for a vehicle with a zero running loss emissions and a comparable exhaust tailpipe $\mathrm{HC}$ concentration (see supporting information). As the bin number increases so does the probability of the vehicle having running loss emissions.

We tested this hypothesis using hot soak emissions data collected at the two Colorado Inspection and Maintenance (I/M) stations in $2008 .{ }^{29} 238$ vehicles were recruited using a stratified sampling plan after being evaluated for running loss emissions by a commercial RSD instrument as they entered the stations. The vehicles were driven on the road for at least 15 minutes and returned to the test locations where two additional RLI measurements were 
collected. The vehicle's engine was shut-off and it was rolled into a temporary (plastic and duct tape) portable hot soak shed (PSHED) and the circulation fans started. The PSHED was sealed and total $\mathrm{HC}$ concentration, temperature and barometric pressure measurements were recorded for the next 15 minutes.

The RLI values assigned each vehicle to Bins -2 to 6 and the resulting distribution is shown in Table 1 and is compared against the PSHED results. Vehicles assigned to RLI Bins -2 , -1 , and 0 were found to have a $9 \%$ chance (21 of 244 measurements) of having a PSHED hot soak emissions of greater than 1 gram VOCs in 15 minutes (the U.S. EPA estimates that Tier 2 vehicles should have less than $0.3 \mathrm{~g} / 15$ minutes). $89 \%$ (51 of 57) of the vehicles with an RLI Bin of 4,5 , or 6 were found to exceed this level. As hypothesized, the probability of finding vehicle evaporative emissions increased with increasing RLI bin number. Since the I/M program exempted the newest seven model years from testing, the fleet represented in Table 1 is not representative of the on-road fleet. Applying this probability distribution to an on-road fleet should significantly reduce the $9 \%$ probability in Bins -2 to 0 due to the large number of newer vehicles that would be included while having less effect on the higher bins.

Generally, the FEAT remote sensing setup does not record the high frequency data (see Figure 1A) for each individual vehicle as it slows the response time of the instrument. For the 2013 and 2015 West Los Angeles measurements, which were collected on the on-ramp from southbound La Brea Ave to eastbound I-10, we were asked by the California Air Resources Board to collect and store the high frequency data. ${ }^{24}$ This resulted in two data sets, the first collected between Saturday April 27 through Saturday May 4, 2013 with 33,806 attempted measurements and 27,247 with valid tailpipe emission measurements and vehicle registration data. The second was 
Table 1. Comparison of RLI Measurements and PSHED Hot Soak Tests

\begin{tabular}{|l|l|l|l|l|}
\hline \multirow{2}{*}{ RLI Bin } & \multicolumn{2}{l|}{ PSHED Tests } & Total Tests & $\begin{array}{l}\text { Percent of Tests } \\
\geq 1 \mathrm{~g} / 15 \mathrm{~min}\end{array}$ \\
\cline { 2 - 4 } & $<1 \mathrm{~g} / 15 \mathrm{~min}$ & $\geq 1 \mathrm{~g} / 15 \mathrm{~min}$ & & $9 \%$ \\
\hline$-2,-1,0$ & 223 & 21 & 244 & $27 \%$ \\
\hline 1 & 90 & 33 & 123 & $59 \%$ \\
\hline 2 & 25 & 36 & 61 & $80 \%$ \\
\hline 3 & 11 & 43 & 54 & $87 \%$ \\
\hline 4 & 4 & 27 & 31 & $100 \%$ \\
\hline 5 & 0 & 17 & 17 & $78 \%$ \\
\hline 6 & 2 & 7 & 9 & \\
\hline
\end{tabular}

collected between Saturday March 28 through Friday April 3, 2015 with 27,413 attempted measurements and had 22,124 valid and registration matched records.

Each attempted measurement included a companion comma delimited file that contained the high frequency data. These files contain the date and time of the measurement, the IR detector normalization voltages (used for normalizing to the background concentrations found in front of the car), 50 voltages (every $10 \mathrm{~ms}$ ) for the IR reference, $\mathrm{CO}, \mathrm{CO}_{2}$ and $\mathrm{HC}$ detectors and the 50 molar concentrations for $\mathrm{CO}, \mathrm{CO}_{2}$, and $\mathrm{HC}$ derived from the voltages. Each ultraviolet spectrophotometer supplies 50 measured concentrations and uncertainty estimates for the NO, $\mathrm{NH}_{3}, \mathrm{SO}_{2}$ and $\mathrm{NO}_{2}$ species. The file also contains the final emission results of the original analysis, validity flags and the measured speed and acceleration if valid. Digital images of the rear of each vehicle with a valid tailpipe emissions measurement were saved with the 2013 data set while the images for all of the measurements (valid or invalid) were recorded for the 2015 data. We developed a program to post process these files to recalculate the original fits and 
results, calculate an RLI index value and assigned that value to its designated bin for each record. For this study, because the standard validity criteria for exhaust measurements could invalidate measurements for vehicles with running loss emissions, we expanded our screening to include all vehicles, not just those we were able to successfully measure the tailpipe emissions.

\section{RESULTS AND DISCUSSION}

Table 2 shows the measurement distribution and the RLI means values for each bin obtained from the RLI screening of all the 2013 and 2015 attempted measurements at the West Los Angeles location. All bins less than or equal to Bin 0 have been combined into Bin 0. Screening the high frequency files found that $96.9 \%$ and $92.9 \%$ of the attempted measurements had RLI measurements that resulted in Bin values of 1 or less and are not expected to have any running loss emissions for the 2013 and 2015 data sets respectively. Conversely where we believe there is a higher probability of running loss emissions, Bins 3 and above, the RLI screening identified $83(\sim 0.2 \%)$ and $656(2.4 \%)$ of the measurements in 2013 and 2015 respectively. The increase between 2013 and 2015 is the result of the $\mathrm{RLI}_{\text {Noise }}$ coefficient increasing by $30 \%$ on a single day (March 30 ${ }^{\text {th }}$ ) above the averaged noise value used in the bin calculations due to unexplained negative voltage deflections in the $\mathrm{HC}$ channel; increasing the number of vehicles in Bins 2, 3 and 4 that were not visually confirmed. Of the 31 visually confirmed vehicles in 20136 have no registration information and similarly 15 out of the 49 visually confirmed vehicles in 2015 .

The RLI screening is a way to search for added noise in each vehicle's tailpipe correlation measurement between $\mathrm{HC}$ and $\mathrm{CO}_{2}$ caused by the addition of non-tailpipe $\mathrm{HC}$. However, there are other sources of measurement noise, electronic and partial physical blockages of the sampling beam for example, which can interfere with the correlation measurements that are not 
Table 2. RLI Measurements and Visual Screening Results for the 2013 and 2015 Data Sets.

\begin{tabular}{|c|c|c|c|c|}
\hline \multirow{2}{*}{$\begin{array}{l}\text { RLI } \\
\text { Bin }\end{array}$} & \multicolumn{2}{|l|}{2013} & \multicolumn{2}{|l|}{2015} \\
\hline & $\begin{array}{l}\text { Measurements }(\%) \\
\text { Mean RLI } \\
(\mathrm{ppm} \cdot \mathrm{cm})\end{array}$ & $\begin{array}{l}\text { Visual } \\
\text { Confirmation } \\
\text { Mean RLI } \\
(\mathrm{ppm} \cdot \mathrm{cm})\end{array}$ & $\begin{array}{l}\text { Measurements (\%) } \\
\text { Mean RLI } \\
(\mathrm{ppm} \cdot \mathrm{cm})\end{array}$ & $\begin{array}{l}\text { Visual } \\
\text { Confirmation } \\
\text { Mean RLI } \\
(\mathrm{ppm} \cdot \mathrm{cm})\end{array}$ \\
\hline$\leq 0$ & $\begin{array}{l}26816(79.32 \%) \\
26\end{array}$ & & $\begin{array}{l}21390(78.10 \%) \\
17\end{array}$ & \\
\hline 1 & $\begin{array}{l}5966(17.64 \%) \\
43\end{array}$ & & $\begin{array}{l}4050(14.79 \%) \\
28\end{array}$ & \\
\hline 2 & $\begin{array}{l}972(2.88 \%) \\
62\end{array}$ & $\begin{array}{l}13(1.3 \%) \\
133\end{array}$ & $\begin{array}{l}1286(4.69 \%) \\
41\end{array}$ & $\begin{array}{l}5(0.4 \%) \\
251\end{array}$ \\
\hline 3 & $\begin{array}{l}72(0.21 \%) \\
105\end{array}$ & $\begin{array}{l}14(19.4 \%) \\
114\end{array}$ & $\begin{array}{l}483(1.76 \%) \\
63\end{array}$ & $\begin{array}{l}10(2.1 \%) \\
218\end{array}$ \\
\hline 4 & $\begin{array}{l}12(0.04 \%) \\
688\end{array}$ & $\begin{array}{l}4(33.3 \%) \\
1616\end{array}$ & $\begin{array}{l}160(0.58 \%) \\
140\end{array}$ & $\begin{array}{l}17(10.6 \%) \\
598\end{array}$ \\
\hline 5 & $\begin{array}{l}1(0.01 \%) \\
232\end{array}$ & 0 & $\begin{array}{l}14(0.05 \%) \\
192\end{array}$ & $\begin{array}{l}9(64.3 \%) \\
224\end{array}$ \\
\hline 6 & 0 & & $\begin{array}{l}6(0.02 \%) \\
256\end{array}$ & $\begin{array}{l}5(83.3 \%) \\
267\end{array}$ \\
\hline 7 & 0 & & $\begin{array}{l}3(0.01 \%) \\
408\end{array}$ & $\begin{array}{l}3(100 \%) \\
408\end{array}$ \\
\hline Totals & $\begin{array}{l}33,806(100 \%) \\
30\end{array}$ & $\begin{array}{l}31(0.1 \%) \\
315\end{array}$ & $\begin{array}{l}27,392(100 \%) \\
21\end{array}$ & $\begin{array}{l}49(0.2 \%) \\
371\end{array}$ \\
\hline
\end{tabular}


caused by gas absorption. We therefore designed a graphical display program to view the high frequency data files and confirm the presence of an added HC signal. Due to the manageable number of suspected vehicles found, we chose to review all of the measurements that were categorized in Bin 2 or higher. This process is necessarily subjective; however, exclusions due to identifiable reasons other than running loss emissions are important for deriving the final numbers and establishing guidelines for any future studies. The results of the visual inspection of the measurements in RLI Bin 2 and higher are also included in Table 2 (see Tables S11 and S12 in supporting information for detailed list). As expected, very few Bin 2 values $(1.3 \%$ in 2013 and $0.4 \%$ in 2015 ) were judged to have any possible running loss emissions. As found with the PSHED testing, the percentage of vehicles flagged by the RLI screening and visually confirmed increased with increasing bin number for both years' data sets.

For the visually confirmed vehicles identified by registration data, California LEV I vehicles (1994 - 2003 model years) account for the largest age group for both years (13 in 2013 and 14 unique vehicles in 2015 with 16 records as one vehicle was identified three times). This represents $52 \%(13 / 25)$ and $47 \%(16 / 34)$ of the visually confirmed and plate-matched vehicles in 2013 and 2015 respectively (see Tables S11 and S12 in the supporting information). For the 2013 and 2015 data sets there were 6 and 9 (this does not count the 1936 coupe visually identified) vehicles respectively in each of the $2004 \&$ newer and 1993 \& older age groups. The 15 vehicles without registration information identified in 2015 that we have plate images for are composed of 3 cars and 11 trucks.

Fewer vehicles were suspected of running loss emissions in 2013 than in 2015 and these differences are in part the result of higher observed instrument noise levels in 2013. The regression results (see Table S9 in the supporting information) can be used to estimate the 
minimum detection limit (MDL) as defined by 40 CFR Part 136 Appendix B for each FEAT data set. ${ }^{30}$ This provides an emissions rate floor for those vehicles visually confirmed and found in Bins 3 and higher. The estimated running loss MDL's for the FEAT 3002 instrument used for both campaigns are 2.8 and $1.6 \mathrm{~g} / \mathrm{mile}$ on a propane basis for the 2013 and 2015 data respectively. For comparison, the Federal Tier 2 and 3 running loss standard is $0.05 \mathrm{~g} / \mathrm{mile}$.

All of the vehicles visually identified possessed emission patterns that suggest the presence of running loss emissions (see the supporting information for a complete listing by measurement year). There were five prominent patterns found in the 2013 and 2015 data that we labeled 1) anti-correlated (19\% and 14\%, see Figure S14A), 2) consistently decreasing HC signal (36\% and $25 \%$, see Figure S14B), 3) HC exponential decay (16\% and 20\%, see Figure 1A), 4) rising or late burst of $\mathrm{HC}$ signal (26\% and 29\%, see Figure 3) and 5) high background (3\% and 12\%). Using the high frequency time series data, Figure S14 in the supporting information gives examples of the anti-correlated and the consistently decreasing $\mathrm{HC}$ signal for two of the suspected running loss emission vehicles. Figure S14A graphs the $\% \mathrm{CO}_{2}$ (-, left axis) and $\% \mathrm{HC}$ ( , right axis) emissions versus time for a 1998 pickup truck measured in 2015 (RLI 246, Bin 5) showing the $\mathrm{HC}$ emissions falling as the $\mathrm{CO}_{2}$ emissions rise and then having that pattern reverse before both species start to decrease together as they dilute behind the truck. This is one of three visually confirmed measurements for this vehicle in 2015. Figure S14B is a similar graph for a 2005 van measured in 2015 (RLI 92, Bin 3) again showing little correlation between the two species with the $\mathrm{HC}$ concentrations consistently decreasing during the $0.5 \mathrm{~s}$ measurement. A third common pattern is an exponential decay (see Figure 1A for an example) that is similar to the pattern shown in Figure S14B but exhibits a steeper decline early in the measurement. 
Since it was not possible to confirm actual running loss emissions from any of the vehicles identified by the RLI screening, we are left to present three proofs of concept identifications that we believe supports this contention. Figure 2 presents the plate image (A) and the emissions time series plot (B) for a pickup truck measured in 2015 (RLI 392, Bin 3). Clearly visible are a large liquefied gas (LP) tank in the bed of the truck and some type of equipment for dispensing tar attached at the rear. This vehicle had an unreadable license plate and was not included in the emissions database but was discovered by the RLI screening. The time series plot for HC and $\mathrm{CO}_{2}$ (Figure 2B) shows apparent correlation during the first half of the measurement but the $\mathrm{HC}$ concentration steadily increases throughout the remainder of the measurement. The FEAT software invalidated the $\mathrm{HC}$ results because of the overall poor correlation. The $\mathrm{HC} / \mathrm{CO}_{2}$ correlation before $0.25 \mathrm{~s}$ is also suspect for two reasons: 1 ) if you look carefully at $0.05 \mathrm{~s}$ in the time series you can see that the $\mathrm{HC}$ concentration starts to rise before the $\mathrm{CO}_{2}$ does indicating separate plumes and 2) the magnitude of the early correlation indicates a gross emitting $\mathrm{HC}$ vehicle $(\mathrm{gHC} / \mathrm{kg}$ of Fuel > 200, 2015 fleet mean was 1.3) yet this vehicle has no tailpipe CO emissions. HC emissions at this level are indicative of a misfire and the unburned fuel would be expected to have been partially converted to $\mathrm{CO}$ on the catalytic converter until the available oxygen is consumed increasing the $\mathrm{CO}$ emissions. These two pieces of information suggest that the early correlation is happen-stance and occurs due to the turbulence behind the truck diluting the tar or LP emissions along with the tailpipe $\mathrm{CO}_{2}$.

Figure 3 includes the plate image (A) for a 1936 antique car (identified by a car buff for the authors) measured in 2015 (RLI 213, Bin 4). This vehicle has more $\mathrm{CO}$ in its exhaust than $\mathrm{CO}_{2}$ as might be expected for its age. Figure $3 \mathrm{~B}$ are the time series plots for $\mathrm{HC}$ and $\mathrm{CO}_{2}$ and shows a late burst in the $\mathrm{HC}$ emissions during the second half of the measurement indicating two $\mathrm{HC}$ 

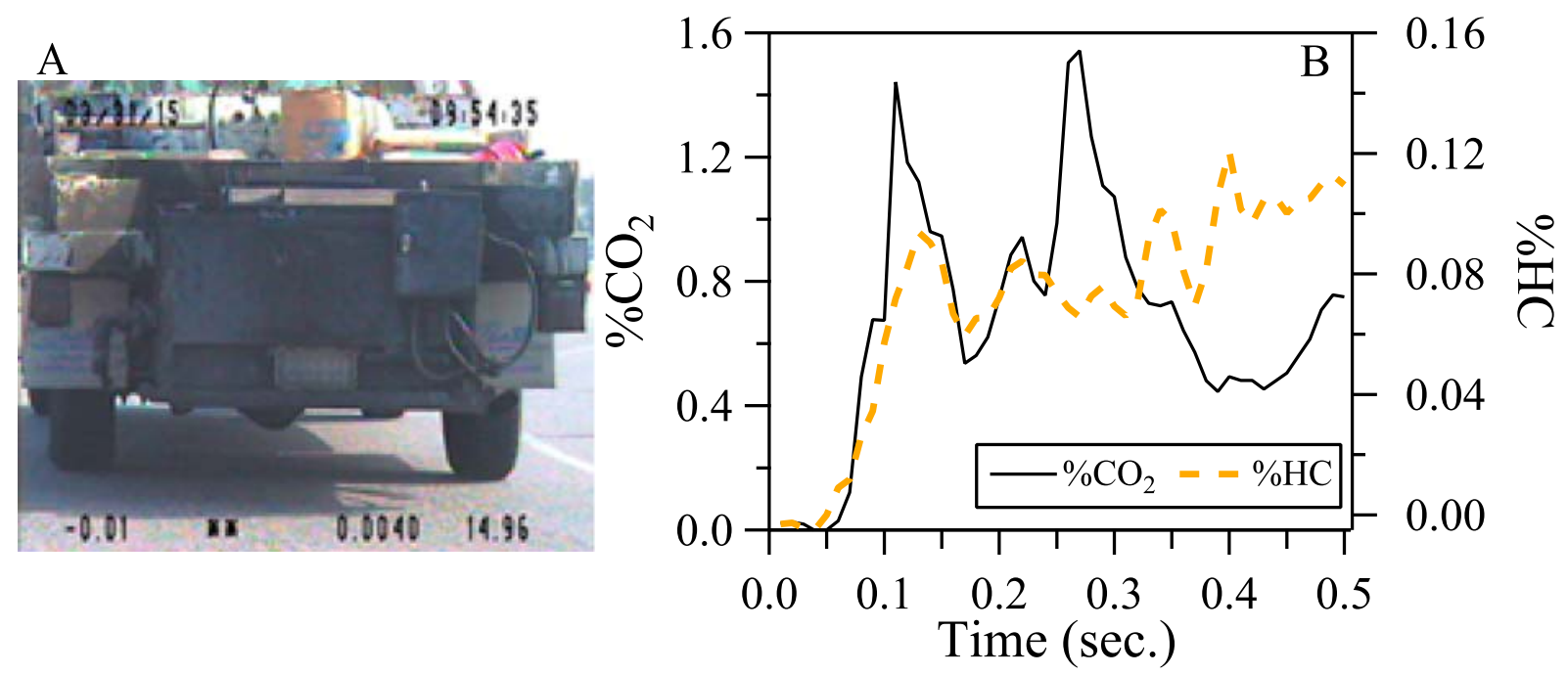

Figure 2. A) Rear image of a pickup truck with a propane tank and some type of asphalt patching system. The image includes counter-clockwise from the lower left, tailpipe $\% \mathrm{CO}, \% \mathrm{HC}$ (stars indicate software invalidated this result), $\% \mathrm{NO}, \% \mathrm{CO}_{2}$, time and date. $\left.\mathrm{B}\right) \% \mathrm{CO}_{2}($ solid line, left axis) and \% HC (dashed line, right axis) versus time for this truck's measurement.
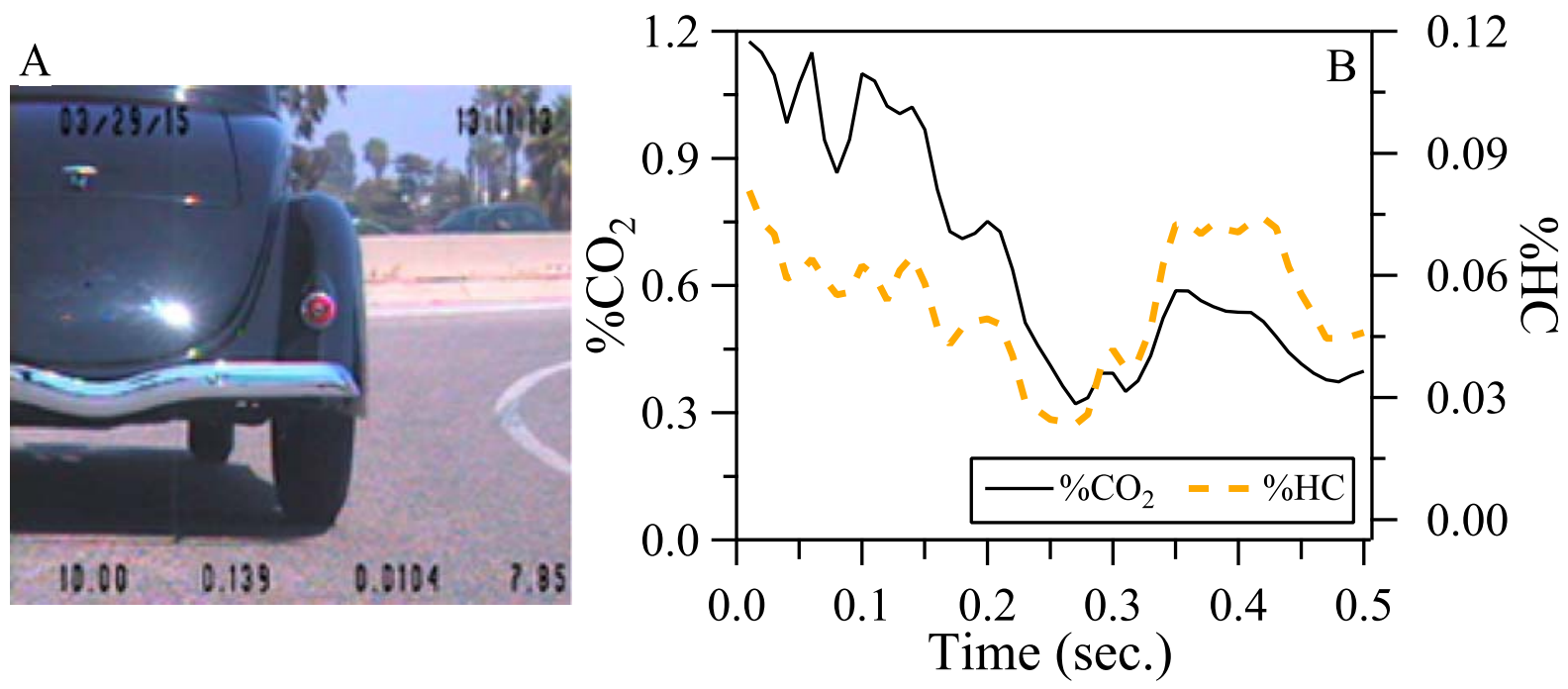

Figure 3. A) Rear image of an antique car, identified as a 1936 Coupe. The image includes counter-clockwise from the lower left, tailpipe $\% \mathrm{CO}, \% \mathrm{HC}, \% \mathrm{NO}, \% \mathrm{CO}_{2}$, time and date. B) $\% \mathrm{CO}_{2}$ (solid line, left axis) and \% $\mathrm{HC}$ (dashed line, right axis) versus time for this car's measurement. 
emission sources. With no catalytic converter and running very rich, there are undoubtedly $\mathrm{HC}$ emissions in the tailpipe exhaust as evidenced by the correlation in the first half of the measurement. This vehicle will also have a gas tank vented to the atmosphere that we suspect is behind the large increase in the $\mathrm{HC}$ concentrations during the second half of the measurement.

The final vehicle is a natural gas powered (identified by the visibility of the cylinder and its blue fill cap in the plate image) garbage truck measured in 2015 (RLI 103, Bin 4). The time series plots of $\mathrm{HC}$ and $\mathrm{CO}_{2}$ in Figure $\mathrm{S} 15 \mathrm{~B}$ in the supporting information shows a burst of methane behind the vehicle well before the exhaust emissions show up around $0.3 \mathrm{~s}$ indicating some type of leak in the vehicle's fuel system or storage container. An elevated exhaust may be behind the delay requiring additional time for the exhaust emissions to reach ground level.

These three vehicles were unknown prior to the RLI screening and not in the West Los Angeles 2015 emissions database because they lacked a readable license plate. While the pickup truck's tar pot may not technically qualify as a running loss emission and the antique car is not typical of today's modern vehicles, they both undoubtedly have a source of hydrocarbon emissions other than from the tailpipe that the screening process found while the third vehicle shows an $\mathrm{HC}$ emission in the absence of any exhaust $\mathrm{CO}_{2}$. For comparison see Figure $\mathrm{S} 16$ in the supporting information for examples of two vehicles with low RLIs, one with high tailpipe HC and one with low.

As previously discussed, additional sources of noise can be introduced by the instrument or the vehicles that can elevate the RLI values and were eliminated as false positives during the visual inspection process. Vehicles can introduce noise through the presence of partial beam blockages during the $0.5 \mathrm{~s}$ emission measurement. The FEAT instrument's reference detector $(3.9 \mu \mathrm{m})$ is a critical signal used by the instrument to detect the difference between physical blockages of the 
light beam and gas absorbance since there are no vehicle emissions that absorb in this wavelength region. As a quality check, if the software detects voltage reductions in this channel that exceed $\pm 2.5 \%$ of the before-car values it eliminates these measurements from use in the correlation graphs. However, the multi-detector system is not perfectly twinned and beam blockages that result in a voltage drop larger than $2.5 \%$ but that are not large enough to trigger a measurement restart can produce outlying points that can inflate the RLI value. Figures S17 and S18, in the supporting information, show data from a medium-duty truck (RLI 43, Bin 2) that illustrates how a physical blockage of the beam during the measurement can inflate the RLI value and produce a false positive.

Assuming that all of the vehicles visually identified from each year's data sets are running loss emitters we found that in 2013 only $0.09 \%$ (31) of the 33,806 attempted measurements were suspected. This doubled in 2015 to $0.18 \%$ (49) of the 27,413 attempted measurements. Assuming the unidentified attempts have the same repeat measurement frequency as the plate matched vehicles, the running loss fleet percentages for unique vehicles increase to $0.13 \%(31 / 24583)$ and $0.22 \%$ (47/21574) for 2013 and 2015 respectively. Therefore, from this screening, between 0.1 and $0.2 \%$ of the in-use fleet at the West Los Angles site in 2013 and 2015 are expected to have running loss emissions that are at least a factor of 32 to 56 times larger than the U.S. Federal Tier 2 and 3 standards.

Unfortunately, there has not been an attempt to directly apportion tailpipe and non-tailpipe VOC emissions since Gentner et al.'s work in $2005 .{ }^{15}$ Their measurements supported the idea that tailpipe $\mathrm{HC}$ emissions remain the dominant source in ambient air in the Los Angeles Basin. Warneke et al. analyzed over five decades of ambient measurements (1960 - 2010) and showed that the VOC/CO ratio has remained constant over this time period again emphasizing the link 
with tailpipe emissions. ${ }^{3}$ Borbon et al. used ground-based and airborne VOC measurements collected in Los Angeles in 2010 to show that the butane/CO ratios were similar during the daytime and nighttime measurements. ${ }^{31}$ Since the heating during the day should elevate evaporative emissions this observation minimizes the importance of non-tailpipe evaporative emissions in the Los Angeles Basin. Our finding of only a small number of vehicles $(0.1-0.2 \%)$ in a 9 year-old fleet in West Los Angeles with measurable running loss emissions is consistent with these ambient measurements.

This work has been a first attempt to produce a non-intrusive screening method applicable to large numbers of vehicles making it possible to estimate the size of an in-use fleet with elevated running loss emissions. Additional research is needed to expand on the confirmation testing previously conducted in Colorado to include vehicles identified on-road and further improve the method and to establish false positive and false negative detection rates.

\section{ASSOCIATED CONTENT}

\section{Supporting Information.}

The Supporting Information is available free of charge on the ACS Publications website at DOI:

EMFAC2017 total organic gas for the South Coast Air Basin in 2015; Measurement summary statistics; \%HC residuals plot; Residual listing; Emissions versus time with no running loss emissions; Correlation graphs for previous measurements; Emissions versus time with running loss emissions; Correlation graphs for the previous measurements; Test vehicle listing; Summary of propane running loss tests; Summary of liquid gasoline running loss tests; Summary of induced running loss tests; Running loss emission rate 
effects; Speed impacts on running loss emissions; Leak location effects; RLI values at different running loss emission rates and speeds; Regression coefficients for first model; Regression coefficients for simplified model; Parity plot for simplified model; Frequency Histogram of transformed RLI values; Mean RLI values by model year; FEAT 2015 speed versus exhaust HC; RLI Bin values versus propane release rate; Examples of anticorrelated and decreasing $\mathrm{HC}$ patterns; Tag image and time series for a CNG garbage truck; Examples of a high and low exhaust $\mathrm{HC}$ and no running loss emissions; Measurement data for a truck visually excluded; Tag image of truck; Listing of 2013 vehicles visually confirmed; Listing of 2015 vehicles visually confirmed; (PDF)

\section{AUTHOR INFORMATION}

\section{Corresponding Author}

*Phone (303) 871-2584. Email: gbishop@ du.edu.

\section{ORCID}

Gary A. Bishop: 0000-0003-0136-997X

\section{Author Contributions}

The manuscript was written through contributions of all authors. All authors have given approval to the final version of the manuscript.

\section{Funding Sources}

Coordinating Research Council E-123-3 funded G. A. Bishop for this research 


\section{Notes}

The authors declare the following competing financial interest(s): G. A. Bishop acknowledges previous receipt of patent royalty payments from Envirotest, an operating subsidiary of Opus Inspection, which previously licensed vehicle emissions testing technology developed at the University of Denver.

\section{ACKNOWLEDGMENT}

The author (G.A.B.) would like to acknowledge the financial support of the Coordinating Research Council (E-123-3) and the Real World Working Group. The California Air Resources Board for funding the collection of the measurements. The authors (T.H.D., J.A.S. and J.M.K) would like to acknowledge the financial support of the U.S. Environmental Protection Agency for the CDPHE study. The results and conclusions presented here are solely the responsibility of the authors and may not represent the views of the sponsors.

\section{REFERENCES}

1. Bishop, G. A.; Haugen, M. J., The story of ever diminishing vehicle tailpipe emissions as observed in the Chicago, Illinois area. Environ. Sci. Technol. 2018, 52, (13), 7587-7593, DOI: 10.1021/acs.est.8b00926.

2. de Foy, B., City-level variations in $\mathrm{NO}_{\mathrm{x}}$ emissions derived from hourly monitoring data in Chicago. Atmos. Environ. 2018, 176, 128-139, DOI:

https://doi.org/10.1016/j.atmosenv.2017.12.028.

3. Warneke, C.; de Gouw, J. A.; Holloway, J. S.; Peischl, J.; Ryerson, T. B.; Atlas, E.; Blake, D.; Trainer, M.; Parrish, D. D., Multiyear trends in volatile organic compounds in Los Angeles, 
California: Five decades of decreasing emissions. Journal of Geophysical Research, [Atmospheres] 2012, 117, (D00V17), 1-10, DOI: 10.1029/2012JD017899

4. McDonald, B. C.; Gentner, D. R.; Goldstein, A. H.; Harley, R. A., Long-term trends in motor vehicle emissions in U.S. urban areas. Environ. Sci. Technol. 2013, 47, (17), 10022-10031, DOI: 10.1021/es401034z.

5. McDonald, B. C.; Dallmann, T. R.; Martin, E. W.; Harley, R. A., Long-term trends in nitrogen oxide emissions from motor vehicles at national, state, and air basin scales. J. Geophys. Res. Atmos. 2012, 117, (D18), 1-11, DOI: 10.1029/2012jd018304.

6. Pang, Y.; Fuentes, M.; Rieger, P., Trends in the emissions of Volatile Organic Compounds (VOCs) from light-duty gasoline vehicles tested on chassis dynamometers in Southern California. Atmos. Environ. 2014, 83, 127-135, DOI: https://doi.org/10.1016/j.atmosenv.2013.11.002.

7. Clean Air Act Text. U. S. Environmental Protection Agency. http://www.epa.gov/air/caa/text.html.

8. National Ambient Air Quality Standards. U. S. Environmental Protection Agency. http://www.epa.gov/air/criteria.html.

9. Pollack, I. B.; Ryerson, T. B.; Trainer, M.; Neuman, J. A.; Roberts, J. M.; Parrish, D. D., Trends in ozone, its precursors, and related secondary oxidation products in Los Angeles, California: A synthesis of measurements from 1960 to 2010. Journal of Geophysical Research, [Atmospheres] 2013, 118, 1-19, DOI: 10.1002/jgrd.50472.

10. Parrish, D. D.; Singh, H. B.; Molina, L.; Madronich, S., Air quality progress in North American megacities: A review. Atmos. Environ. 2011, 45, 7015-7025, DOI: doi:10.1016/j.atmosenv.2011.09.039. 
11. Parrish, D. D.; Young, L. M.; Newman, M. H.; Aikin, K. C.; Ryerson, T. B., Ozone Design Values in Southern California's Air Basins: Temporal Evolution and U.S. Background Contribution. J. Geophys. Res. Atmos. 2017, 122, (20), 11,166-11,182, DOI: 10.1002/2016jd026329.

12. Liu, H.; Man, H.; Tschantz, M.; Wu, Y.; He, K.; Hao, J., VOC from Vehicular Evaporation Emissions: Status and Control Strategy. Environ. Sci. Technol. 2015, 49, (24), 14424-14431, DOI: 10.1021/acs.est.5b04064.

13. Pierson, W. R.; Schorran, D. E.; Fujita, E. M.; Sagebiel, J. C.; Lawson, D. R.; Tanner, R. L., Assessment of nontailpipe hydrocarbon emissions from motor vehicles. J. Air Waste Manage. Assoc. 1999, 49, 498-519, DOI: https://doi.org/10.1080/10473289.1999.10463827.

14. Rubin, J. I.; Kean, A. J.; Harley, R. A.; Millet, D. B.; Goldstein, A. H., Temperature dependence of volatile organic compound evaporative emissions from motor vehicles. $J$. Geophys. Res. Atmos. 2006, 111, (D3), DOI: 10.1029/2005JD006458.

15. Gentner, D. R.; Harley, R. A.; Miller, A. M.; Goldstein, A. H., Diurnal and Seasonal Variability of Gasoline-Related Volatile Organic Compound Emissions in Riverside, California. Environ. Sci. Technol. 2009, 43, (12), 4247-4252, DOI: 10.1021/es9006228.

16. EMFAC Emissions Database. California Environmental Protection Agency; Air Resources Board. http://www.arb.ca.gov/emfac/ (July, 2019).

17. Fujita, E. M.; Campbell, D. E.; Zielinska, B.; Chow, J. C.; Lindhjem, C. E.; DenBleyker, A.; Bishop, G. A.; Schuchmann, B. G.; Stedman, D. H.; Lawson, D. R., Comparison of the MOVES2010a, MOBILE6.2 and EMFAC2007 mobile source emissions models with on-road traffic tunnel and remote sensing measurements. J. Air Waste Manage. Assoc. 2012, 62, (10), 1134-1149, DOI: 10.1080/10962247.2012.699016. 
18. Pang, Y.; Fuentes, M.; Rieger, P., Trends in selected ambient volatile organic compound (VOC) concentrations and a comparison to mobile source emission trends in California's South Coast Air Basin. Atmos. Environ. 2015, 122, 686-695, DOI: 10.1016/j.atmosenv.2015.10.016. 19. Gentner, D. R.; Worton, D. R.; Isaacman, G.; Davis, L. C.; Dallmann, T. R.; Wood, E. C.; Herndon, S. C.; Goldstein, A. H.; Harley, R. A., Chemical Composition of Gas-Phase Organic Carbon Emissions from Motor Vehicles and Implications for Ozone Production. Environ. Sci. Technol. 2013, 47, (20), 11837-11848, DOI: 10.1021/es401470e.

20. Sampling and analytical systems; evaporative emissions. In Code of Federal Regulations; Title 40 Part 86.107-96, Section 2014.

21. Nowak, J. B.; Neuman, J. A.; Bahreini, R.; Middlebrook, A. M.; Holloway, J. S.; McKeen, S.; Parrish, D. D.; Ryerson, T. B.; Trainer, M., Ammonia sources in the California South Coast Air Basin and their impact on ammonium nitrate formation. Geophys. Res. Lett. 2012, 39, L07804, DOI: 10.1029/2012GL051197.

22. McDonald, B. C.; McKeen, S. A.; Cui, Y. Y.; Ahmadov, R.; Kim, S.-W.; Frost, G. J.;

Pollack, I. B.; Peischl, J.; Ryerson, T. B.; Holloway, J. S.; Graus, M.; Warneke, C.; Gilman, J. B.; de Gouw, J. A.; Kaiser, J.; Keutsch, F. N.; Hanisco, T. F.; Wolfe, G. M.; Trainer, M., Modeling Ozone in the Eastern U.S. using a Fuel-Based Mobile Source Emissions Inventory. Environ. Sci. Technol. 2018, 52, (13), 7360-7370, DOI: 10.1021/acs.est.8b00778.

23. Hassler, B.; McDonald, B. C.; Frost, G. J.; Borbon, A.; Carslaw, D. C.; Civerolo, K.;

Granier, C.; Monks, P. S.; Monks, S.; Parrish, D. D.; Pollack, I. B.; Rosenlof, K. H.; Ryerson, T. B.; von Schneidemesser, E.; Trainer, M. C. G. L., Analysis of long-term observations of $\mathrm{NO}_{\mathrm{x}}$ and $\mathrm{CO}$ in megacities and application to constraining emissions inventories. Geophys. Res. Lett.

2016, 43, (18), 9920-9930, DOI: 10.1002/2016g1069894. 
24. Bishop, G. A.; Stedman, D. H., Measuring real-world emissions from the on-road passenger fleet; California Air Resources Board: Sacramento, CA, 2016;

http://www.feat.biochem.du.edu/assets/databases/Cal/Univ_Denver_ARB_12_303_Final_report 2016.pdf.

25. Singer, B. C.; Harley, R. A.; Littlejohn, D.; Ho, J.; Vo, T., Scaling of infrared remote sensor hydrocarbon measurements for motor vehicle emission inventory calculations. Environ. Sci.

Technol. 1998, 32, 3241-3248, DOI: 10.1021/es980392y.

26. Burgard, D. A.; Bishop, G. A.; Stadtmuller, R. S.; Dalton, T. R.; Stedman, D. H., Spectroscopy applied to on-road mobile source emissions. Appl. Spectrosc. 2006, 60, 135A148A, DOI: 10.1366/000370206777412185.

27. Burgard, D. A.; Dalton, T. R.; Bishop, G. A.; Starkey, J. R.; Stedman, D. H., Nitrogen dioxide, sulfur dioxide, and ammonia detector for remote sensing of vehicle emissions. Rev. Sci. Instrum. 2006, 77, (014101), 1-4, DOI: 10.1063/1.2162432.

28. Bishop, G. A.; Starkey, J. R.; Ihlenfeldt, A.; Williams, W. J.; Stedman, D. H., IR long-path photometry, A remote sensing tool for automobile emissions. Anal. Chem. 1989, 61, 671A677A, DOI: 10.1021/ac00185a746.

29. DeFries, T. H.; Palacios, C. F.; Weatherby, M. F.; Kishan, S., Estimated summer hot-soak evaporative emissions distributions for the Denver fleet; Austin, TX, 2012.

30. Definition and Procedure for the Determination of the Method Detection Limit - Revision 2. In Code of Federal Regulations; Title 40, Part 136, Appendix B, Section 2017.

31. Borbon, A.; Gilman, J. B.; Kuster, W. C.; Grand, N.; Chevaillier, S.; Colomb, A.; Dolgorouky, C.; Gros, V.; Lopez, M.; Sarda-Esteve, R.; Holloway, J.; Stutz, J.; Petetin, H.; McKeen, S.; Beekmann, M.; Warneke, C.; Parrish, D. D.; de Gouw, J. A., Emission ratios of 
anthropogenic volatile organic compounds in northern mid-latitude megacities: Observations versus emission inventories in Los Angeles and Paris. J. Geophys. Res. Atmos. 2013, 118, (4), 2041-2057, DOI: 10.1002/jgrd.50059. 


\section{Supporting Information For:}

A Vehicle Exhaust Remote Sensing Device Method to Screen Vehicles for Evaporative Running Loss Emissions

Gary A. Bishop $^{\dagger *}$, Timothy H. DeFries ${ }^{\ddagger}$, James A. Sidebottom ${ }^{\S}$ and James M. Kemper ${ }^{\S}$

${ }^{\dagger}$ Department of Chemistry and Biochemistry, University of Denver, Denver, Colorado 80208, United States

"Eastern Research Group, Inc., 3508 Far West Blvd., Suite 210, Austin, TX 78731, United States

${ }^{\S}$ Colorado Department of Public Health and Environment, 4300 Cherry Creek Drive South, Denver, Colorado 80246, United States

*Corresponding author: Gary A. Bishop, gbishop@du.edu

Number of pages: 33

Number of tables: 12

Number of figures: 18 
Table S1. Total Organic Gases Results using EMFAC2017 for the South Coast Air Basin in 2015

https://www.arb.ca.gov/emfac/2017/

EMFAC2017 (v1.0.2) Emissions Inventory

Region Type: Air Basin

Region: SOUTH COAST

Calendar Year: 2015

Season: Summer

Vehicle Classification: EMFAC2011 Categories

Units: tons/day for Emissions

$\begin{array}{lrrrrrrrrr}\text { Fuel } & \text { RUNEX } & \text { IDLEX } & \text { STREX } & \text { TOTEX } & \text { DIURN } & \text { HTSK } & \text { RUNLS } & \text { RESTL } & \text { TOG_TOTAL } \\ \text { DSL } & 8.16 & 0.58 & 0.00 & 8.74 & 0.00 & 0.00 & 0.00 & 0.00 & 8.74 \\ \text { ELEC } & 0.00 & 0.00 & 0.00 & 0.00 & 0.00 & 0.00 & 0.00 & 0.00 & 0.00 \\ \text { GAS } & 40.54 & 0.23 & 28.40 & 69.17 & 10.41 & 11.25 & 28.47 & 7.92 & 127.22 \\ \text { NG } & 6.30 & 0.00 & 0.00 & 6.30 & 0.00 & 0.00 & 0.00 & 0.00 & 6.30 \\ & & & & & & & & & 142.26\end{array}$

Gasoline Running Exhaust 69.17 tons/day (49\% of TOG_TOTAL of 142.26)

Gasoline Evaporative Emissions 58.05 tons/day (41\% of TOG_TOTAL of 142.26) 
Table S2. Summary Statistics for 2013 and 2015 West Los Angeles Measurements.

\begin{tabular}{|c|c|c|c|c|c|}
\hline \multirow[b]{2}{*}{ Dates } & \multirow{2}{*}{$\begin{array}{l}\text { Attempts / Plates / Matched } \\
\text { Mean Model Year } \\
\text { Mean Speed (mph) } \\
\text { Mean Acceleration (mph/s) }\end{array}$} & \multicolumn{4}{|c|}{ Mean $(\mathrm{g} / \mathrm{kg})$ of Fuel Emissions and SEMs ${ }^{\mathrm{a}}$} \\
\hline & & $\mathrm{CO}$ & $\mathrm{HC}$ & $\begin{array}{c}\mathrm{NO}^{\mathrm{b}} \\
\mathrm{NO}_{2} \\
\mathrm{NO}_{\mathrm{x}}{ }^{\mathrm{c}} \\
\end{array}$ & $\mathrm{NH}_{3}$ \\
\hline $\begin{array}{c}4 / 27-5 / 4 \\
2013\end{array}$ & $\begin{array}{c}33806 / 27808 / 27247 \\
2004.7 \\
21.9 \\
-0.2 \\
\end{array}$ & $16.4 \pm 0.6$ & $2.2 \pm 0.2$ & $\begin{aligned} 2.1 & \pm 0.1 \\
0.15 & \pm 0.02 \\
3.4 & \pm 0.1\end{aligned}$ & $0.58 \pm 0.02$ \\
\hline $\begin{array}{c}3 / 28-4 / 3 \\
2015\end{array}$ & $\begin{array}{c}27413 / 25908 / 22124 \\
2006.9 \\
18.8 \\
1.2\end{array}$ & $13.2 \pm 0.4$ & $1.3 \pm 0.1$ & $\begin{array}{c}1.8 \pm 0.1 \\
-0.06 \pm 0.01 \\
2.6 \pm 0.2\end{array}$ & $0.72 \pm 0.02$ \\
\hline
\end{tabular}

${ }^{\mathrm{a}}$ Calculated using a carbon mass fraction of 0.86 . Standard error of the means (SEMs) are calculated using the daily measurements.

${ }^{b}$ moles of NO.

${ }^{c}$ moles of $\mathrm{NO}_{2}$. 


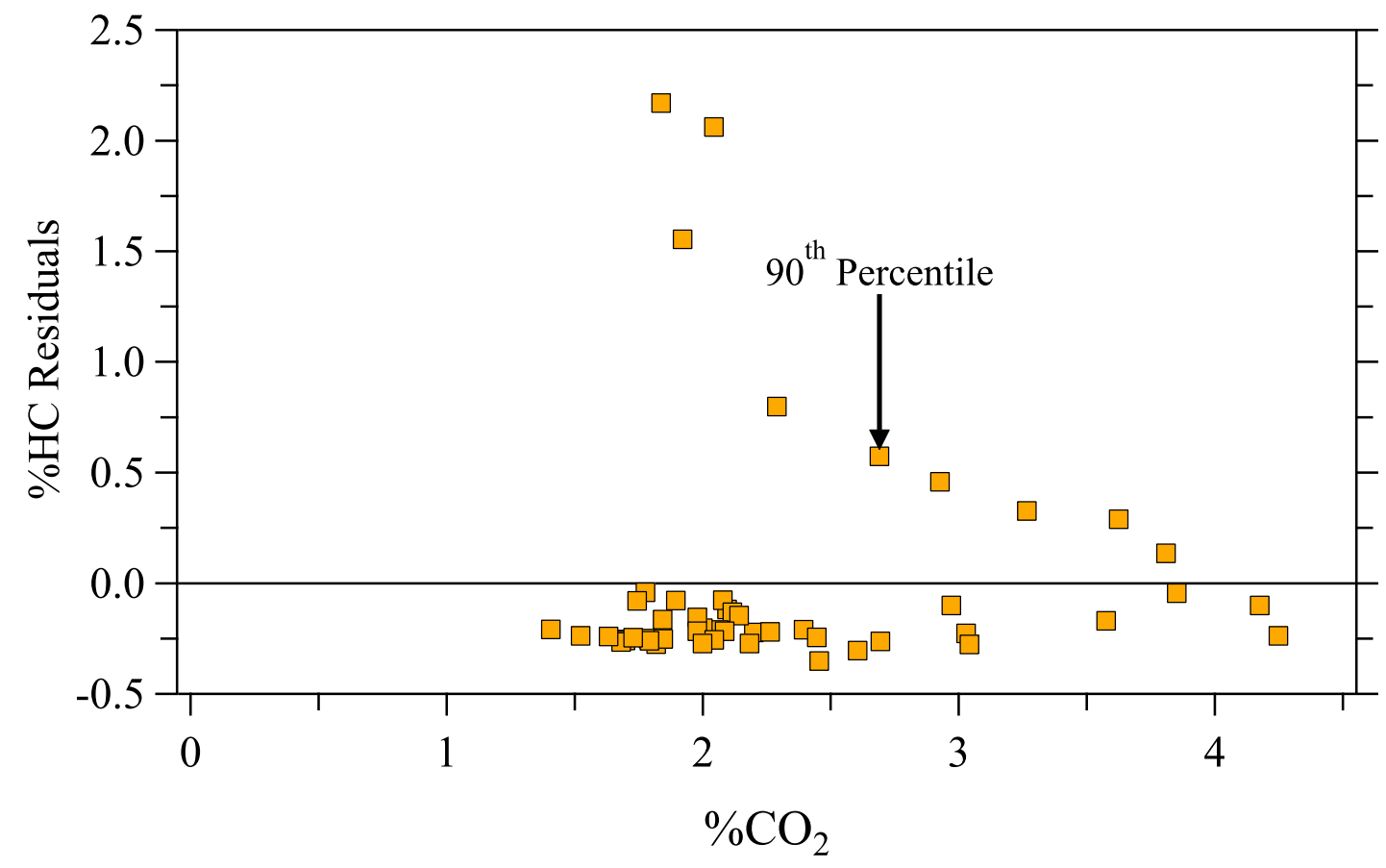

Figure S1. \%HC residuals plotted versus \%CO2 for a 1967 sedan measured in Los Angeles in 2015 with the $90^{\text {th }}$ percentile point marked by the arrow. The residuals are calculated using the least squares best fit line shown in Figure $1 \mathrm{C}$ in the manuscript text. The FEAT HC concentration data is recorded as percent but the RLI index by definition is expressed in $\mathrm{ppm} \cdot \mathrm{cm}$. The $90^{\text {th }}$ percentile and RLI index for this vehicle is 5,731, Bin 4. 
Table S3. Measurements and Residuals for Figure S1 Rank Ordered by \%HC Residuals with the $90^{\text {th }}$ Percentile Highlighted.

\begin{tabular}{|c|c|c|c|c|}
\hline Measurement Seconds & $\% \mathrm{CO}_{2}$ (Measured) & $\% \mathrm{HC}$ (Measured) & \%HC (Best Fit) & \%HC (Residual) \\
\hline 0.02 & 1.837 & 2.6555 & 0.4851 & 2.1703 \\
\hline 0.01 & 2.044 & 2.5773 & 0.5160 & 2.0613 \\
\hline 0.03 & 1.921 & 2.0522 & 0.4976 & 1.5546 \\
\hline 0.04 & 2.289 & 1.3510 & 0.5528 & 0.7982 \\
\hline 0.05 & 2.690 & 1.1859 & 0.6129 & 0.5731 \\
\hline 0.06 & 2.926 & 1.1060 & 0.6483 & 0.4577 \\
\hline 0.07 & 3.266 & 1.0261 & 0.6992 & 0.3268 \\
\hline 0.08 & 3.624 & 1.0419 & 0.7529 & 0.2890 \\
\hline 0.09 & 3.809 & 0.9157 & 0.7806 & 0.1351 \\
\hline 0.34 & 1.776 & 0.4344 & 0.4760 & -0.0416 \\
\hline 0.1 & 3.851 & 0.7413 & 0.7869 & -0.0456 \\
\hline 0.26 & 2.079 & 0.4439 & 0.5213 & -0.0774 \\
\hline 0.33 & 1.896 & 0.4155 & 0.4938 & -0.0784 \\
\hline 0.35 & 1.744 & 0.3916 & 0.4712 & $\begin{array}{l}-0.0796 \\
\end{array}$ \\
\hline 0.14 & 2.971 & 0.5545 & 0.6550 & -0.1006 \\
\hline 0.11 & 4.175 & 0.7344 & 0.8355 & -0.1011 \\
\hline 0.25 & 2.095 & 0.4048 & 0.5237 & -0.1189 \\
\hline 0.27 & 2.116 & 0.3963 & 0.5268 & -0.1305 \\
\hline 0.28 & 2.142 & 0.3845 & 0.5307 & -0.1462 \\
\hline 0.32 & 1.980 & 0.3511 & 0.5064 & -0.1553 \\
\hline 0.36 & 1.844 & 0.3219 & 0.4861 & -0.1642 \\
\hline 0.13 & 3.575 & 0.5752 & 0.7455 & -0.1703 \\
\hline 0.31 & 2.000 & 0.3059 & 0.5096 & -0.2036 \\
\hline 0.5 & 1.407 & 0.2119 & 0.4206 & -0.2087 \\
\hline 0.18 & 2.394 & 0.3586 & 0.5686 & -0.2099 \\
\hline 0.29 & 2.063 & 0.3071 & 0.5190 & -0.2118 \\
\hline 0.3 & 2.085 & 0.3056 & 0.5222 & -0.2166 \\
\hline 0.37 & 1.980 & 0.2893 & 0.5064 & -0.2171 \\
\hline 0.2 & 2.264 & 0.3297 & 0.5490 & -0.2193 \\
\hline 0.19 & 2.200 & 0.3165 & 0.5395 & -0.2230 \\
\hline 0.15 & 3.029 & 0.4376 & 0.6637 & -0.2261 \\
\hline 0.12 & 4.249 & 0.6086 & 0.8465 & -0.2379 \\
\hline 0.49 & 1.524 & 0.2000 & 0.4381 & -0.2381 \\
\hline 0.48 & 1.632 & 0.2143 & 0.4544 & -0.2401 \\
\hline 0.21 & 2.445 & 0.3311 & 0.5762 & -0.2451 \\
\hline 0.47 & 1.728 & 0.2221 & 0.4687 & -0.2466 \\
\hline 0.44 & 1.789 & 0.2268 & 0.4778 & -0.2510 \\
\hline 0.45 & 1.846 & 0.2340 & 0.4864 & -0.2524 \\
\hline 0.41 & 1.693 & 0.2087 & 0.4635 & -0.2547 \\
\hline 0.38 & 2.044 & 0.2605 & 0.5161 & -0.2556 \\
\hline 0.42 & 1.698 & 0.2057 & 0.4642 & -0.2585 \\
\hline 0.46 & 1.791 & 0.2181 & 0.4782 & -0.2601 \\
\hline 0.17 & 2.694 & 0.3500 & 0.6134 & -0.2634 \\
\hline 0.43 & 1.682 & 0.1966 & 0.4618 & -0.2651 \\
\hline 0.24 & 2.182 & 0.2648 & 0.5368 & -0.2720 \\
\hline 0.39 & 1.999 & 0.2363 & 0.5094 & -0.2730 \\
\hline 0.4 & 1.818 & 0.2069 & 0.4822 & -0.2753 \\
\hline 0.16 & 3.042 & 0.3893 & 0.6656 & -0.2764 \\
\hline 0.22 & 2.605 & 0.2964 & 0.6002 & -0.3038 \\
\hline 0.23 & 2.455 & 0.2267 & 0.5777 & -0.3509 \\
\hline
\end{tabular}


Development of the Running Loss Index

In spite of turbulence, the optical absorbance (concentration*path length, $\mathrm{ppm} \cdot \mathrm{cm}$ ) for all exhaust pollutants will be proportional to each other during a single on-road RSD measurement because the exhaust gases are well mixed, constant with time, and no reactions occur in the plume during the $0.5 \mathrm{~s}$ measurement. Many RSD instruments take measurements every $10 \mathrm{~ms}$ for $500 \mathrm{~ms}$ or more after the light beam is unblocked by the vehicle. While different calculation algorithms can be used, the basic idea is that plots of exhaust $\mathrm{HC}(\mathrm{ppm} \cdot \mathrm{cm}), \mathrm{CO}(\%-\mathrm{cm})$, or NO $(\mathrm{ppm} \cdot \mathrm{cm})$ vs. $\mathrm{CO}_{2}(\% \cdot \mathrm{cm})$ have a strong tendency to be straight lines with a slope proportional to the tailpipe exhaust $\mathrm{HC}, \mathrm{CO}$, or NO concentration (refer to Figures S2 and S3).

Running losses from a vehicle are hydrocarbons emitted from a non-tailpipe source on the vehicle. These include permeation from fuel system connections, breakthrough from the evaporative emissions control canister, a cracked rubber vapor line, or a leaking fuel-injector. Therefore, the running loss HC is likely not well-mixed with the tailpipe exhaust gas emissions plume. If a portion of the running loss emission plume wafts into the RSD light beam, some of the fifty $\mathrm{HC}$ absorbance measurements will have higher absorption values than if absent the running loss emissions. Figures S2 - S5 demonstrate the effect of running loss emissions on the RSD data for two runs of a test vehicle driven at $12 \mathrm{mph}$ without and with $15 \mathrm{scfh}$ (standard cubic feet per hour, $70^{\circ} \mathrm{F}, 760$ torr) propane running loss emissions added by simulating a leak at the fuel fill door. Figure S2 shows the time series of the first measurement pass with $1100 \mathrm{ppm}$ of propane from the tailpipe exhaust and Figure S3 shows the resulting correlation graphs. All of the species measured show excellent correlation with $\mathrm{CO}_{2}$.

Figures S4 and S5 show the results of the second pass of the test vehicle this time with an added simulated leak of $15 \mathrm{scfh}$ of propane released from the fuel fill door. Figure $\mathrm{S} 4$ is the time series of species absorbance versus time. Notice that the $\mathrm{HC}$ and $\mathrm{CO}_{2}$ concentrations at the beginning of the measurement appear well correlated but from 150 to $350 \mathrm{~ms}$ the running losses produce a large increase in the $\mathrm{HC}$ absorbance that is not correlated with $\mathrm{CO}_{2}$. Figure $\mathrm{S} 5$ is the resulting correlation graph for each species versus $\mathrm{CO}_{2}$ and shows how the correlation of $\mathrm{HC}$ versus $\mathrm{CO}_{2}$ has broken down.

Data Collection. The Colorado Department of Public Health and Environment (CDPHE) and Eastern Research Group (ERG) constructed an emissions test program to collect in-use drive-by emissions data on seven test vehicles (see Table S4) using a commercial ESP Series 4600 remote sensing instrument and standard data collection procedures. Vehicle 0 was the State of Colorado's on-road audit truck that has its exhaust pipe re-routed to release exhaust high above the truck cab so that the combustion gases have a low probability of being detected by the ground-level RSD instrument. The truck is equipped with a compressed gas cylinder rack that allows different known mixtures of dry simulated vehicle exhaust to be released during testing. For this testing three gas mixtures were used 1) $15.07 \%$ carbon dioxide $\left(\mathrm{CO}_{2}\right)$ in nitrogen, 2) 1100 ppm propane, $3 \%$ carbon monoxide $(\mathrm{CO}), 500 \mathrm{ppm}$ nitric oxide (NO) and $12.92 \% \mathrm{CO}_{2}$ in 


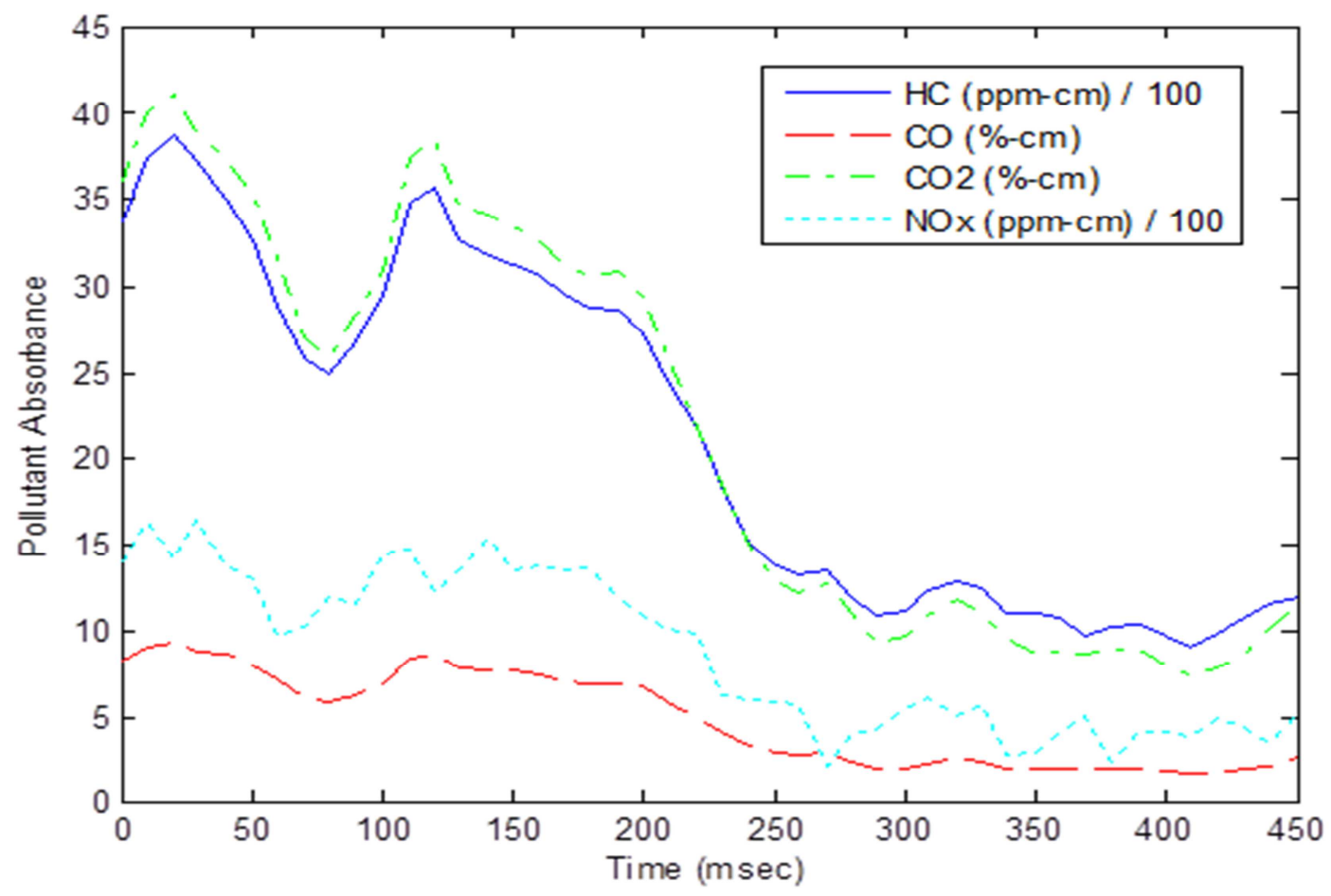

Figure S2. Emissions versus time for a tailpipe exhaust measurement of the test vehicle with no additional running loss emissions added.

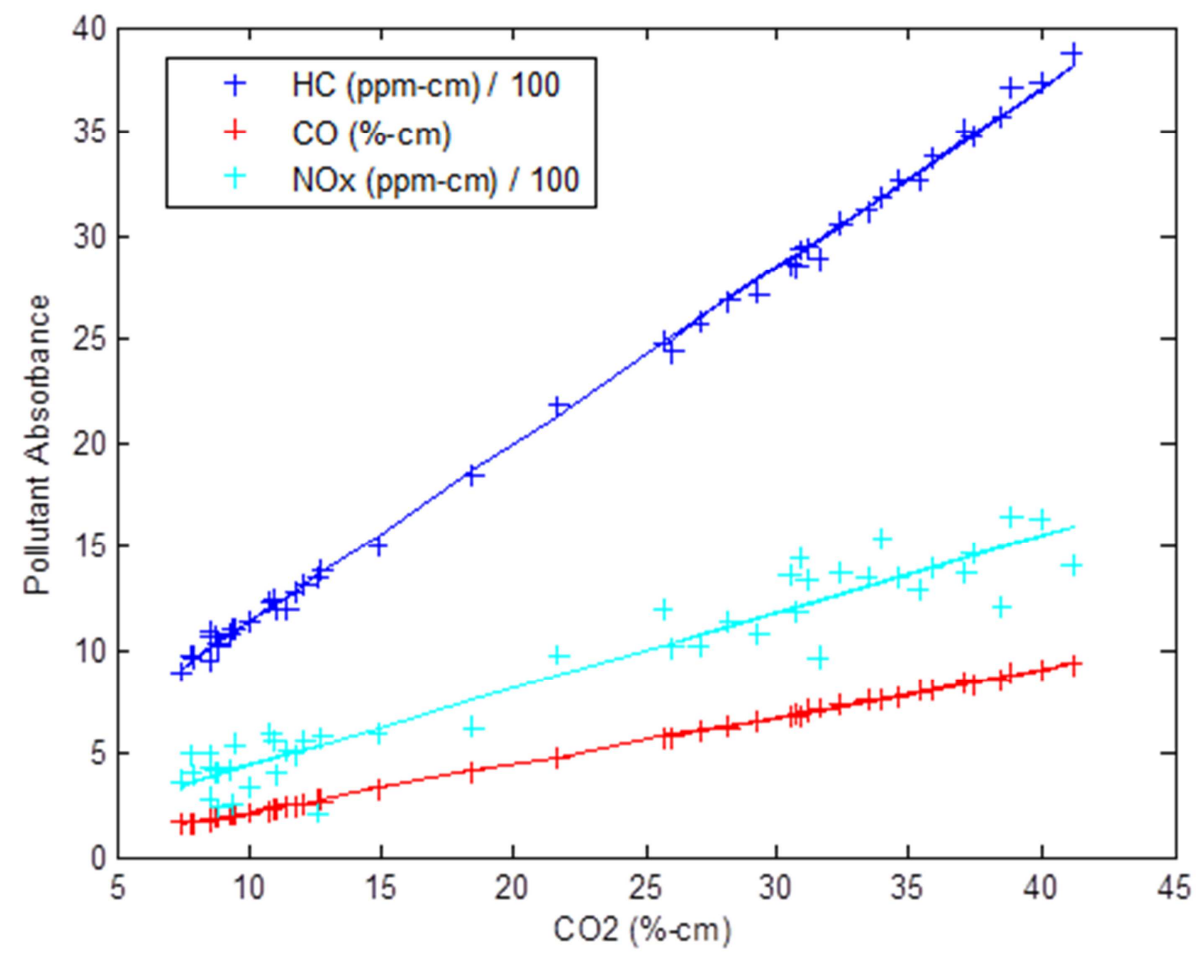

Figure S3. Correlation graphs for the tailpipe exhaust measurement of the test vehicle without adding simulated running loss emissions. 


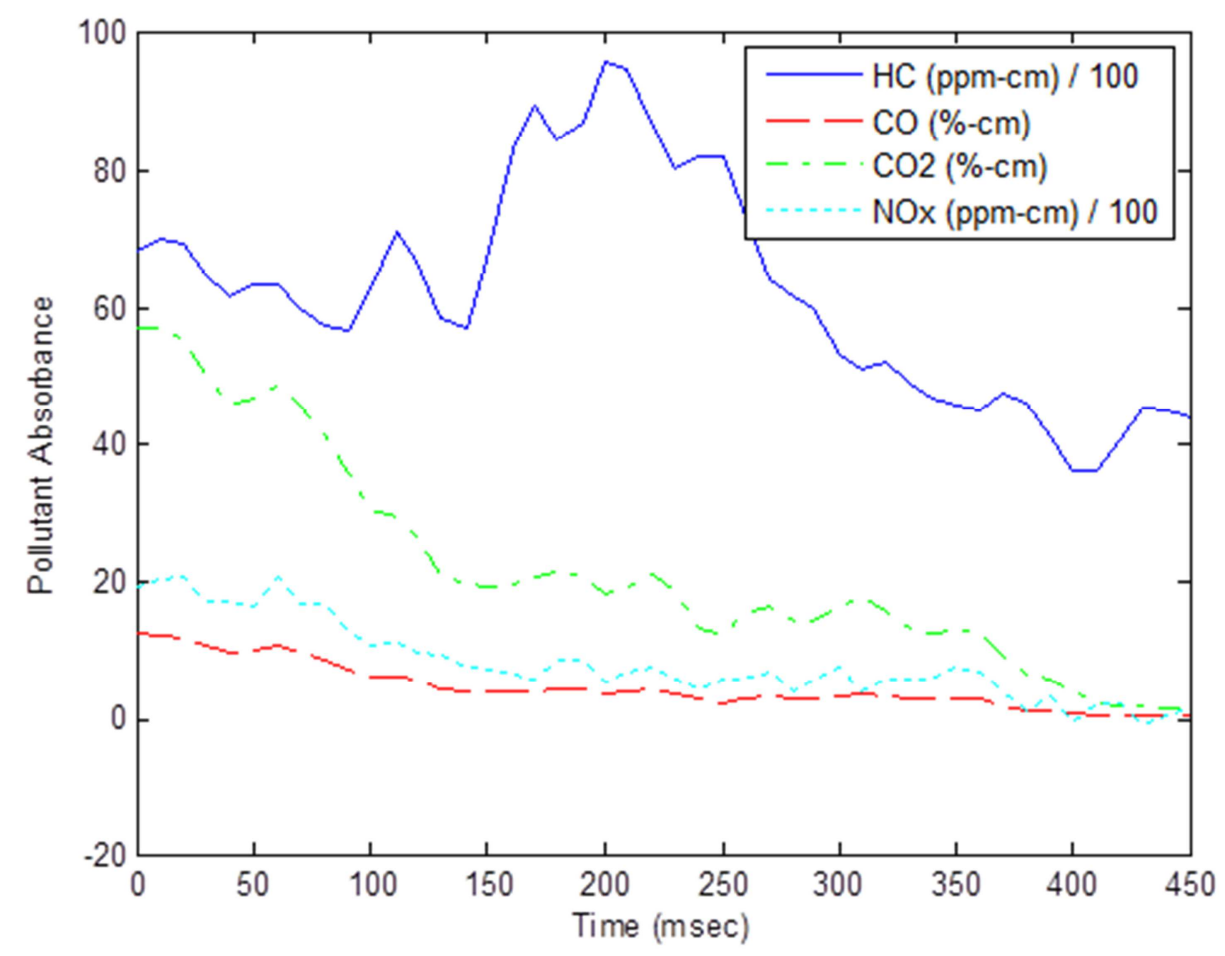

Figure S4. Emissions versus time for a tailpipe exhaust measurement of the test vehicle with $15 \mathrm{scfh}$ of propane released from the fuel fill door of the vehicle.

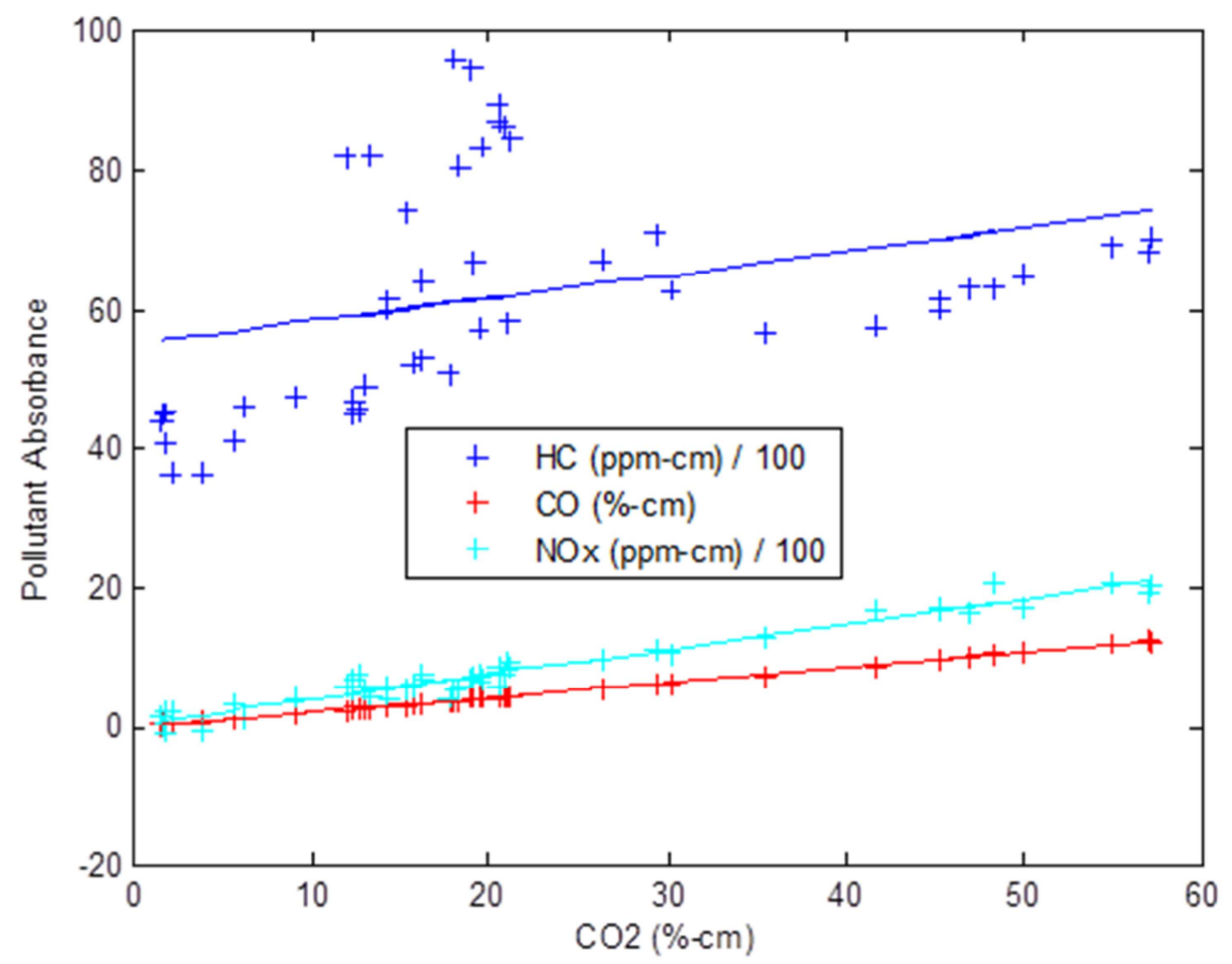

Figure S5. Correlation graphs for the tailpipe exhaust measurement of the test vehicle with added simulated running loss emissions. 
Table S4. Test Vehicles used for Staged Running Loss Emissions Measurements.

\begin{tabular}{|c|c|l|l|}
\hline Test Vehicle & Model Year & \multicolumn{1}{|c|}{ Make } & \multicolumn{1}{|c|}{ Model } \\
\hline 0 & N/A & Audit Truck & N/A \\
\hline 1 & 2008 & Ford & Escape \\
\hline 2 & 1992 & Oldsmobile & Eighty-Eight \\
\hline 3 & 1982 & Chevrolet & Caprice \\
\hline 4 & 1989 & Dodge & Caravan \\
\hline 5 & 1992 & Chevrolet & Corsica \\
\hline 6 & 1990 & Chevrolet & Lumina \\
\hline
\end{tabular}

nitrogen and 3) $6015 \mathrm{ppm}$ propane, 5\% CO, $250 \mathrm{ppm} \mathrm{NO}$ and $11.55 \% \mathrm{CO}_{2}$ in nitrogen. The truck released these simulated dry exhaust gases at approximately $30 \mathrm{scfm}$ (standard cubic feet per minute, $70^{\circ} \mathrm{F}, 760$ torr) to an artificial tailpipe located at the traditional tailpipe location for each measurement pass.

Equipment to produce metered, simulated running loss emissions was added to each of the test vehicles. Gaseous running loss emissions were produced by metering propane from a small bottle through a rotameter. Tubing from the rotameter routed the propane to a desired release location on the vehicle. Liquid gasoline running loss emissions were produced by releasing gasoline using a metering valve on a peristaltic pump via thin tubing to a release location on the vehicle. In general, the tubing was situated to drop the gasoline directly onto the pavement where it would not be run over by the tires of the vehicle. In addition to producing simulated gaseous running loss emissions, running loss emissions were attempted by defeating the evaporative emissions control systems on several of the test vehicles. Note that the presence of running loss emissions was not confirmed by independent measurements for these tests.

RSD measurement data were collected by driving the test vehicles past the instrument at approximately 12,34 , or $55 \mathrm{mph}$, with steady accelerator position, and with light acceleration to keep the vehicle specific power in the 5 to $20 \mathrm{~kW} /$ tonne range. The simulated running loss emissions, either propane gas or liquid gasoline, were released at different locations on the vehicles to evaluate the ability of RSD to detect running losses emitted from different points at the different speeds. For some tests, running loss emissions were induced by either removing the gas cap or disconnecting the vapor lines to the evaporative emissions control canister.

Each test condition was made up of twenty-eight to forty vehicle passes - twenty with the added running loss state (propane flowing, gasoline dripping, or evaporative emission control system defeated) and eight to twenty in the no-running-loss state (propane off, gasoline off, and evaporative emission control system operating). Within each test condition, the twenty measurements with running losses were conducted in groups of five runs with two to five runs without running losses interspersed between the groups. Table S5 shows the summary of the 138 test conditions and 3,501 RSD measurements using propane to simulate vapor running loss emissions. The flow of propane was started about 10 seconds before the measurement and was 
Table S5. Summary of Propane Vapor Running Loss Tests Performed.

\begin{tabular}{|c|c|l|l|l|}
\hline \multirow{2}{*}{$\begin{array}{c}\text { Test } \\
\text { Vehicle }\end{array}$} & \multirow{2}{*}{$\begin{array}{c}\text { Measured Exhaust } \\
\text { HC (ppmC } \text { ( }_{3} \text { Range }\end{array}$} & \multirow{2}{*}{$\begin{array}{c}\text { Speed } \\
\text { (mph) }\end{array}$} & \multicolumn{1}{|c|}{$\begin{array}{c}\text { Artificial Running Loss } \\
\text { Rate (scfs) }\end{array}$} & Release Location \\
\hline 0 & -98 to 42 & 12,34 & $0,0.15,0.45,1.5,4.5,15$ & Fuel Fill Door \\
& 1033 to 1158 & 12,34 & $0,0.15,0.45,1.5,4.5,15$ & Fuel Fill Door \\
& 5594 to 6468 & 12,34 & $0,0.15,0.45,1.5,4.5,15$ & Fuel Fill Door \\
\hline 1 & -30 to 14 & $12,34,55$ & $0,0.15,0.45,1.5,4.5,15$ & Under Hood \\
& -44 to 59 & $12,34,55$ & $0,4.5$ & Top of Gas Tank \\
& -31 to 6 & $12,34,55$ & $0,4.5$ & Fuel Fill Door \\
\hline 2 & 1183 to 5604 & $12,34,55$ & $0,0.15,0.45,1.5,4.5,15$ & Under Hood \\
& 1468 to 4765 & $12,34,55$ & $0,4.5$ & Top of Gas Tank \\
& 1974 to 4684 & $12,34,55$ & $0,4.5$ & Fuel Fill Door \\
\hline 3 & 9387 to 12039 & $12,34,55$ & $0,0.15,0.45,1.5,4.5,15$ & Under Hood \\
& 8924 to 13356 & $12,34,55$ & $0,4.5$ & Top of Gas Tank \\
& 8509 to 12617 & $12,34,55$ & $0,4.5$ & Fuel Fill Door \\
\hline 6 & 14906 to 19373 & 12 & $0,0.15,0.45,1.5,4.5,15$ & Under Hood \\
\hline 7 & -137 to 219 & 12 & $0,0.15,0.45,1.5,4.5,15$ & Under Hood \\
\hline
\end{tabular}

${ }^{\mathrm{a}}$ The exhaust ranges are from measurements with no artificial running loss emissions.

not turned off until well after the vehicle passed the instrument. Table S6 shows the summary for the 38 test conditions and 1,040 RSD measurements using liquid gasoline releases. The flow of gasoline was left on for each set of five with-running-loss RSD measurements to minimize the possibility of vapor bubbles forming in the line to the release point. Table S7 details the 22 defeats of the evaporative emissions control systems on five of the test vehicles to attempt to induce vapor running loss emissions. These tests produced 44 test conditions and 682 RSD measurements.

Table S6. Summary of Liquid Gasoline Running Loss Tests Performed.

\begin{tabular}{|c|c|c|c|c|}
\hline \multirow{2}{*}{$\begin{array}{l}\text { Test } \\
\text { Vehicle }\end{array}$} & \multirow{2}{*}{$\begin{array}{l}\text { Measured Exhaust } \\
\mathrm{HC}_{\left(\mathrm{ppmC}_{3}\right) \text { Range }^{\mathrm{a}}}\end{array}$} & \multirow[b]{2}{*}{$\begin{array}{l}\text { Speed } \\
(\mathrm{mph})\end{array}$} & \multicolumn{2}{|c|}{ Artificial Running Loss } \\
\hline & & & $\begin{array}{l}\text { Gasoline Emission } \\
\text { Rate }(\mathrm{ml} / \mathrm{sec})\end{array}$ & Release Location \\
\hline 2 & $\begin{array}{r}1738 \text { to } 5404 \\
921 \text { to } 3974\end{array}$ & $\begin{array}{l}12,34 \\
12,34\end{array}$ & $\begin{array}{l}0,0.1,0.3,1.0 \\
0,0.1,0.3,1.0\end{array}$ & $\begin{array}{l}\text { Front Bumper } \\
\text { Rear Bumper }\end{array}$ \\
\hline 5 & 931 to 1299 & 12 & $0,0.8$ & Passenger Door \\
\hline 6 & $\begin{array}{l}17228 \text { to } 20130 \\
16471 \text { to } 21072\end{array}$ & $\begin{array}{l}12 \\
12\end{array}$ & $\begin{array}{l}0,0.05,0.1,0.5,1.0 \\
0,0.05,0.1,0.5,1.0\end{array}$ & $\begin{array}{l}\text { Left Front Wheel } \\
\text { Rear Bumper }\end{array}$ \\
\hline 7 & $\begin{array}{l}-70 \text { to } 85 \\
-82 \text { to } 61\end{array}$ & $\begin{array}{l}12 \\
12\end{array}$ & $\begin{array}{l}0,0.05,0.1,0.5,1.0 \\
0,0.05,0.1,0.5,1.0\end{array}$ & $\begin{array}{l}\text { Front Bumper } \\
\text { Rear Bumper }\end{array}$ \\
\hline
\end{tabular}

${ }^{a}$ The exhaust ranges are from measurements with no artificial running loss emissions. 
Table S7. Summary of Induced Running Loss Tests Performed.

\begin{tabular}{|c|c|c|c|}
\hline Test Vehicle & $\begin{array}{c}\text { Measured Exhaust } \\
\mathrm{HC}\left(\mathrm{ppmC}_{3}\right) \\
\text { Range }^{\mathrm{a}}\end{array}$ & $\begin{array}{l}\text { Speed } \\
(\mathrm{mph})\end{array}$ & $\begin{array}{l}\text { Method of Disabling } \\
\text { Evaporative Emission } \\
\text { Control System }\end{array}$ \\
\hline 0 & $\begin{array}{r}-100 \text { to } 31 \\
-57 \text { to } 47\end{array}$ & $\begin{array}{l}12 \\
12\end{array}$ & $\begin{array}{l}\text { Canister Disconnected } \\
\text { Gas Cap Removed }\end{array}$ \\
\hline 1 & $\begin{array}{l}-52 \text { to } 11 \\
-41 \text { to } 23\end{array}$ & $\begin{array}{l}12,34,55 \\
12,34,55\end{array}$ & $\begin{array}{l}\text { Canister Disconnected } \\
\text { Gas Cap Removed }\end{array}$ \\
\hline 2 & $\begin{array}{l}2610 \text { to } 4950 \\
1817 \text { to } 4734\end{array}$ & $\begin{array}{l}12,34,55 \\
12,34,55\end{array}$ & $\begin{array}{l}\text { Canister Disconnected } \\
\text { Gas Cap Removed }\end{array}$ \\
\hline 3 & $\begin{array}{l}7687 \text { to } 11925 \\
8593 \text { to } 11989\end{array}$ & $\begin{array}{l}12,34,55 \\
12,34,55\end{array}$ & $\begin{array}{l}\text { Canister Disconnected } \\
\text { Gas Cap Removed }\end{array}$ \\
\hline 4 & $\begin{array}{l}93 \text { to } 370 \\
11 \text { to } 220\end{array}$ & $\begin{array}{l}12 \\
12\end{array}$ & $\begin{array}{l}\text { Canister Disconnected } \\
\text { Gas Cap Removed }\end{array}$ \\
\hline
\end{tabular}

${ }^{\mathrm{a}}$ The exhaust ranges are from measurements collected with canister connected and the gas cap properly installed.

Data Trends. The amount of the scatter in the $\mathrm{HC}$ vs. $\mathrm{CO}_{2} 10$-ms plots induced by the addition of a running loss plume is affected by a combination of several different factors. The first is the running loss emissions rate. Figure $\mathrm{S} 6$ shows $\mathrm{HC}$ vs. $\mathrm{CO}_{2} 10$-ms data plots for $0,0.15,0.45,1.5$, 4.5 , and $15 \mathrm{scfh}$ propane releases at $12 \mathrm{mph}$ from Vehicle 0 with the $1100 \mathrm{ppmC}_{3}$ simulated dry exhaust mixture. Deviations from linearity are clear for the highest three propane release rates, but as the running loss emissions rate drops below $1.5 \mathrm{scfh}$, the correlations return to being reasonably linear and are comparable to the scatter for the 0 scfh case (the black symbols).

The speed of the vehicle can also influence the RSD observed absorption signal of the running loss emissions. Depending on the vehicle and the local conditions as speed increases the running loss emission plumes generally experience higher dilution rates. This lowers the HC concentrations behind the vehicle and consequently lowers the observed absorption values. Additionally, higher speeds can lower turbulence behind the vehicle (laminar flow) and prevent the running loss plume from intersecting the sampling beam. Both of these issues work to lower the running loss signals in the RSD data stream.

The plots in Figure S7 demonstrate the effect speed can have on the RSD absorption measurements. For this figure, $4.5 \mathrm{scfh}$ of propane was released from the top of the fuel tank of Vehicle 2, which had a measured exhaust concentration of about $3000 \mathrm{ppmC}_{3}$, and the vehicle was driven at 12,34 and $55 \mathrm{mph}$. The plots show that the correlation is relatively constant for the three speeds, but the data scatter, which reflects the running loss emissions, decreases as speed increases. For reference, the plot also shows a black trace for a test when no propane was released from the test vehicle.

A third factor that can affect plume detectability of the running loss emission plume is the 


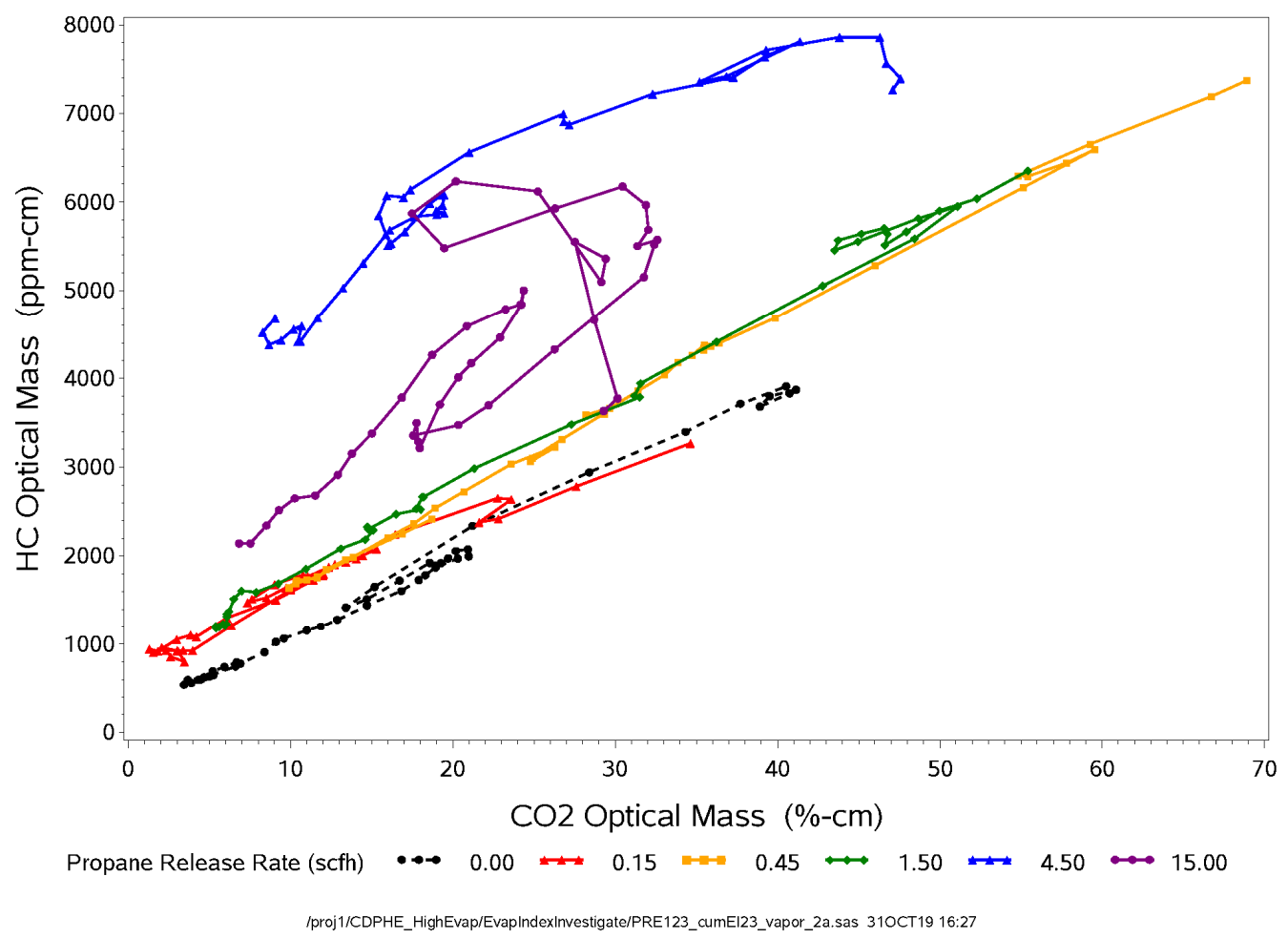

Figure S6. $\mathrm{HC}$ versus $\mathrm{CO}_{2}$ for Vehicle 0 at $12 \mathrm{mph}$ and $1100 \mathrm{ppmC}_{3}$ exhaust hydrocarbon for different running loss release rates from the fuel fill door.

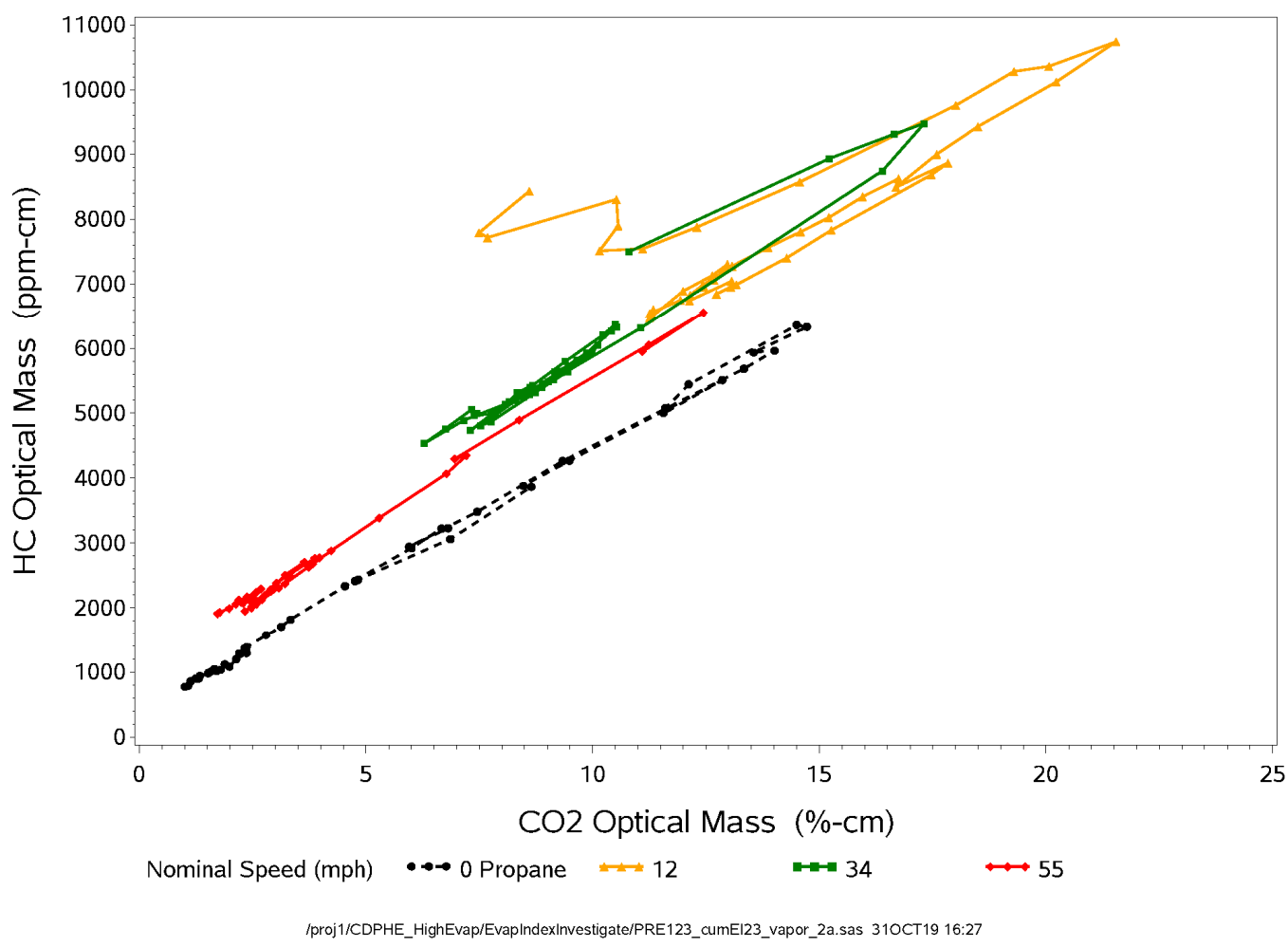

Figure S7. $\mathrm{HC}$ versus $\mathrm{CO}_{2}$ for Vehicle 2 with $3000 \mathrm{ppmC}_{3}$ exhaust hydrocarbon for exhaust only and a $4.5 \mathrm{scfh}$ running loss release rate from the top of the fuel tank at 12, 34, and $55 \mathrm{mph}$. 
location of the release point on the vehicle. Figure S8 shows Vehicle 2 operated at $12 \mathrm{mph}$ as propane was released at $4.5 \mathrm{scfh}$ under the hood, at the top of the gas tank, and at the fuel fill door. The plot shows similar and substantially larger scatter for the traces corresponding to running loss releases from the three test locations in comparison with the no propane release (in black) for the same speed.

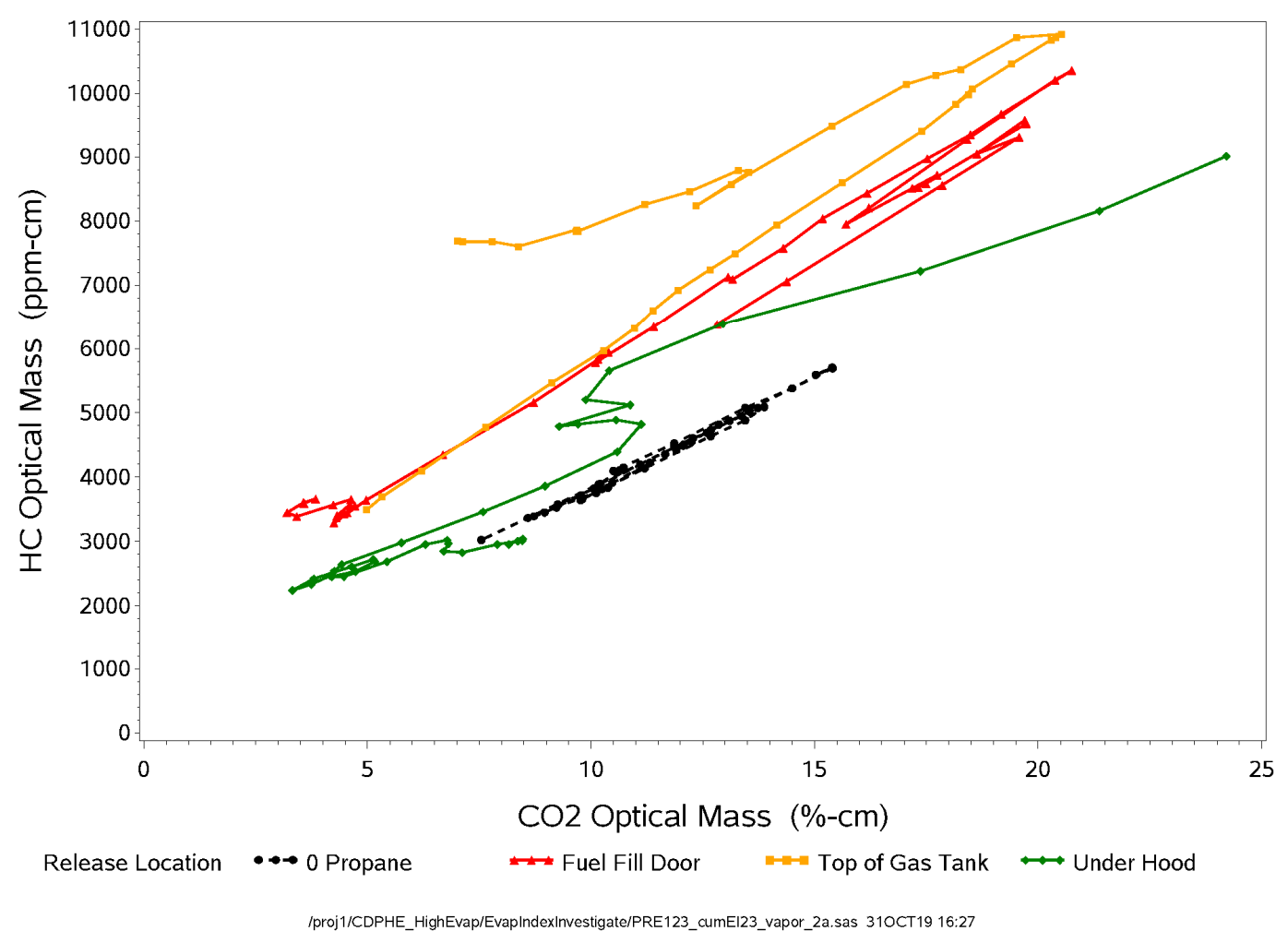

Figure S8. $\mathrm{HC}$ versus $\mathrm{CO}_{2}$ for Vehicle 2 with $3000 \mathrm{ppmC}_{3}$ exhaust hydrocarbon for exhaust only and a $4.5 \mathrm{scfh}$ running loss release rate from three release locations at $12 \mathrm{mph}$.

The development of the RSD running loss index (RLI) was aimed at quantifying the $\mathrm{HC}$ versus $\mathrm{CO}_{2}$ point scatter induced by the running loss plume. Because running losses are not emitted from the tailpipe, the running loss plume may waft across the light beam many times or one time (or never) during the $0.5 \mathrm{~s}$ RSD data acquisition period. In addition, the plume may waft across the light beam early or late in the data acquisition period. Because of these characteristics, an index based on all of the residuals, such as the standard error or the average residual of the regression, would not give equal weight to measurements that consisted of a single pass versus multiple passes of the running loss plume through the light beam. The data collected in the CDPHE study indicated that when running loss plumes are convincingly picked up by the RSD instrument, the plume usually elevates at least three or four of the $\mathrm{HC}$ absorbance values. A single elevated 10-ms HC value is rarely observed, and if one does appear to be observed, it is difficult to distinguish it as a true running loss indicator versus a single outlier point. 
Consequently, designation of a vehicle as an elevated running loss emitter using an index based on the largest residual would be uncertain and unreasonably noisy. The choice of the ninetieth percentile residual was a compromise between using all and one regression residual.

Figure $\mathrm{S} 9$ shows the results for Vehicle $1\left(0 \mathrm{ppmC}_{3}\right.$ tailpipe) and how the RLI values change with propane release rate (scfh) and vehicle speed. The RLI values were measured at 12, 34, and $55 \mathrm{mph}$ and with under-hood propane release rates of $0,0.15,0.45,1.5,4.5$, and $15 \mathrm{scfh}$. Using a log scale, each plot shows the cumulative distribution of 20 replicate RLI values measured at each test condition. The eighteen distributions shown in the figure all have similar widths, although there may be a tendency for wider relative widths for larger RLI values. RLI distribution widths are influenced by the variability in the measured optical absorption values and the location of the running loss plumes with respect to the RSD light beam location.

As a reference, the black curve on the left of each panel defines the RLI distribution when no propane is released (0 running loss emissions) and establishes the lower bound for the RLI values. The propane release rates $(0.15,0.45,1.5,4.5,15 \mathrm{scfh})$ were deliberately chosen for testing to be evenly spaced by factors of 3. Figure S9 shows that when propane release rates are substantially above the zero-running-loss (black) distribution, the RLI distributions are close to being evenly spaced on the log scale. This implies that RLI values tend to be proportional to the propane release rate ( $\mathrm{scfh}$ ). A comparison of the location of the curves as speed increases from Figures S9a to S9b to S9c shows that all constant-release-rate curves move to lower RLI values until they begin "piling up" at the black zero-running-loss-emissions line. This behavior implies that RLI values for non-zero propane release rates are inversely related to vehicle speed.

Any of the RLI distribution plots can be used to judge if a given running loss rate is capable of being detected by a single RLI measurement. If an RLI value, when running loss emissions are present, and the mean RLI value when running loss emissions are not present are separated by more than three standard deviations $(3 \sigma)$ of the distribution of RLIs, then the running loss is detected. For the purposes of visually judging detection from the plots, the definition can be approximated for this evaluation: If the median of the RLI when running losses are present is larger than the largest RLI value of the 20 values in the RLI distribution when running losses are not present, then the running loss is detected. For example, the blue curve in Figure S9a indicates that for $12 \mathrm{mph}$ and $4.5 \mathrm{scfh}$ propane the RLI values ranged from about 250 to 1000 with a median of about 500. The repeatability (the relative distribution width) for RLIs at this condition is therefore about $+200 \%$ and $-50 \%$. Thus, the difference in location of a colored curve and the black curve shows the effect on the RLI values of the propane being released.

Using the $3 \sigma$ definition of detection, Figure $S 9 \mathrm{a}$, for $12 \mathrm{mph}$, indicates that the upper three propane release rates $(1.5,4.5$, and $15 \mathrm{scfh})$ are successfully detected by RLI. Note that in Figure $\mathrm{S} 9 \mathrm{a}$ the median ( $\mathrm{y}$-axis $=0.5$ ) of the green curve for $1.5 \mathrm{scfh}$ is just larger than the largest value of the 0 scfh curve (black dots). However, the medians of the red $(0.15 \mathrm{scfh})$ and orange $(0.45$ scfh) curves stay within the range of the 0 scfh RLI values. While the release rates lower than 


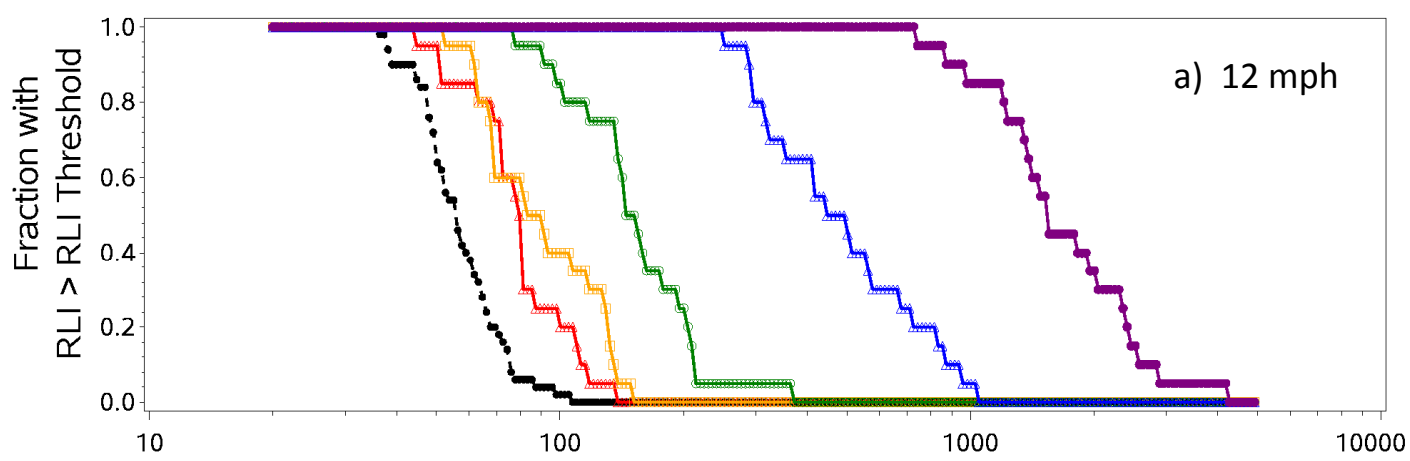

RLI Threshold
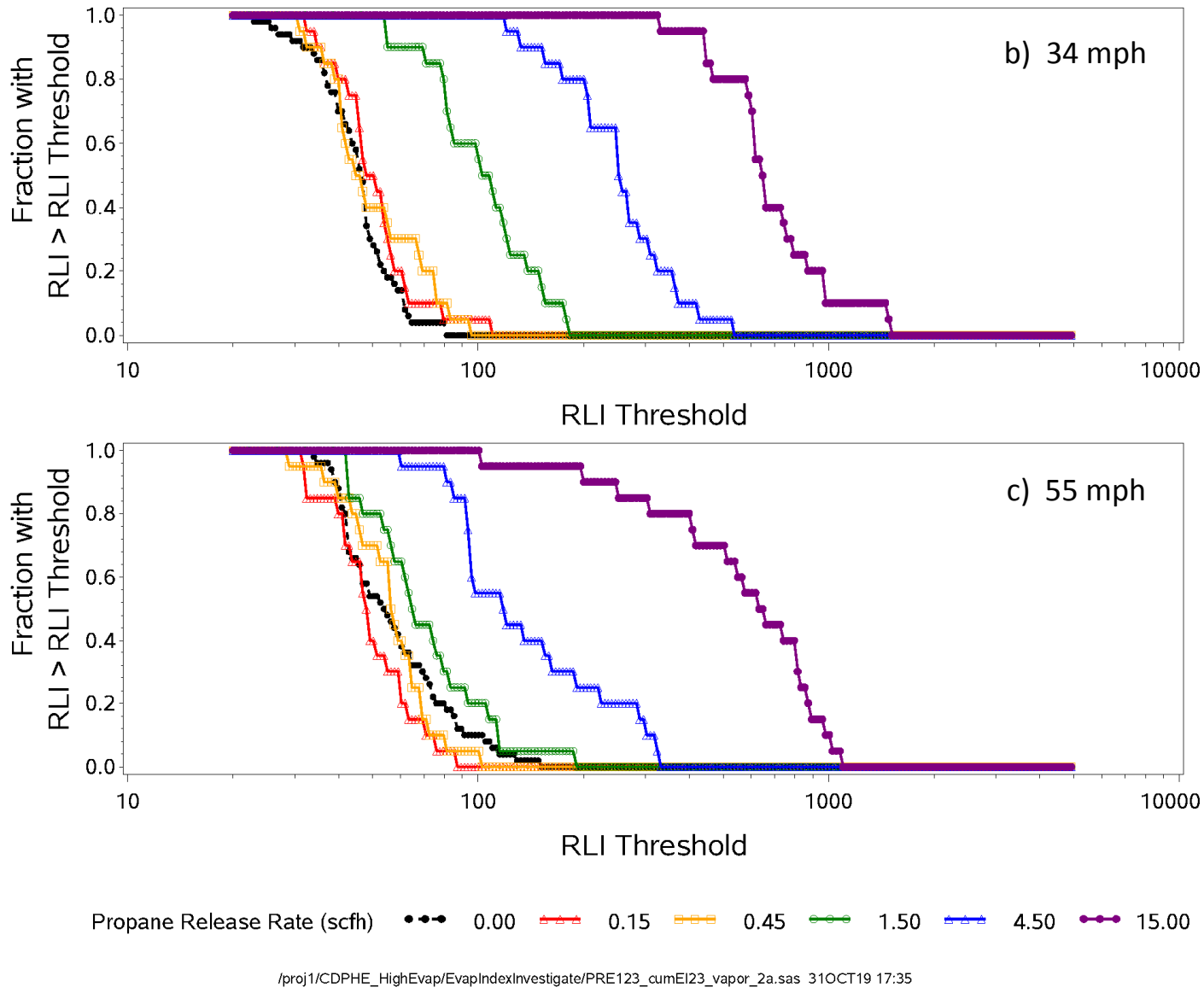

Figure S9. Cumulative distributions of RLI values for replicate tests of Vehicle $1\left(0 \mathrm{ppmC}_{3}\right.$ tailpipe) driving at three speeds while releasing propane from under the hood at six flow rates. Top graph is $12 \mathrm{mph}$, middle is $34 \mathrm{mph}$, and bottom is $55 \mathrm{mph}$.

$1.5 \mathrm{scfh}$ do not meet the $3 \sigma$ definition for a positive identification they do suggest that the RLI values may be used as a screening test to increase the probability of selecting a vehicle that has elevated running loss emissions. At $34 \mathrm{mph}$, Figure S9b (middle graph) shows that 0.15 and 0.45 scfh propane releases are not distinguishable from $0 \mathrm{scfh}$. Again, the medians for the 1.5, 4.5, and $15 \mathrm{scfh}$ curves are all above the largest $0 \mathrm{scfh}$ RLI values indicating a positive detection. 
Similarly, Figure S9c (bottom graph) shows that at $55 \mathrm{mph}$ the RLI distributions for 0.15, 0.45, and $1.5 \mathrm{scfh}$ are close to the same location as for $0 \mathrm{scfh}$, and therefore those running loss rates are not detected. At $55 \mathrm{mph}$ only the propane released at $15 \mathrm{scfh}$ (purple line) is unequivocally detected though the $4.5 \mathrm{scfh}$ release (blue curve) is substantially shifted with respect to the $0 \mathrm{scfh}$ curve indicating detection of that running loss emission. These plots show that as speed increases, the RLI distributions for all non-zero propane release rates shift toward the no release distribution.

For in-use measurements we need a method to establish the baseline zero running loss emission RLI distribution since we generally will not use an audit vehicle for this purpose. We know that the majority of vehicles in the on-road fleet have negligible tailpipe and running loss $\mathrm{HC}$ emissions. Thus, we will use the RLI measurements collected from the late model vehicles to approximate the RLI zero running loss characteristics of the RSD instrument to define this baseline distribution.

Regression Modeling. The plots such as those in Figure S9 indicated that the relationship between RLI, running loss emission rate ( $\mathrm{g} / \mathrm{mile}$ ) and vehicle operating conditions might be able to be quantified using the 3,501-observation staged test dataset. Early, project-specific functions of RLI were used by RSDs in the driveways of inspection/maintenance facilities at Ken Caryl and Broomfield stations in the Denver, Colorado area to screen for vehicles with elevated hotsoak evaporative emissions. ${ }^{1,2}$ At the time, RLI was called EI23. For the analysis of this West Los Angeles data, we developed a new, more widely applicable function of RLI to better screen for running loss emissions.

The trends of RLI vs. exhaust HC, speed, and propane release rate indicate that the RLI values can be thought of as being made up of two parts: 1) a running loss emissions signal (RLI Signal $_{\text {) }}$ influenced by propane release location on the vehicle, propane release rate, vehicle speed, and exhaust $\mathrm{HC}$ concentration, and 2) a variability and noise floor ( $\mathrm{RLI}_{\text {Noise }}$ ) influenced by RSD instrument noise and measurement variability, exhaust $\mathrm{HC}$, and vehicle speed. Their effects on the measured RLI can be described using the square root of the sum of their squares:

$$
\mathrm{RLI}=\mathrm{SQRT}\left(\mathrm{RLI}_{\text {Signal }}{ }^{2}+\mathrm{RLI}_{\text {Noise }}{ }^{2}\right)
$$

Raw data plotting, like that above, and early models using categorical variables for the propane release rate and the nominal vehicle speed indicated that the running loss emissions signal was close to proportional to the propane release rate and inversely proportional to the vehicle speed. Exhaust $\mathrm{HC}$ was not expected to influence the running loss signal, but a term was included in the model statement in the event that an effect was present. The resulting regression model statement for the running loss signal is given by:

$$
\mathrm{RLI}_{\text {Signal }}=\exp \left[\text { Location }+\mathrm{a} * \ln (\text { Propane })+\mathrm{b}^{*} \ln (\text { Speed })+\mathrm{c}^{*} \text { Exhaust_HC }\right]
$$

Where: 
Location $=$ a categorical variable for the vehicle and location of the propane release, Propane $=$ propane flow rate in $\mathrm{g} / \mathrm{hr}\left(1 \mathrm{scfh} \mathrm{C}_{3} \mathrm{H}_{8}=51.8 \mathrm{~g} / \mathrm{hr} \mathrm{C} \mathrm{C}_{3} \mathrm{H}_{8}\right)$, Speed $=$ vehicle speed in miles/hr at the time of the RSD measurement,

Exhaust_HC $=$ the RSD exhaust HC concentration in parts per thousand propane.

The noise floor signal is defined to be the RLI value when the vehicle has zero running losses. Therefore, the noise floor does not depend on propane release rate. In addition, when exhaust HC is present, more noise is introduced into RLI arising from the detection of the exhaust HC. More specifically, $\mathrm{RLI}_{\text {Noise }}$ is influenced by the slope of the plot of $\mathrm{HC}$ absorption vs. $\mathrm{CO} 2$ absorption. When exhaust HC concentrations are zero, the zero slope can be either positive or negative because zero measurements are normally distributed around zero. Examination of the data indicated that negative slopes affect $\mathrm{RLI}_{\mathrm{Noise}}$ just as positive slopes do. Therefore, we quantify the influence of the slope on $\mathrm{RLI}_{\text {Noise }}$ using the absolute value (abs) of the RSD-reported exhaust $\mathrm{HC}$ concentration. The one exception is for negative slopes that have been invalidated by the RSD software. In these few cases the Exhaust_HC is set to zero. Speed was not expected to influence the noise floor signal, but a term was included in the model statement in case an effect was present. The resulting regression model statement for the noise floor signal is given by:

$$
\mathrm{RLI}_{\text {Noise }}=\text { Instrument }+\mathrm{d} * \text { abs }(\text { Exhaust_HC })+\mathrm{e} * \text { Speed }
$$

Where:

Instrument $=$ a categorical variable for the RSD instrument collecting the data, Exhaust_HC $=$ the RSD exhaust HC concentration in parts per thousand propane, Speed $=$ vehicle speed in miles/hr at the time of the RSD measurement.

Examination of the replicate measured RLI values at each test condition in the dataset revealed that the variance of the RLI values was inhomogeneous across test conditions. We therefore chose to make the variance of the modeled response variable more homogeneous while retaining the functional form of Equation S1 by transforming both sides of the equation using a power and then using non-linear regression (SAS NLIN procedure) to estimate the coefficients in Equations S2 and S3. The power of the transformation was adjusted until the optimal Box-Cox lambda (SAS TRANSREG procedure) for the observed transformed RLI values against the predicted transformed RLI values, was found to be 1 . The optimum power for the transformation of RLI was found to be -0.281 . The resulting regression coefficients for Equations S2 and S3 are given in Table S8. In the transformed space, the model had an r-square of 0.702, an F-value of 9357, and the model's residuals for the transformed RLI values $\left(\mathrm{RLI}^{\wedge}{ }^{\wedge}-0.281\right.$ ) had a standard deviation of 0.0344 .

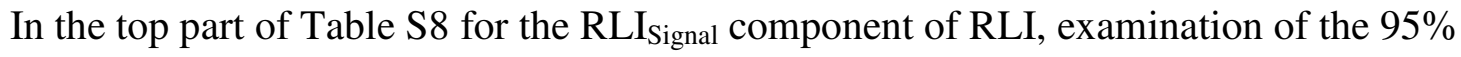
confidence intervals of the Location coefficients indicates that nine of the twelve coefficients are not significantly different from each other. The other three Location coefficients differ from the first nine but not substantially so. We conclude, while there are probably differences in the 
Table S8. Regression coefficients for first regression model.

\begin{tabular}{|c|c|c|c|c|c|c|}
\hline & \multirow{2}{*}{ Variable } & \multirow{2}{*}{ Coefficient } & \multirow{2}{*}{$\begin{array}{l}\text { Estimate of } \\
\text { Coefficient }\end{array}$} & \multirow{2}{*}{$\begin{array}{c}\text { Approximate } \\
\text { Standard } \\
\text { Error }\end{array}$} & \multicolumn{2}{|c|}{$\begin{array}{l}\text { Approximate } 95 \% \\
\text { Confidence Limits } \\
\end{array}$} \\
\hline & & & & & Lower & Upper \\
\hline \multirow{15}{*}{ 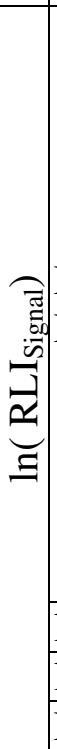 } & \multirow{12}{*}{$\begin{array}{l}\text { Leak } \\
\text { Location }\end{array}$} & Veh. 0 Fuel Fill Door & 3.4505 & 0.1823 & 3.0930 & 3.8080 \\
\hline & & Veh. 1 Fuel Fill Door & 3.2877 & 0.1993 & 2.8968 & 3.6785 \\
\hline & & Veh. 1 Top of Gas Tank & 4.2171 & 0.2029 & 3.8192 & 4.6149 \\
\hline & & Veh. 1 Under Hood & 3.9754 & 0.1819 & 3.6187 & 4.3321 \\
\hline & & Veh. 2 Fuel Fill Door & 3.7328 & 0.2091 & 3.3229 & 4.1427 \\
\hline & & Veh. 2 Top of Gas Tank & 3.8500 & 0.2083 & 3.4416 & 4.2584 \\
\hline & & Veh. 2 Under Hood & 3.8737 & 0.1942 & 3.4929 & 4.2545 \\
\hline & & Veh. 3 Fuel Fill Door & 4.2763 & 0.2471 & 3.7917 & 4.7608 \\
\hline & & Veh. 3 Top of Gas Tank & 3.9499 & 0.2795 & 3.4019 & 4.4979 \\
\hline & & Veh. 3 Under Hood & 3.9583 & 0.2390 & 3.4897 & 4.4270 \\
\hline & & Veh. 6 Under Hood & 3.8220 & 0.3272 & 3.1805 & 4.4636 \\
\hline & & Veh. 7 Under Hood & 2.9728 & 0.1995 & 2.5818 & 3.3639 \\
\hline & $\ln$ (Propane_gph) & $\mathrm{a}$ & 0.9727 & 0.0313 & 0.9114 & 1.0340 \\
\hline & $\ln ($ Speed_mph $)$ & $\mathrm{b}$ & -1.1210 & 0.0464 & -1.2121 & -1.0300 \\
\hline & ExhaustHC_ppthC 3 & c & -0.0205 & 0.0128 & -0.0456 & 0.0047 \\
\hline \multirow{5}{*}{ 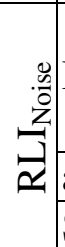 } & \multirow{3}{*}{ Instrument } & RSD Unit 4627 & 92.6701 & 2.2596 & 88.2399 & 97.1003 \\
\hline & & RSD Unit 4628 & 50.6895 & 2.5090 & 45.7702 & 55.6089 \\
\hline & & RSD Unit 4630 & 43.2663 & 2.4780 & 38.4078 & 48.1247 \\
\hline & abs(ExhaustHC_ppthC 3 ) & d & 13.1632 & 0.3541 & 12.4690 & 13.8574 \\
\hline & Speed_mph & $\mathrm{e}$ & 0.1227 & 0.0646 & -0.0039 & 0.2493 \\
\hline
\end{tabular}

response of RLI to running loss emissions release locations and vehicle body shapes, all of the vehicles and locations tested displayed some major response.

We also note that coefficients $\mathrm{a}, \mathrm{b}$, and $\mathrm{c}$ have values not significantly different from or quite near to $1,-1$, and 0 , respectively. These coefficients lead us to conclude that $\mathrm{RLI}_{\text {Signal }}$ has no significant dependence on Exhaust_HC concentration. Since the modeled quantity was the log of RLI $_{\text {Signal, }} a$ is the coefficient for $\ln$ (Propane_gph), and $b$ is the coefficient for $\ln$ (Speed_mph), the regression indicates that $\mathrm{RLI}_{\text {Signal }}$ is close to directly proportional to the ratio of grams per hour divided by miles per hour, which is grams per mile.

The model for the $\mathrm{RLI}_{\text {Noise }}$ component in the bottom part of Table S8 indicates that the Instrument coefficient dominates this RLI component. Three different commercial RSD instruments were used to collect the staged data. While the statistical significance of the $d$ coefficient for the absolute value of Exhaust_HC concentration is strong, the effect on RLI $\mathrm{I}_{\text {Noise }}$ is relatively small unless the exhaust $\mathrm{HC}$ concentration is quite large.

Overall, the regression indicates that $\mathrm{RLI}_{\text {Signal }}$ is approximately proportional to release rate $(\mathrm{g} / \mathrm{hr})$ and inversely proportional to speed (miles/hr), but when those two predictors are combined 
$(\mathrm{g} / \mathrm{hr} / \mathrm{miles} / \mathrm{hr}=\mathrm{g} / \mathrm{mile})$, it becomes apparent that $\mathrm{RLI}_{\text {Signal }}$ is proportional to emission rate ( $\mathrm{g} / \mathrm{mile}$ ) and is independent of speed. Speed has no significant effect on $\mathrm{RLI}_{\text {Noise }}$.

Based on the Table $S 8$ regression results of the first regression model, we performed a second regression on the same data but used some simplifying assumptions. We forced a, b, c, and e to be exactly $1,-1,0$, and 0 , respectively, and assumed that there were no differences in the response of $\mathrm{RLI}_{\text {Signal }}$ to Location. The coefficients for the new regression are given in Table S9. In the transformed space $\left(\mathrm{RLI}^{-0.281}\right)$, the Table S9 model, which was built on 3,501 data points, had an r-square of 0.687, an F-value of 35724, the residuals for the transformed RLI values had a standard deviation of 0.0353 , and the distribution of the residuals was not significantly different from a normal distribution. The parity plot of measured vs. predicted values in the transformed space in Figure S10 shows that regression residuals are near homogeneous.

Table S9. Regression coefficients for second regression model.

\begin{tabular}{|c|c|c|c|c|c|c|}
\hline & \multirow{2}{*}{ Variable } & \multirow{2}{*}{ Coefficient } & \multirow{2}{*}{$\begin{array}{l}\text { Estimate of } \\
\text { Coefficient }\end{array}$} & \multirow{2}{*}{$\begin{array}{c}\text { Approximate } \\
\text { Standard } \\
\text { Error }\end{array}$} & \multicolumn{2}{|c|}{$\begin{array}{l}\text { Approximate } 95 \% \\
\text { Confidence Limits }\end{array}$} \\
\hline & & & & & Lower & Upper \\
\hline \multirow{4}{*}{ 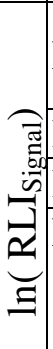 } & Leak Location & $\begin{array}{l}\text { Any vehicle, } \\
\text { any release location }\end{array}$ & 3.1275 & 0.0231 & 3.0822 & 3.1728 \\
\hline & $\ln$ (Propane_gph) & $\mathrm{a}$ (forced to 1$)$ & 1 & & & \\
\hline & $\ln ($ Speed_mph $)$ & $\mathrm{b}$ (forced to -1$)$ & -1 & & & \\
\hline & ExhaustHC_ppthC 3 & c (forced to 0) & 0 & & & \\
\hline \multirow{5}{*}{. } & \multirow{3}{*}{ Instrument } & RSD Unit 4627 & 92.8842 & 2.1476 & 88.6734 & 97.0949 \\
\hline & & RSD Unit 4628 & 56.1785 & 1.1100 & 54.0023 & 58.3548 \\
\hline & & RSD Unit 4630 & 46.8141 & 1.2154 & 44.4310 & 49.1971 \\
\hline & abs(ExhaustHC_ppthC 3 ) & $\mathrm{d}$ & 13.1897 & 0.3576 & 12.4887 & 13.8908 \\
\hline & Speed_mph & e (forced to 0 ) & 0 & & & \\
\hline
\end{tabular}

Using the regression coefficients from Table S9 and substituting, Equation $\mathrm{S} 2$ in steps can be reduced to:

$$
\ln \left(\mathrm{RLI}_{\text {Signal }}\right) \quad=3.1275+1 * \ln (\text { Propane })+(-1) * \ln (\text { Speed })+0 * \text { Exhaust_HC }
$$

taking the exponential of both sides:

$$
\begin{gathered}
\mathrm{RLI}_{\text {Signal }}=\exp (3.1275) *(\text { Propane })^{1} *(\text { Speed })^{-1} \\
\mathrm{RLI}_{\text {Signal }}=22.8 *(\text { Propane }) /(\text { Speed })
\end{gathered}
$$




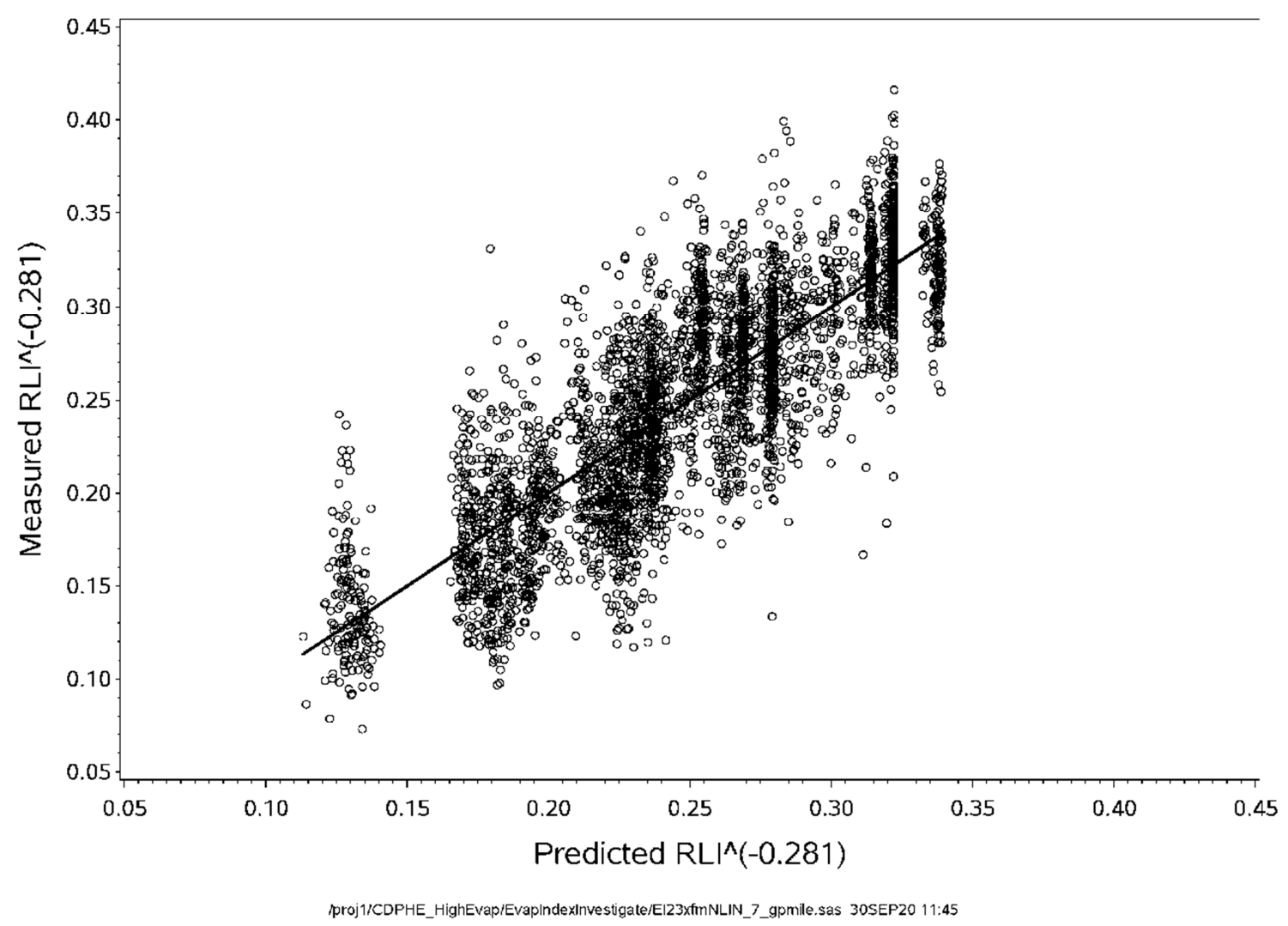

Figure S10. Parity plot of the 3,501 measurements as modeled by the second regression summarized by the coefficients in Table S9.

Propane is in $\mathrm{g} /$ hour and speed is in miles/hr which condenses to $\mathrm{g} / \mathrm{mile}$ :

$$
\mathrm{RLI}_{\text {Signal }}=22.8 * \text { Propane }(\mathrm{g} / \mathrm{mile})
$$

Similarly, using the regression coefficients from Table S9 and substituting into Equation S3 results in the following:

$$
\begin{gathered}
\operatorname{RLI}_{\text {Noise }}=\text { Instrument }+13.1897 * \operatorname{abs}(\text { Exhaust_HC })+0 * \text { Speed } \\
\operatorname{RLI}_{\text {Noise }}=\text { Instrument }+13.2 * \text { abs }(\text { Exhaust_HC })
\end{gathered}
$$

Overall, Equations S1, S7 and S9 quantify the influences of running loss emission rate (g/mile), exhaust HC concentration, and RSD instrument noise on RLI. However, these relationships were developed using commercial RSD instrument data collected during 3,501 staged running loss emissions tests. Therefore, it is important to ask about the general applicability of these equations and specifically their usefulness for describing the running loss emission measurements collected with the FEAT instrument in West Los Angeles. The commercial RSD instruments used in the equations' development are based on the FEAT instrument and are therefore technically similar and have similar operating and measurement protocols. In addition, the $\mathrm{RLI}^{-0.281}$ power transformation produced normally distributed residuals for the regression analysis that produced 
Equations S1, S7 and S9. Figure S11 shows the distribution of $\mathrm{RLI}^{-0.281}$ power transformed values for the 2015 FEAT West Los Angeles dataset. The distribution is close to normally distributed and has a standard deviation of 0.0442 , which is only $25 \%$ higher than the regression standard deviation. The similarities of the FEAT running loss measurements and the commercial instruments staged running loss measurements for vehicles, that are expected to generally have low running loss emissions and exhaust $\mathrm{HC}$ emissions, supports the use of Equations S1, S7 and S9 with the FEAT measurements after the proper instrument coefficient is calculated.

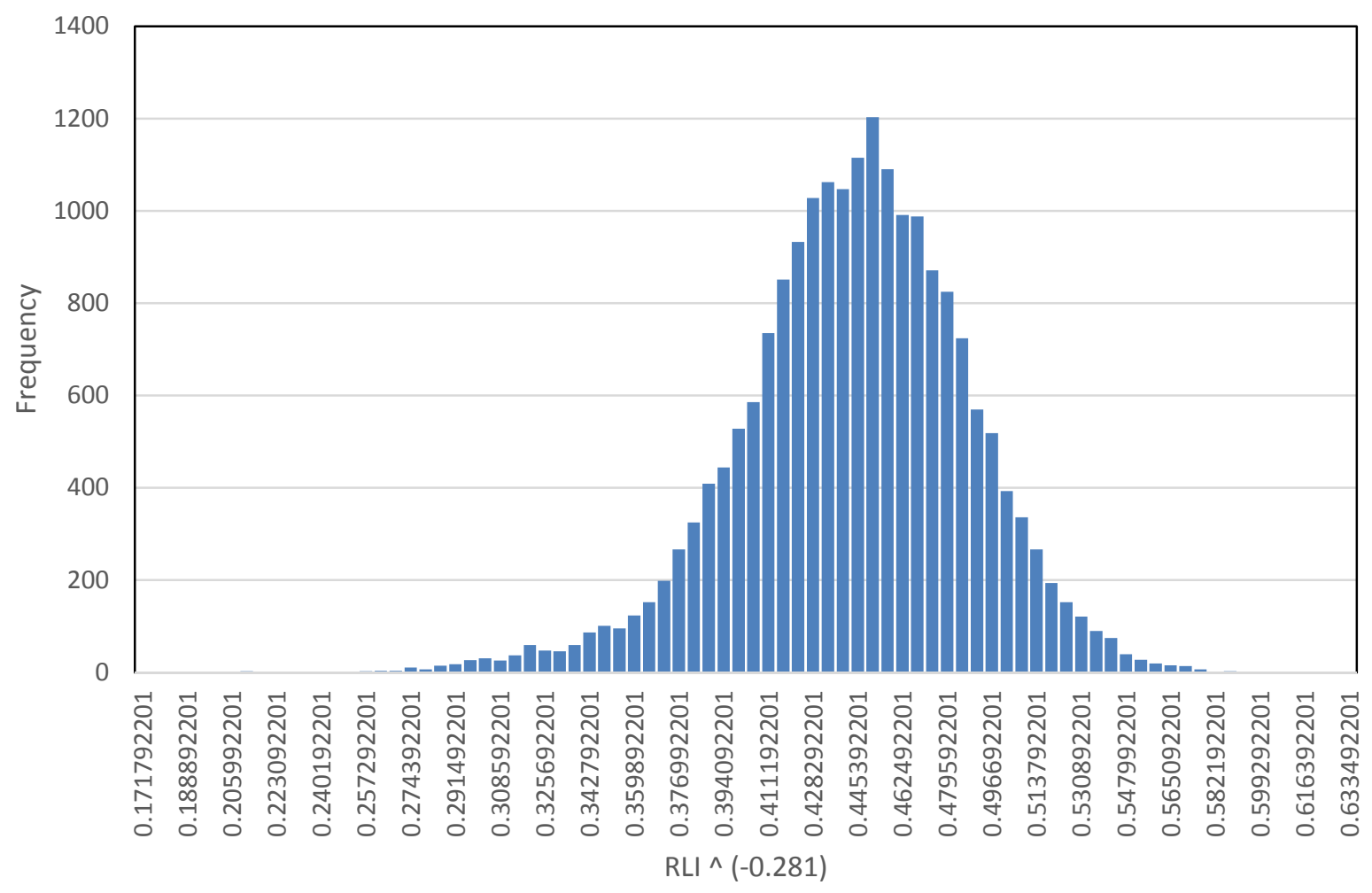

Figure S11. Distribution of 1999 - 2015 model year RLI values for the FEAT 2015 West Los Angeles dataset.

As mentioned earlier, the Equation S9 instrument coefficient is equal to the RLI for vehicles that have running loss emissions that are near $0 \mathrm{~g} /$ mile and have exhaust $\mathrm{HC}$ concentrations that are near $0 \mathrm{ppm}$. The newest model year light-duty gasoline vehicles will be dominated by vehicles with these characteristics. Thus, the instrument coefficient can be estimated for the FEAT instrument for each dataset by determining the average RLI for late model year vehicles. Accordingly, Table S10 shows the average RLI by model year for the 2013 and 2015 West Los Angeles datasets. The average RLI for the 2013 measurements is 29.6 and 20.4 for the 2015 dataset. The increase in the instrument coefficient value for the 2013 measurements mirrors the reported differences in the measurement noise for the FEAT instruments $\mathrm{HC}$ channel with the 2013 HC measurements experiencing 28\% higher noise levels than the 2015 measurements. ${ }^{3}$ Also, the RLI noise stability is demonstrated by the day-by-day average RLIs of the 1999-2015 
model year vehicles for the seven testing days from 3/28/2015 to 4/3/2015: 16.4, 18.4, 23.1, 18.1, 18.0, 18.9, and 17.0.

RLI Minimum Detection Limit. The Table S9 regression results can be used to estimate the FEAT running loss emission rate (g/mile) minimum detection limit (MDL) as defined by 40 CFR Part 136 Appendix B. ${ }^{4}$ This defines the MDL as the lowest emission rate at which there is a $99 \%$ chance that the emission rate is greater than zero. For a zero-emission vehicle the RLI value is determined from Equation S1 and is just the instrument coefficient previously determined. We calculate the $99 \%$ confidence interval from these values in the transformed space where residuals are near normal and are separated by 2.326 standard deviations (0.0353). For the 2013 and 2015 measurement campaigns, the FEAT instrument had average zero running loss RLIs of 29.6 and 20.4 as shown in Table S10. To get up to the corresponding MDL 99\% probability RLIs of 69

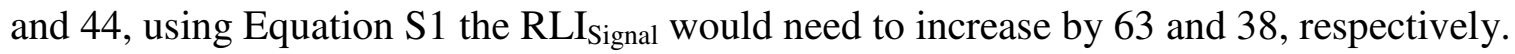
According to Equation S7, these increases would be provided by running loss emissions of 2.8 and $1.6 \mathrm{~g} / \mathrm{mile}$, respectively.

Table S10. RLI Statistics for FEAT 2015 and 2013 West Los Angeles Data.

\begin{tabular}{|c|c|c|c|c|}
\hline Model Year & 2015 Counts & 2015 Mean RLI & 2013 Counts & 2013 Mean RLI \\
\hline 2015 & 929 & 19.7 & & \\
\hline 2014 & 2208 & 20.0 & & \\
\hline 2013 & 2035 & 20.1 & 1401 & 29.1 \\
\hline 2012 & 1523 & 19.7 & 2268 & 29.3 \\
\hline 2011 & 1126 & 20.1 & 1717 & 29.9 \\
\hline 2010 & 1059 & 19.6 & 1417 & 28.9 \\
\hline 2009 & 932 & 20.0 & 1187 & 29.6 \\
\hline 2008 & 1153 & 19.7 & 1684 & 29.2 \\
\hline 2007 & 1395 & 20.3 & 1901 & 29.3 \\
\hline 2006 & 1276 & 20.4 & 1858 & 29.8 \\
\hline 2005 & 1242 & 21.0 & 1804 & 29.8 \\
\hline 2004 & 1035 & 21.2 & 1592 & 29.7 \\
\hline 2003 & 1047 & 21.7 & 1542 & 30.0 \\
\hline 2002 & 937 & 20.7 & 1369 & 30.4 \\
\hline 2001 & 812 & 20.7 & 1301 & 30.1 \\
\hline 2000 & 734 & 21.9 & 1129 & 29.7 \\
\hline 1999 & 602 & 21.7 & 1059 & 30.1 \\
\hline \hline Total / Average & 20,045 & 20.4 & 23,229 & 29.6 \\
\hline
\end{tabular}

Accordingly, the running loss emission rate MDL for the FEAT 2013 measurement campaign is approximately $2.8 \mathrm{~g} / \mathrm{mile}$ and the MDL for FEAT 2015 measurements is $1.6 \mathrm{~g} / \mathrm{mile}$. These MDLs are independent of speed but are a weak function of exhaust $\mathrm{HC}$ concentration. The MDL's speed independence might seem contrary to the speed trends seen in Figure S9. The reason is that the contours in Figure $S 9$ are for release rate $(\mathrm{g} / \mathrm{hr})$. For a constant emission rate 
(g/mile), release rates are proportionally higher at higher speeds. For example, for an emission rate at the $1.6 \mathrm{~g} / \mathrm{mile} \mathrm{MDL}$, the release rate at $12 \mathrm{mph}$ would be $19 \mathrm{~g} / \mathrm{hr}$, and at $55 \mathrm{mph}$ the release rate would be $88 \mathrm{~g} / \mathrm{hr}$. The MDLs are a weak function of exhaust HC concentration. For example, for the FEAT instrument's 2015 West Los Angeles dataset when the exhaust HC increases from 0 to $1000 \mathrm{ppmC}_{3}$, the MDL increases from 1.6 to $3.3 \mathrm{~g} / \mathrm{mile}$.

RLI Probabilistic Method. The above analysis and discussion show that, in the absence of noise and RLI variability, RLI is directly proportional to running loss emission rate ( $\mathrm{g} / \mathrm{mile}$ ). However, because of the functional form of Equation S1 and because most vehicles in the fleet have small values of $\mathrm{RLI}_{\text {Signal }}$ compared to values of $\mathrm{RLI}_{\text {Noise }}$, it is not possible to explicitly solve Equations S1, S7 and S9 for the running loss emission rate Propane (g/mile) given measured RLI values.

We have not found a reliable way to correct the dependences of RLI on tailpipe HC concentration, but these effects need to be accounted for so that the assignment of vehicles using the RLI values is not systematically biased. This dependence arises due to the simple fact that for large $\mathrm{HC} / \mathrm{CO}_{2}$ values the $90^{\text {th }}$ percentile, even for a well correlated relationship, can produce large RLI values. Instead of correcting the RLI values, the values of RLI are binned using bin boundaries that are dependent on the observed tailpipe $\mathrm{HC}$ emissions. In this way, the positive bias introduced by increasing levels of tailpipe $\mathrm{HC}$ emissions can be compensated for. Bins are calculated for each RLI measurement, taking into account the RSD measured exhaust HC concentration, and the RLI value is placed in its appropriate bin. As the bin number increases so does the expected certainty of the vehicle having running loss emissions.

Relative rankings are based on the number of standard deviations (RLI Bin) that the transformed measured RLI ( $\left.\mathrm{RLI}_{\text {meas }}{ }^{-0.281}\right)$ is above the transformed expected $\mathrm{RLI}\left(\mathrm{RLI}_{\text {clean }}{ }^{-0.281}\right.$ ) for a reference vehicle with a zero running loss emission rate but with an exhaust $\mathrm{HC}$ concentration at the concentration measured by the RSD. We use the RSD-measured value of exhaust HC concentration since it is the best measure of exhaust $\mathrm{HC}$ concentration available. We also use the staged standard deviation value of 0.0353 since it has been determined using the 3,501 staged tests over a wide range of test conditions. Finally, we round the number of standard deviations to integers for convenience. The relationship is given by Equation S10:

$$
\text { RLI Bin }=\operatorname{round}\left[\left(\operatorname{RLI}_{\text {meas }}{ }^{-0.281}-\operatorname{RLI}_{\text {clean }^{-0.281}}\right) /(-0.0353)\right]
$$

Where $\mathrm{RLI}_{\text {clean }}=$ the RLI value determined by Equations S1, S7 and S9 using:

Propane $=0 \mathrm{~g} / \mathrm{mile}$,

Exhaust_HC (ppthC $\left.\mathrm{p}_{3}\right)$ as determined for the vehicle by the RSD measurement, and Instrument coefficient determined by the average measured RLI of late model vehicles.

As an internal check, the probabilistic method described above was tested against the staged data that was used to develop Equations S1, S7 and S9. We cannot do this check with the FEAT 
measurement data because we do not have any propane release rate data to compare against. However, we can select conditions from the FEAT measurement campaign as the test conditions. Figure S12 shows the distribution of speeds and exhaust HC concentrations measured by the FEAT instrument in the 2015 West Los Angeles dataset. These ranges were used to select the staged test conditions (Exhaust $\mathrm{HC} \leq 3000 \mathrm{ppmC}_{3}$, Speed $=12$ and $34 \mathrm{mph}$ ) to display the relationship between RLI Bin and propane release rate $(\mathrm{g} / \mathrm{mile})$ measurements in the staged tests. Figure S13 shows that the calculated RLI Bins from the commercial RSD instrument increase with increasing propane release rate. The horizontal reference lines demarcate the integer RLI Bins. The plot clearly shows substantial scatter in the decimal and integer RLI Bin values. This is a consequence of noise and variability ( $\mathrm{RLI}_{\text {Noise }}$ component) in the detection of running loss emissions by the instrument. Nevertheless, Figure S13, in addition to Equations S1, S7 and S9, provides a clear indication of the ability to sense running loss emissions.

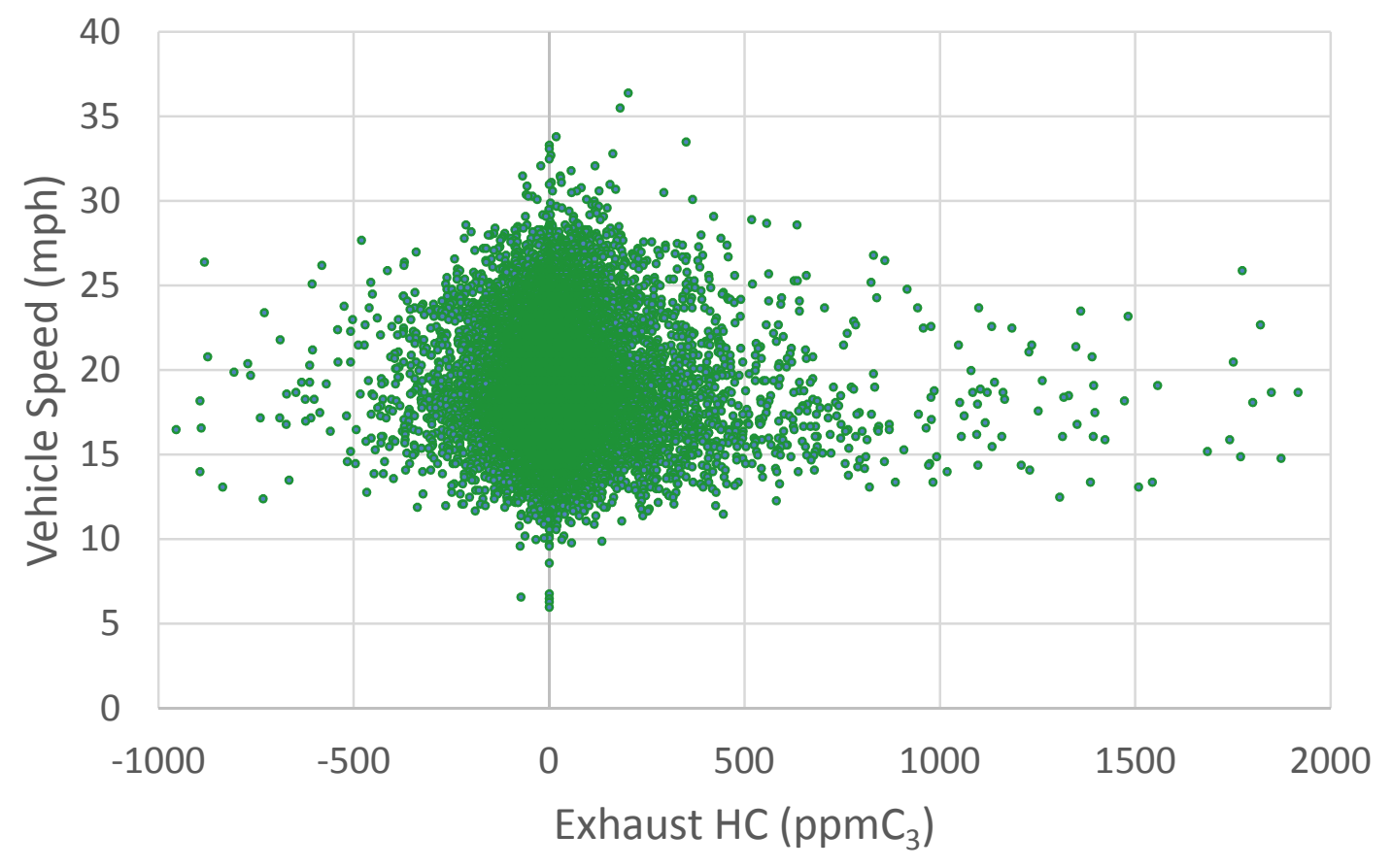

Figure S12. Distribution of Speed and Exhaust HC for the FEAT 2015 West Los Angeles dataset. The FEAT speed system does not report speeds below $6 \mathrm{mph}$. 


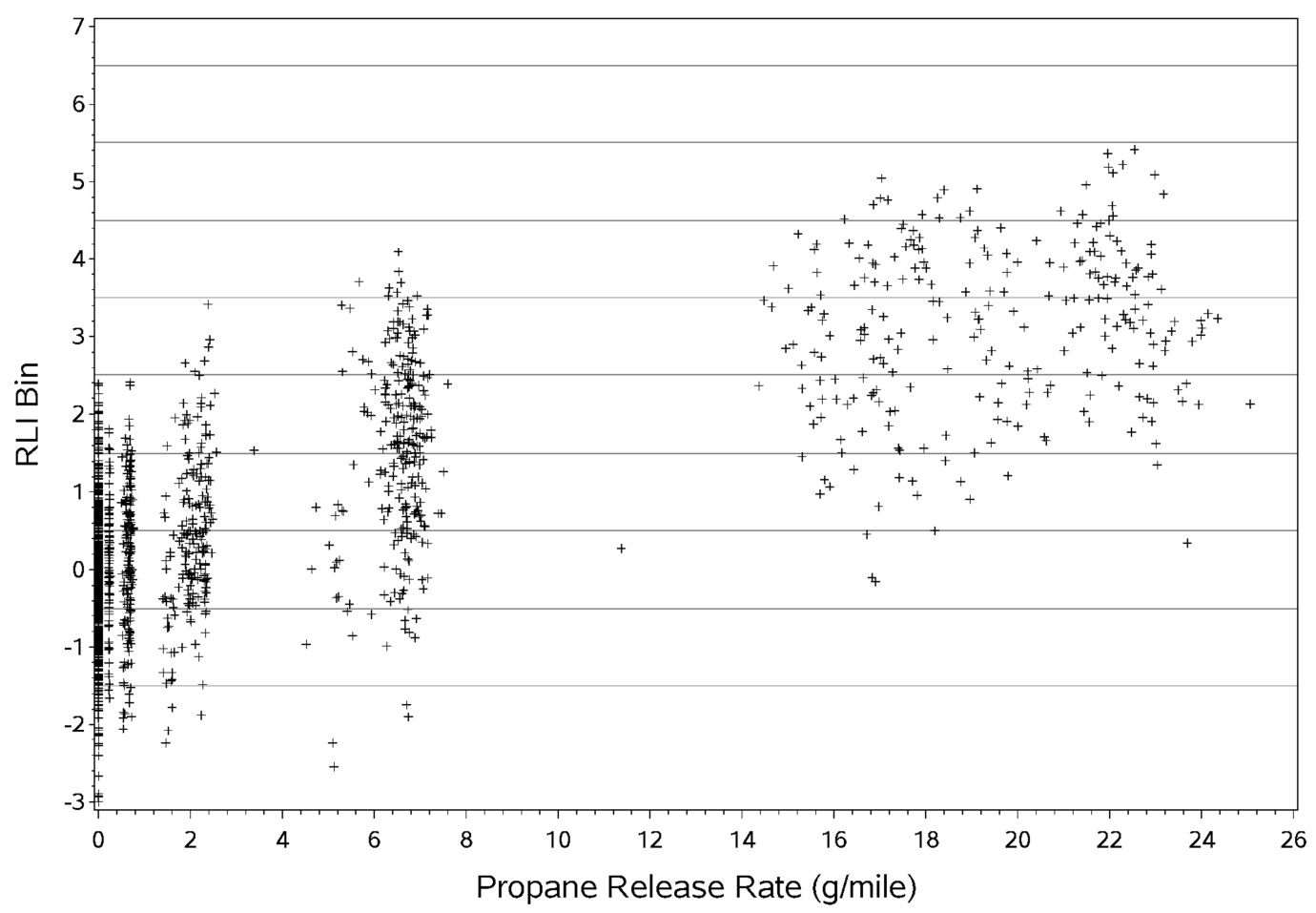

/proj1/CDPHE_HighEvap/EvapIndexInvestigate/ApplyEl23toTraindata_3.sas 05MAY20 11:43

Figure S13. Relationship between RLI Bin and propane release rate for staged tests selected using 2015 FEAT measurement campaign conditions.

Literature Cited

1. DeFries, T.H., Palacios, C.F., Weatherby, M.F., Stanard, A.P., Kishan, S., Estimated Summer Hot-Soak Distributions for Denver's Ken Caryl I/M Station Fleet, Final Report, Version 8, EPA-420-R-14-008, March 2014, prepared by Eastern Research Group, February 8, 2012, revised December 20, 2013.

2. DeFries, T.H., Palacios, C.F., Weatherby, M.F., Kishan, S., Estimated Summer Hot-Soak Distributions for the Denver Fleet, prepared by Eastern Research Group, submitted to Colorado Department of Public Health and Environment, November 19, 2012.

3. Bishop, G. A.; Haugen, M. J., Measuring Real-World Emissions from the On-road Passenger Fleet; California Air Resources Board: Sacramento, CA, 2016; http://www.feat.biochem.du.edu/assets/databases/Cal/Univ_Denver_ARB_12_303_Final _report_2016.pdf.

4. Definition and Procedure for the Determination of the Method Detection Limit - Revision 2. In Code of Federal Regulations; Title 40, Part 136, Appendix B, 2017. 

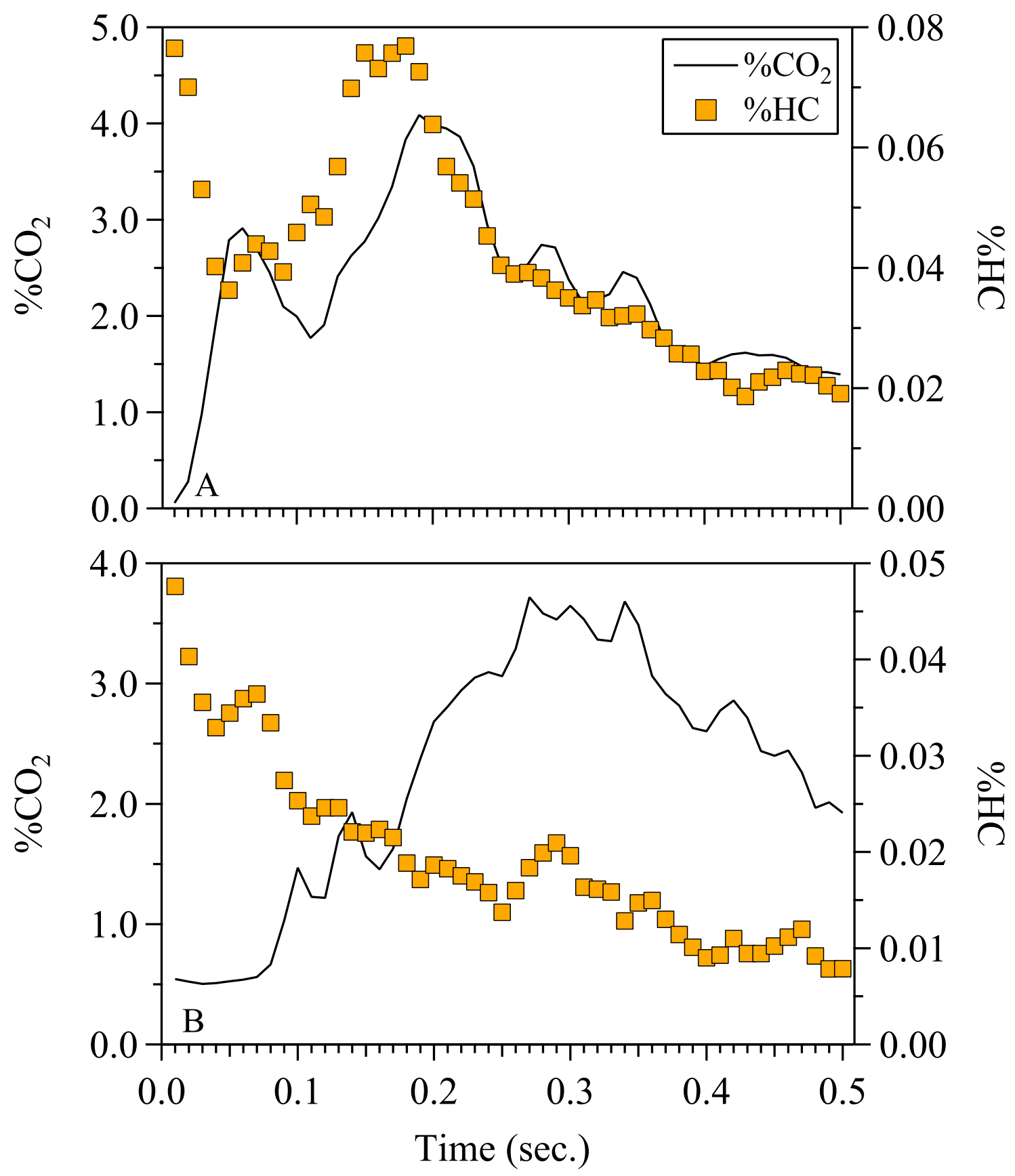

Figure S14. A) Percent $\mathrm{CO}_{2}$ (-, left axis) and $\% \mathrm{HC}(\square$, right axis) emissions versus time for a 1998 pickup (RLI 246, Bin 5) measured in 2015 demonstrating an anti-correlated pattern. B) $\% \mathrm{CO}_{2}$ (-, left axis) and $\% \mathrm{HC}(\square$, right axis) emissions versus time for a 2005 van (RLI 92, Bin 3) measured in 2015 demonstrating a decreasing HC pattern. Percentages are calculated assuming that all of the exhaust has been compressed into an $8 \mathrm{~cm}$ cell and there is no excess air involved in combustion. 

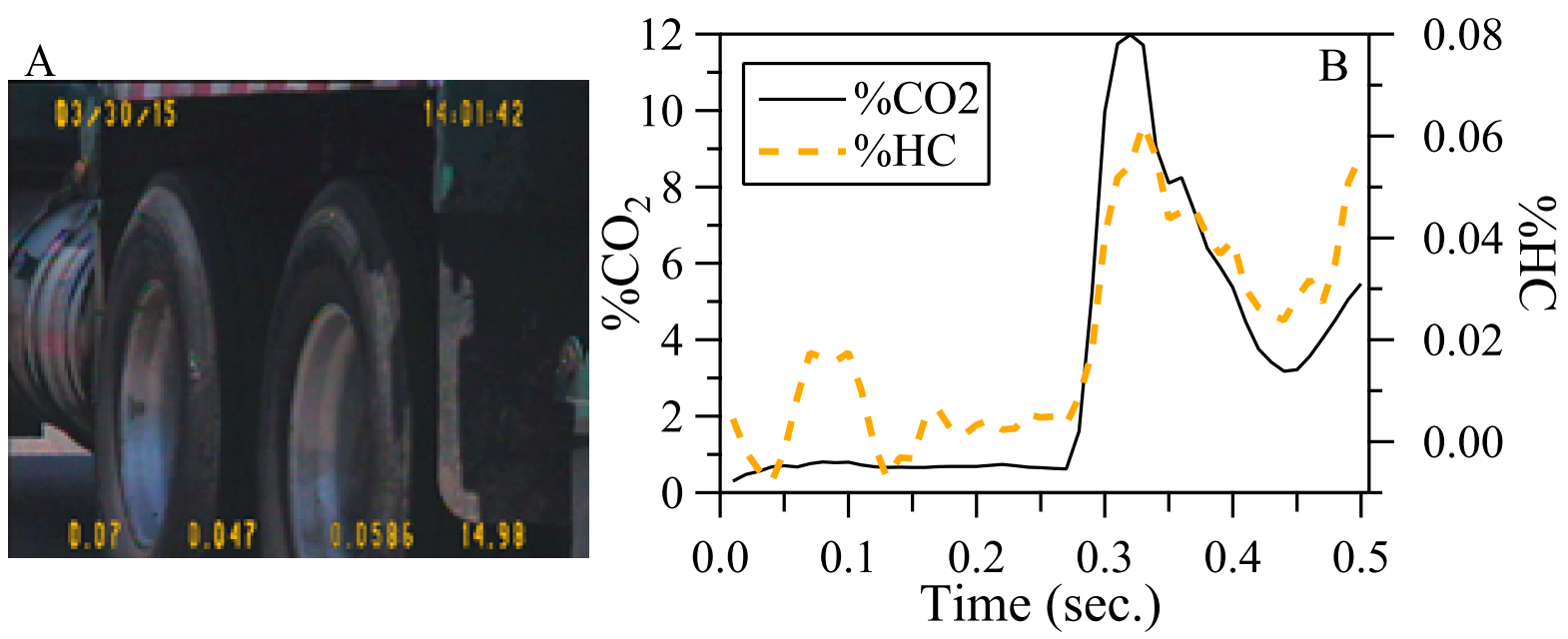

Figure S15. A) Rear image of a CNG (see tank and cylinder cap along left side of image) powered garbage truck (RLI 103, Bin 4). The image includes counter-clockwise from the lower left, tailpipe $\% \mathrm{CO}, \% \mathrm{HC}, \% \mathrm{NO}, \% \mathrm{CO}_{2}$, time and date. B) $\% \mathrm{CO}_{2}$ (solid line, left axis) and $\% \mathrm{HC}$ (dashed line, right axis) versus time for this truck's measurement. 

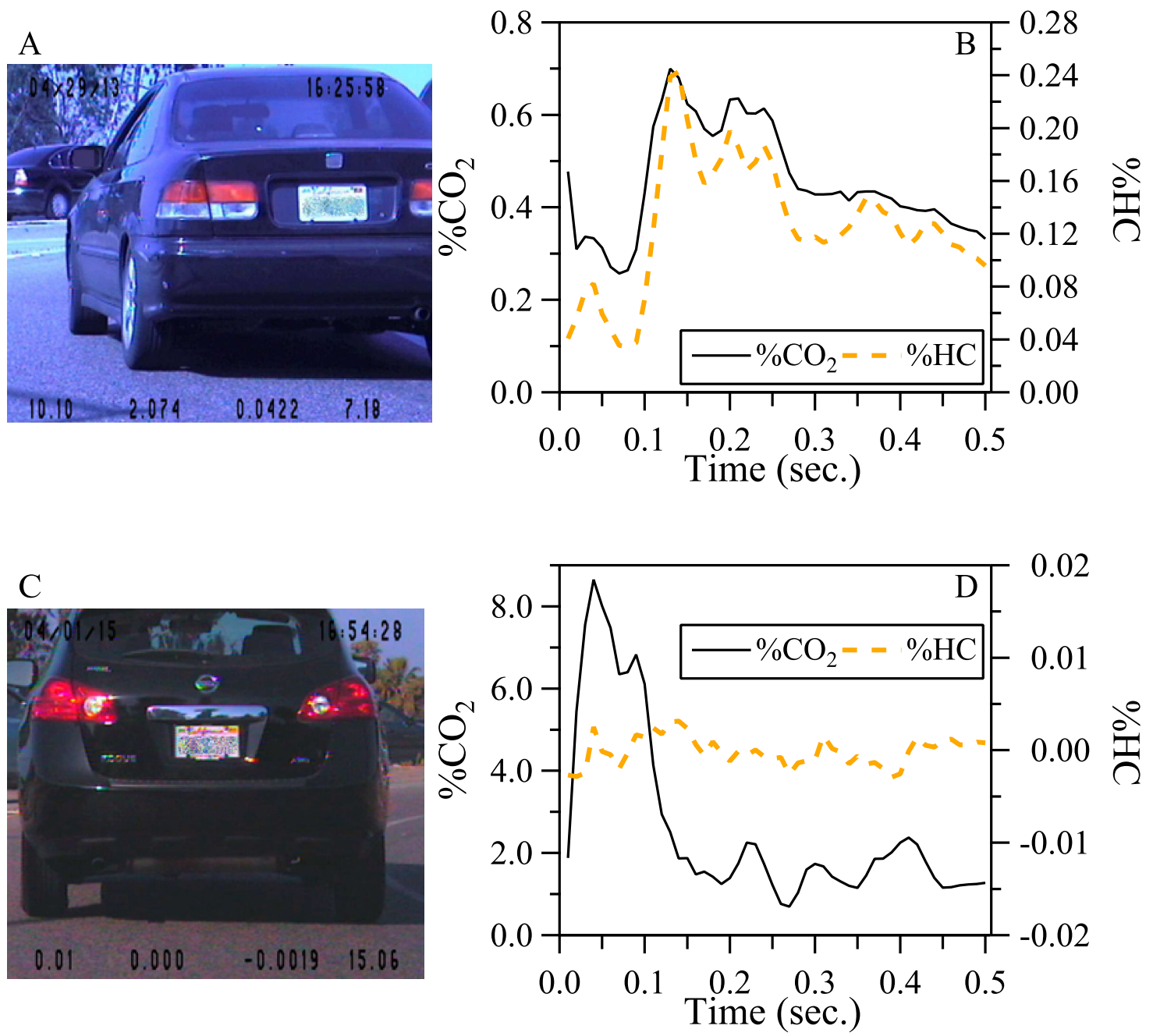

Figure S16. The top panel shows a 1997 Honda (A) with excessively high $\mathrm{CO}$ and $\mathrm{HC}$ tailpipe emissions (two-stroke snowmobile levels) and the well correlated $\mathrm{CO}_{2}$ and $\mathrm{HC}$ time series (B, \%CO2 (solid line, left axis) and \%HC (dashed line, right axis) versus time). This vehicle had a reported RLI of 232 but when corrected for tailpipe $\mathrm{HC}$ it was placed in bin 0 . The bottom panel shows a 2013 Nissan (C) emitting only $\mathrm{CO}_{2}(\mathrm{D}, \% \mathrm{CO} 2$ (solid line, left axis) and \%HC (dashed line, right axis) versus time). This vehicle had a reported RLI of 24 and was placed in bin 1 . The images includes counter-clockwise from the lower left, tailpipe $\% \mathrm{CO}, \% \mathrm{HC}, \% \mathrm{NO}, \% \mathrm{CO} 2$, time and date. 

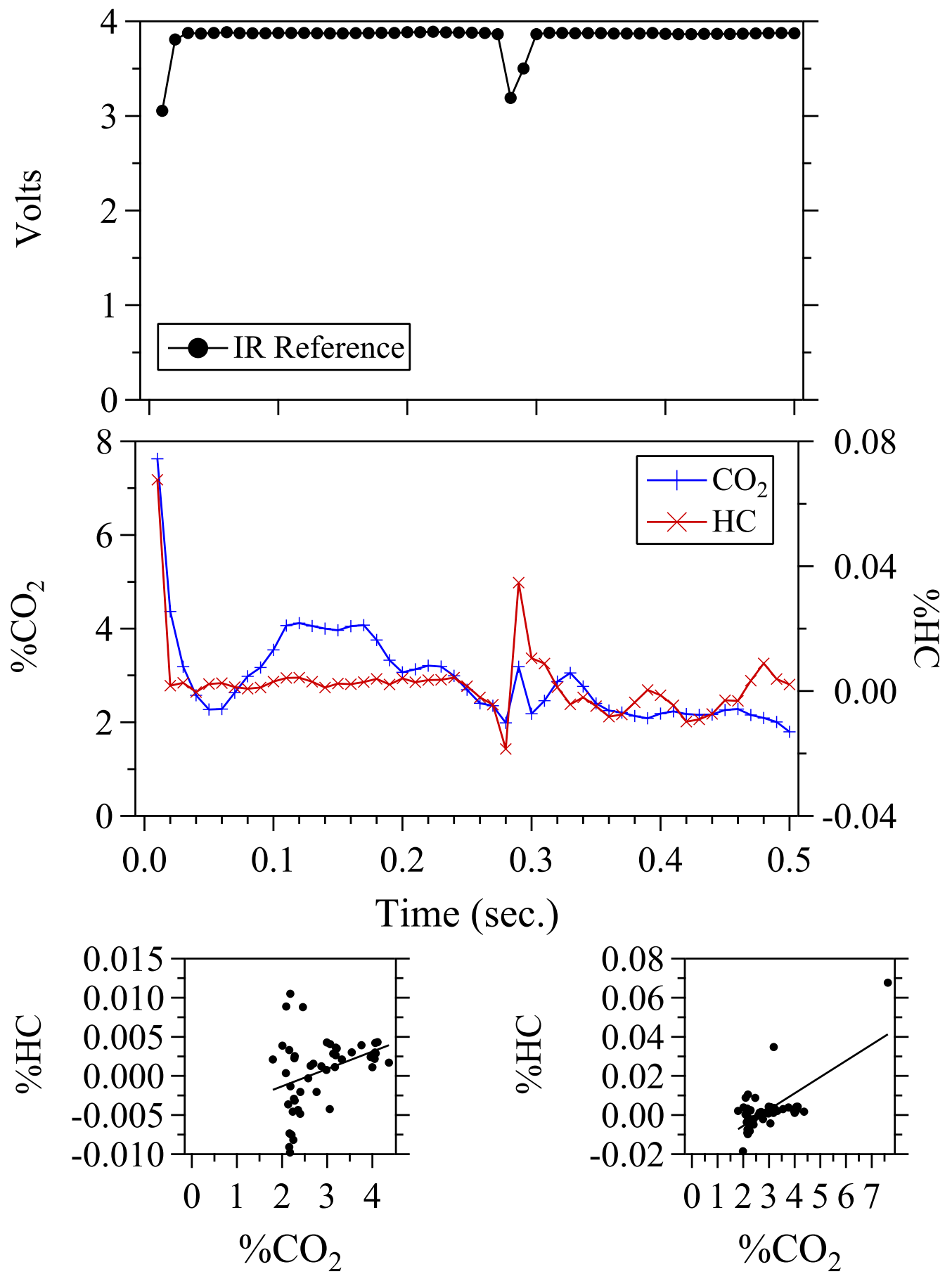

Figure S17. Example measurement data for a vehicle excluded from consideration of nontailpipe HC emissions. The top panel is the time series of the IR reference voltage. The middle panel is the time series of the calculated $\% \mathrm{CO} 2$ (left axis) and $\% \mathrm{HC}$ (right axis) values for the half second measurement. The bottom left graph is $\% \mathrm{HC}$ versus $\% \mathrm{CO} 2$ for the quality controlled data points and the bottom right graph is a similar plot using all of the points. The lines are the least squares best-fit lines. 


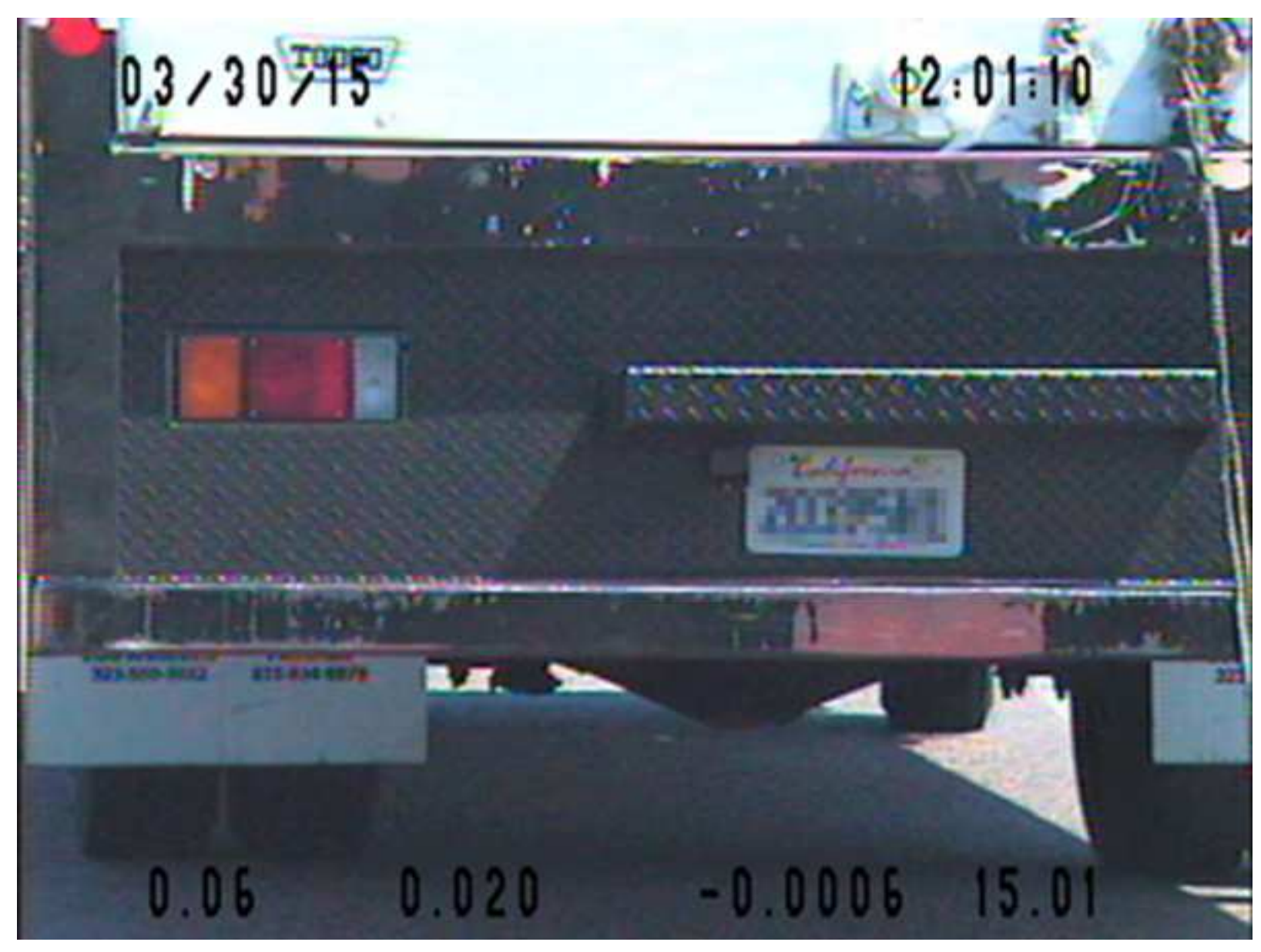

Figure S18. Tag image of the vehicle measured and graphed in Figure S17 (RLI 43, Bin 2).

The reference voltage is reduced at the beginning and in the middle of the sampling time series (see Figure S17). From the license plate image, it is speculated that the first partial blockage is caused by the vehicle mud flaps and the second partial blockage may be due to the long rope tied to the back of the cargo door. The quality controlled data results plotted in the bottom left graph of Figure $\mathrm{S} 17$ results in a reasonable $\mathrm{HC} / \mathrm{CO}_{2}$ slope determination. However, the physical blockages still increase the scatter in a number of points that led to this vehicle's RLI of 43 and Bin 2 designation and subsequent elimination from consideration during the visual inspection. 
Table S11. Listing of 2013 Vehicles Visually Confirmed.

\begin{tabular}{|c|c|c|c|c|c|c|c|}
\hline Date & Time & Year & Make / Type & $\begin{array}{c}\text { RLI } \\
\text { Value }\end{array}$ & $\begin{array}{l}\text { RLI Bin } \\
\text { (Shape) }\end{array}$ & $\begin{array}{l}\mathrm{gCO} / \mathrm{kg} \\
\text { of Fuel }\end{array}$ & $\begin{array}{l}\mathrm{gHC} / \mathrm{kg} \\
\text { of Fuel }\end{array}$ \\
\hline $4 / 27 / 13$ & $11: 18: 35$ & 2010 & HOND / 4D & 52 & $2(\mathrm{~F})$ & 4.65 & \\
\hline $4 / 29 / 13$ & $9: 19: 27$ & & & 54 & $2(\mathrm{~F})$ & & \\
\hline $5 / 4 / 13$ & $14: 41: 38$ & 2006 & MITS / UT & 59 & $2(\mathrm{R})$ & -19.96 & \\
\hline $4 / 27 / 13$ & $10: 51: 38$ & 1987 & MAZD / PK & 60 & $2(\mathrm{R})$ & 151.73 & -1.44 \\
\hline $5 / 3 / 13$ & 14:09:56 & 2001 & FORD / SN & 61 & $2(\mathrm{R})$ & -0.40 & -6.44 \\
\hline $5 / 1 / 13$ & 16:05:31 & 2004 & TOYT / 2L & 61 & $2(\mathrm{~F})$ & 4.21 & 16.65 \\
\hline $5 / 4 / 13$ & $15: 24: 12$ & 2005 & VOLV / UT & 81 & $2(\mathrm{E})$ & 3.27 & 18.44 \\
\hline $5 / 3 / 13$ & 9:07:49 & 1968 & FORD / 2D & 103 & $2(\mathrm{~A})$ & 34.10 & 64.23 \\
\hline $4 / 28 / 13$ & $18: 14: 13$ & 2002 & PORS / CV & 136 & $2(\mathrm{E})$ & -0.25 & 63.10 \\
\hline $5 / 3 / 13$ & $17: 43: 00$ & 2003 & MERC / 4D & 147 & $2(\mathrm{E})$ & 39.55 & \\
\hline $5 / 2 / 13$ & $16: 06: 23$ & 1995 & FORD / PK & 148 & $2(\mathrm{~F})$ & 204.73 & \\
\hline $4 / 29 / 13$ & $10: 27: 38$ & & & 163 & $2(\mathrm{~F})$ & & \\
\hline $4 / 30 / 13$ & $13: 20: 25$ & 2001 & JAGU / 4D & 598 & $2(\mathrm{E})$ & 1.45 & 357.44 \\
\hline $4 / 27 / 13$ & 12:19:11 & 1996 & LNDR / SW & 82 & $3(\mathrm{~A})$ & 225.82 & 1.70 \\
\hline $5 / 1 / 13$ & 17:09:54 & 2000 & ACUR / 4D & 93 & $3(\mathrm{R})$ & 0.67 & 1.51 \\
\hline $5 / 4 / 13$ & $9: 45: 39$ & & & 97 & $3(\mathrm{R})$ & & \\
\hline $5 / 2 / 13$ & $12: 57: 58$ & 2001 & GMC / VN & 99 & $3(\mathrm{~F})$ & 36.09 & 12.46 \\
\hline $5 / 2 / 13$ & 17:19:19 & 1995 & FORD / VN & 100 & $3(\mathrm{E})$ & 5.54 & \\
\hline $4 / 28 / 13$ & $14: 35: 41$ & 1990 & CHEV / CP & 102 & $3(\mathrm{~A})$ & 22.42 & 8.58 \\
\hline $4 / 30 / 13$ & 8:19:59 & 2007 & FORD / SW & 110 & $3(\mathrm{~F})$ & 38.02 & 11.95 \\
\hline $5 / 2 / 13$ & 16:08:24 & & & 110 & $3(\mathrm{~A})$ & 14.08 & -0.54 \\
\hline $5 / 3 / 13$ & 9:33:31 & 2002 & TOYT / UT & 113 & $3(\mathrm{~F})$ & 2.48 & 21.68 \\
\hline $4 / 29 / 13$ & 14:10:09 & 1999 & GMC / LL & 114 & $3(\mathrm{~A})$ & 24.39 & -8.30 \\
\hline $5 / 3 / 13$ & $10: 26: 22$ & 2011 & VOLK / 4D & 118 & $3(\mathrm{R})$ & 6.50 & 7.59 \\
\hline $4 / 29 / 13$ & $7: 36: 43$ & & & 118 & $3(\mathrm{~F})$ & & \\
\hline $5 / 4 / 13$ & $8: 33: 36$ & 1994 & INFI / 4D & 149 & $3(\mathrm{~F})$ & 14.99 & 31.15 \\
\hline $5 / 1 / 13$ & $14: 25: 57$ & 1978 & FORD / PK & 186 & $3(\mathrm{~A})$ & 64.43 & -37.83 \\
\hline $5 / 1 / 13$ & 9:45:09 & & & 134 & $4(\mathrm{H})$ & 66.43 & \\
\hline $5 / 1 / 13$ & 11:41:41 & 1989 & FORD / PK & 170 & $4(\mathrm{R})$ & 733.66 & -17.57 \\
\hline $4 / 28 / 13$ & 18:06:20 & 1998 & FORD / CP & 260 & $4(\mathrm{~F})$ & -1.87 & \\
\hline $5 / 3 / 13$ & $10: 26: 15$ & 1991 & FORD / PK & 5899 & $4(\mathrm{R})$ & 250.78 & \\
\hline
\end{tabular}

Leak shape definitions:

A - Anti-correlation between the $\mathrm{HC}$ and $\mathrm{CO}_{2}$ emissions

D - Consistently decreasing HC signal that does not look exponential

E - Exponential decay of $\mathrm{HC}$ emissions

$\mathrm{H}$ - Consistently high $\mathrm{HC}$ emissions

$\mathrm{R}$ - Rising HC emissions or Late Burst 
Table S12. Listing of 2015 Vehicles Visually Confirmed.

\begin{tabular}{|c|c|c|c|c|c|c|c|}
\hline Date & Time & Year & Make / Type & $\begin{array}{c}\text { RLI } \\
\text { Value }\end{array}$ & $\begin{array}{l}\text { RLI Bin } \\
\text { (Shape) }\end{array}$ & $\begin{array}{l}\mathrm{gCO} / \mathrm{kg} \\
\text { of Fuel }\end{array}$ & $\begin{array}{l}\mathrm{gHC} / \mathrm{kg} \\
\text { of Fuel }\end{array}$ \\
\hline $3 / 28 / 15$ & $10: 50: 21$ & & & 50 & $2(\mathrm{R})$ & 5.05 & 5.05 \\
\hline $4 / 1 / 15$ & $13: 26: 44$ & & CHEV / VN & 64 & $2(\mathrm{R})$ & 25.96 & 21.52 \\
\hline $3 / 28 / 15$ & $15: 28: 50$ & 1999 & GMC / SV & 80 & $2(\mathrm{D})$ & 87.91 & 39.55 \\
\hline $3 / 31 / 15$ & $8: 22: 55$ & 2008 & TOYT / 2D & 112 & $2(\mathrm{H})$ & -25.90 & 66.58 \\
\hline $4 / 1 / 15$ & $6: 55: 13$ & 1974 & VOLK $/ 2 \mathrm{D}$ & 952 & $2(\mathrm{E})$ & 784.51 & \\
\hline $4 / 1 / 15$ & $12: 29: 30$ & 2013 & TOYT / 4D & 51 & $3(\mathrm{E})$ & 26.02 & \\
\hline $4 / 3 / 15$ & $7: 52: 52$ & 1998 & DODG /PK & 54 & $3(\mathrm{~A})$ & 22.30 & 0.88 \\
\hline $4 / 3 / 15$ & $12: 52: 37$ & & MD Truck & 72 & $3(\mathrm{D})$ & 0.00 & 0.00 \\
\hline $3 / 31 / 15$ & $9: 57: 42$ & 1997 & CHEV / UT & 73 & $3(\mathrm{D})$ & 89.65 & 13.39 \\
\hline $4 / 2 / 15$ & 10:50:19 & & Garbage Truck & 75 & $3(\mathrm{~A})$ & 0.00 & 0.00 \\
\hline $4 / 3 / 15$ & $9: 14: 54$ & 2005 & DODG / SV & 92 & $3(\mathrm{D})$ & 10.01 & -18.36 \\
\hline $4 / 3 / 15$ & $14: 45: 49$ & 1997 & FORD / VN & 128 & $3(\mathrm{D})$ & 54.50 & 61.26 \\
\hline $4 / 3 / 15$ & $12: 51: 35$ & 2000 & $\mathrm{CHEV} / \mathrm{PK}$ & 135 & $3(\mathrm{R})$ & 88.85 & 74.14 \\
\hline $3 / 31 / 15$ & $9: 54: 35$ & & Tar PK & 392 & $3(\mathrm{R})$ & -1.34 & \\
\hline $4 / 3 / 15$ & 12:00:43 & & $\mathrm{CHEV} / 2 \mathrm{D}$ & 1111 & $3(\mathrm{D})$ & -1.08 & \\
\hline $3 / 30 / 15$ & $15: 47: 33$ & & MD Truck & 78 & $4(\mathrm{R})$ & & \\
\hline $3 / 28 / 15$ & $13: 40: 34$ & 1997 & DODG / SV & 86 & $4(\mathrm{D})$ & 3.89 & -6.70 \\
\hline $4 / 3 / 15$ & $8: 58: 15$ & 2015 & AUDI / UT & 87 & $4(\mathrm{R})$ & -2.96 & -8.53 \\
\hline $3 / 28 / 15$ & 11:57:01 & 2002 & MAZD / 4H & 87 & $4(\mathrm{D})$ & -3.56 & 11.49 \\
\hline $4 / 3 / 15$ & $14: 42: 10$ & 2015 & HYUN / 4D & 97 & $4(\mathrm{R})$ & 2.26 & 1.92 \\
\hline $4 / 1 / 15$ & $10: 12: 06$ & & MD Truck & 98 & $4(\mathrm{~A})$ & 24.82 & 8.51 \\
\hline $3 / 30 / 15$ & 14:01:42 & & Garbage Truck & 103 & $4(\mathrm{H})$ & 9.04 & 19.18 \\
\hline $3 / 28 / 15$ & 13:06:53 & & & 113 & $4(\mathrm{R})$ & 1.58 & 10.78 \\
\hline $3 / 31 / 15$ & 10:52:09 & 1979 & DODG / VN & 146 & $4(\mathrm{D})$ & 479.68 & 35.68 \\
\hline $4 / 2 / 15$ & $8: 04: 50$ & 2000 & MERZ / UT & 152 & $4(\mathrm{~A})$ & 3.13 & 24.08 \\
\hline $4 / 2 / 15$ & $16: 12: 38$ & 1992 & HOND / CP & 163 & $4(\mathrm{~A})$ & 681.63 & 41.10 \\
\hline $3 / 29 / 15$ & 13:11:13 & $1936^{*}$ & FORD / CP & 213 & $4(\mathrm{R})$ & 0.00 & 0.00 \\
\hline $4 / 2 / 15$ & $8: 20: 10$ & 2003 & NISS / 4D & 224 & $4(\mathrm{E})$ & 67.18 & 53.52 \\
\hline $3 / 30 / 15$ & $11: 46: 35$ & 2004 & HOND / 4D & 528 & $4(\mathrm{E})$ & -1.44 & 111.22 \\
\hline $3 / 28 / 15$ & $12: 48: 47$ & 1997 & HYUN / SW & 645 & $4(\mathrm{E})$ & 50.35 & \\
\hline $3 / 28 / 15$ & $12: 25: 59$ & 1998 & DODG / PK & 1619 & $4(\mathrm{R})$ & 5.11 & \\
\hline $4 / 1 / 15$ & $13: 26: 34$ & 1967 & CHRY & 5731 & $4(\mathrm{E})$ & 396.08 & \\
\hline $4 / 3 / 15$ & $10: 49: 10$ & 1992 & TOYT / 4D & 119 & $5(\mathrm{~A})$ & 99.13 & -3.60 \\
\hline $3 / 30 / 15$ & $14: 02: 54$ & 1999 & $\mathrm{CHEV} / \mathrm{SV}$ & 145 & $5(\mathrm{H})$ & 11.51 & 6.69 \\
\hline $4 / 3 / 15$ & $12: 00: 51$ & 2014 & MERZ / 4D & 169 & $5(\mathrm{H})$ & -2.25 & 6.79 \\
\hline $3 / 28 / 15$ & $12: 47: 23$ & 2004 & ACUR / 2H & 186 & $5(\mathrm{E})$ & 20.77 & 12.02 \\
\hline $4 / 2 / 15$ & $14: 18: 34$ & 1993 & TOYT / CB & 204 & $5(\mathrm{R})$ & 145.90 & 26.66 \\
\hline $4 / 1 / 15$ & 9:01:37 & 1998 & DODG / PK & 246 & $5(\mathrm{H})$ & 10.19 & 34.80 \\
\hline $4 / 3 / 15$ & $12: 12: 15$ & 2003 & CHEV / VN & 257 & $5(\mathrm{D})$ & 13.15 & 23.00 \\
\hline
\end{tabular}

Highlighted rows indicate same vehicle. 
Table S12 Continued. Listing of 2015 Vehicles Visually Confirmed.

\begin{tabular}{|c|c|c|c|c|c|c|c|}
\hline Date & Time & Year & Make / Type & $\begin{array}{c}\text { RLI } \\
\text { Value }\end{array}$ & $\begin{array}{c}\text { RLI Bin } \\
\text { (Shape) }\end{array}$ & $\begin{array}{c}\text { gCO/kg } \\
\text { of Fuel }\end{array}$ & $\begin{array}{c}\text { gHC/kg } \\
\text { of Fuel }\end{array}$ \\
\hline $3 / 30 / 15$ & $11: 39: 34$ & 1997 & FORD/ UT & 293 & $5(\mathrm{E})$ & 2.84 & 39.11 \\
\hline $4 / 3 / 15$ & $14: 46: 52$ & 1999 & $\mathrm{CHEV} / 3 \mathrm{C}$ & 400 & $5(\mathrm{E})$ & 8.75 & 52.51 \\
\hline $3 / 28 / 15$ & $16: 43: 27$ & 1986 & $\mathrm{CHEV} / \mathrm{CP}$ & 174 & $6(\mathrm{H})$ & 28.15 & \\
\hline $4 / 1 / 15$ & $14: 46: 53$ & 1972 & $\mathrm{MERC} / \mathrm{CP}$ & 198 & $6(\mathrm{D})$ & 143.34 & \\
\hline $4 / 3 / 15$ & $12: 28: 24$ & 2005 & $\mathrm{CHRY} / \mathrm{SV}$ & 273 & $6(\mathrm{E})$ & 3.22 & -7.08 \\
\hline $3 / 31 / 15$ & $13: 59: 51$ & & $\mathrm{PK}$ & 292 & $6(\mathrm{R})$ & & \\
\hline $3 / 30 / 15$ & $11: 56: 30$ & & $\mathrm{NISS} / \mathrm{PK}$ & 400 & $6(\mathrm{R})$ & 664.28 & 27.92 \\
\hline $4 / 3 / 15$ & $12: 38: 25$ & 1983 & FORD / VN & 339 & $7(\mathrm{~A})$ & 7.15 & \\
\hline $4 / 1 / 15$ & $13: 41: 26$ & & $\mathrm{PK}$ & 345 & $7(\mathrm{D})$ & & \\
\hline $3 / 30 / 15$ & $9: 19: 08$ & & $\mathrm{Car}$ & 541 & $7(\mathrm{R})$ & & \\
\hline
\end{tabular}

"This vehicle was visually identified but not plate matched and is not counted with the nine plate matched vehicles discussed in the text. 